\title{
ADDRESS TERMS IN NEW ZEALAND ENGLISH: \\ TRACKING CHANGES TO THE SOCIAL INDEXICALITY OF GENDERED TERMS OF ADDRESS
}

BY

\section{AMY GILES-MITSON}

\begin{abstract}
A thesis
submitted to the Victoria University of Wellington in fulfilment of the requirements for the degree of Master of Arts in Linguistics
\end{abstract}

Victoria University of Wellington 2016 


\section{Acknowledgements}

First and foremost I would like to thank my supervisor Miriam Meyerhoff for all her help and invaluable guidance throughout this study. I would also like to thank all the people who have given me their time, in particular, Bernadette Vine for her help with the LWP data, and Matt Plummer for assisting me with various technical issues. 
Table of Contents

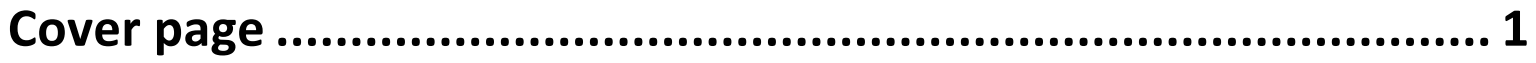

Acknowledgements ............................................................ 2

Table of Contents ................................................................... 3

A note on reading this thesis ................................................ 5

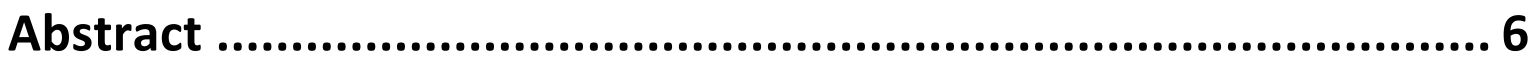

1. Introduction .................................................................... 7

2. Literature Review ........................................................ 9

3. Methods ..................................................................... 16

3.1 Choice of lexemes ............................................. 17

3.2 Data sources....................................................... 18

3.3 Data limitations................................................. 21

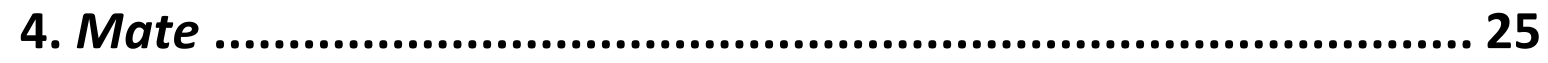

4.1 Overall trends in the corpora: frequency of tokens and token function............................................... 25

4.2 Overall trends in spontaneous and scripted speech in the media ................................................................. 28

4.3 Interactional functions of mate in the corpora........ 30

4.4 Structural considerations................................... 46

4.5 Functions of mate in the media data .................... 48

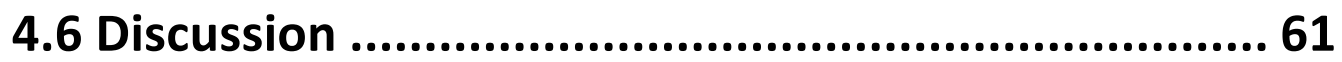

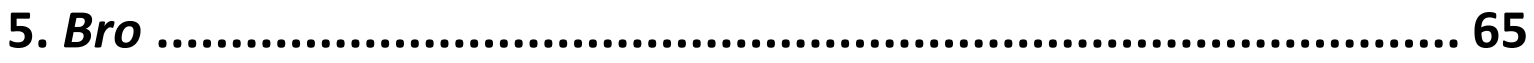


5.1 Overall trends of token frequency and function in the corpus data 65

5.2 Overall trends of token and function frequency in the media data 68

5.3 Functions of bro in the corpora............................ 69

5.4 Functions of bro in the media data ....................... 76

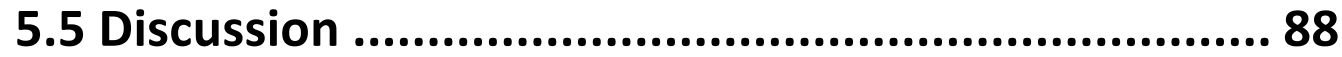

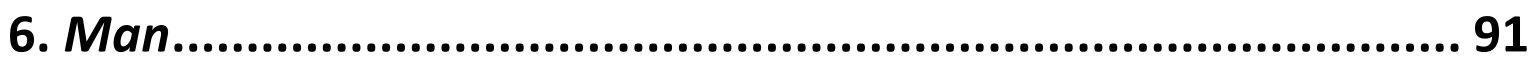

6.1 Considerations of the grammaticalisation of $\operatorname{man} . . .91$

6.2 Man in the corpus data ...................................... 92

6.3 Man in the media data ...................................... 101

6.4 Discussion ................................................... 108

7. Guys ............................................................... 110

7.1 Guys as a gender neutral address term ................ 110

7.2 Guys in the corpora ......................................... 111

7.3 Guys in the media............................................ 115

7.4 Generic guys: some potential factors.................. 120

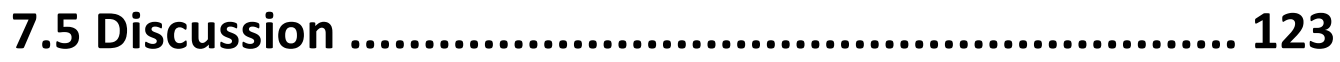

8. General Discussion ......................................................... 125

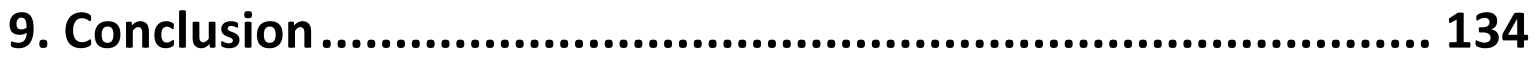

10. References............................................................... 136

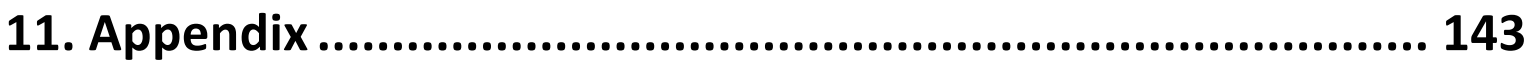




\section{A note on reading this thesis}

There are several options for reading this thesis:

1. Hard copy - If you are reading the hard copy, please find attached a USB with each of the media files I refer to on it. They are in chronological order and their titles correspond to each of the example titles found throughout.

2. Electronic PDF - If you are accessing the electronic PDF, please follow the hyperlinks embedded in the video stills in order to view the media files via my YouTube channel.

3. Online - due the large amount of media content this is perhaps the most convenient way to read this thesis, as you will have direct access to the media files in the body of text. Should you wish to read it online, you can access it at: http://www.ob3.io/ by logging in and clicking on the thesis title: "Address terms in New Zealand English." Please use these details to log in:

Username: addressterms@gmail.com

Password: linguistics

A couple of notes about reading online on OceanBrowser (OB3):

- If you would like to add a comment, click on the paragraph in question and click the + button on the right hand side to leave a note.

- By clicking on Table of Contents in the top right hand corner you can go directly to any heading, sub-heading or example. 


\begin{abstract}
Recent research has suggested that some conventionally masculine address terms are becoming more gender neutral in English speaking countries. This study examines the four most prominent gendered address forms in New Zealand English: mate, bro, man and guys in order to gain insight into the terms' social indexicalities, and track any shifts towards gender neutrality. The study takes a mixed-methods approach to analysing two distinct data sets: four corpora of spoken New Zealand English and a data set collected from a range of current media sources. Results from this study suggest that mate is in retreat in younger New Zealanders' speech, while bro may be increasing in usage as an unmarked form. Results also suggest that both man and guys have a largely gender free status and are being used frequently in New Zealand. These findings contribute to the growing interest sociolinguists are taking in informal address terms by providing an analysis of the interactional and social functions of address forms in New Zealand English.
\end{abstract}




\section{Introduction}

In recent years linguists have begun to look at how address terms are being used by speakers to do social things like expressing solidarity, identity and gender. Contemporary studies have demonstrated that some male gendered address forms are being used by both men and women, with young female speakers' actively renegotiating conventionally masculine terms. Kiesling (2004) has investigated the use of dude in American English and Rendle-Short (2009) has examined how mate is being used in Australia, however, while some studies have looked at address terms in specific locations in New Zealand (Bauer \& Bauer, 2002; Wilson, 2010) little research has considered the terms with respect to gender.

This study examines the use of informal address terms In New Zealand English (NZE). Specifically, those terms of address that are traditionally thought of as predominantly masculine: mate, bro, man and guys. The aim is to explore the usage of these terms and what they index with regards to gender, and any other social indexicalities they possess. Of particular interest is whether there are any shifts towards conventionally masculine terms becoming more gender neutral.

An examination of informal aspects of NZE such as familiar address forms is valuable, as in addition to tracking linguistic changes, it highlights some potential shifts in attitudes towards, and representation of, New Zealand identity in a broader sense. For instance, in contrast to Rendle-Short's (2009) findings, mate does not appear to be being used by young NZE speakers of either sex, yet bro seems to be growing in usage as an unmarked form and is a potential candidate for gender neutral use. This is arguably indicative of the changing face of New Zealand identity, i.e. the dated 'man of the land' philosophy with which mate seems to be associated is being replaced with a more contemporary set of New Zealand values e.g. the familiarity and unflappability embodied in the iconic Kiwi phrase, sweet as, bro.

In direct contrast to the infrequent use of mate, the use of man, and most profusely, guys, is prevalent in younger New Zealanders' speech. This finding, in addition to the 
indication that bro is growing in popularity, suggests that the semantic field of masculine address terms in NZE is in the process of being actively renegotiated and refunctionalised along multiple dimensions by younger New Zealanders.

In order to investigate the different address terms, speech data collected from a wide range of media sources is complemented by extensive spoken corpora of NZE, which together form the data base for this study. A socio-pragmatic approach is taken to the analysis, in the hope that it will help to gain a nuanced understanding of how the terms are being used, as they serve interactional functions and carry social meaning quite distinct from their original semantics.

This study explores how the use of familiar address terms represent gender, and analyses the wider range of characteristics of a relationship that each term indexes (e.g. solidarity, intimacy, or ethnicity). The four address terms under investigation are analysed individually, yet in relation to each other, in both the corpus and media data sets. It is hoped that the findings will contribute to a wider understanding of the potential trend towards [+male] forms achieving gender neutral status, and highlight the need for further research into the use of informal address terms in NZE, as they can provide meaningful information about how we express gender concepts, through language. 


\section{Literature Review}

While a considerable amount of attention has been given to personal address forms following the work of Brown and Gilman (1960), it seems only recently that sociolinguists have been taking an interest in the use of informal address terms (e.g. Kiesling, 2004; Leech, 1999; Rendle-Short, 2009; Wilson, 2010). These informal forms, of which Leech (1999) has termed 'familiarizers' have a range of social functions in interaction. Leech suggests the three key functions are: to select an addressee, to attract attention and to engender solidarity between interlocutors. However, others have shown that terms of address can serve multiple functions, be used in non-literal ways such as in jest or irony (Fitch, 1991) and, critically, that they have the capacity to carry social meaning distinct from both their semantic meaning and their homonymous reference form.

Investigation into the relationship between forms of address and forms of reference has shown that the address meaning of a word cannot be assumed to be the same as its referential meaning (Dickey, 1997). Likewise, it's been recognised that restricting focus to the semantic content of an address term is often unhelpful in analysing how that term is being used. Braun (1988) has highlighted that the social meaning of an address form does not necessarily have a close connection to that word's literal meaning. Sequeira (1993) has further noted that speakers apply their own personal meaning to address forms which often differ from the conventional interpretation. Braun claims that it's possible for forms to be much less complimentary than one might expect from their literal meaning, exemplified by the ability for familial address terms to be used with negative intent (e.g. Rendle-Short, 2010). However, there is scope for a great deal more research that looks at the antagonistic use of familiarisers.

A further case where literal meaning cannot be relied on is in a number of address terms that semantically denote the male sex, as despite some criticism (Hofstadter, 1997; Kleinman, 2007; Kleinman \& Ezzell, 2002) a resurgence of historically male forms being used generically appears to be happening (e.g. Clancy, 1999; Heyd, 2010). Furthermore, recent research has revealed some important findings on conventionally masculine terms 
being renegotiated by younger speakers in terms of gender (cf. Kiesling, 2004; RendleShort, 2009).

Although women using masculine terms, or being referents of [+male] words has not been given a great deal of attention in New Zealand, compared to the U.S. (Clancy, 1999; Heyd, 2010; Kiesling, 2004; Kleinman, 2007) or Australia (Rendle-Short, 2009), it has been noted that the dominant iconography of New Zealand identity is masculine. Bannister (2005) highlights how in a 2004 ethnographic and semiotic study comparing concepts of national identity in the U.S., Australia and New Zealand (for advertising agency FCB), researchers observed the 'blokiness' of Kiwi culture. Specifically, when they looked at what symbolised New Zealand it was the same for men and women (e.g. rugby, barbeques, gumboots) in contrast to America where the female symbols were distinct (e.g. apple pie, friendship diaries). These masculine identity symbols are arguably embodied by the resolute 'Kiwi bloke' image. Although it has been suggested that the 'Kiwi bloke' as a normative archetype no longer exists (Campbell, 1995), others claim it is still the most visible representation of New Zealand masculinity (Law, Campbell, \& Dolan, 1999). There is no distinct boundary in the New Zealand literature on masculinity between academic and non-academic texts, yet masculinities have been widely discussed (e.g. Bannister, 2005; Honeyfield, 1997; Law, Campbell, \& Dolan, 1999; Phillips, 1987) and appear to have a more identifiable place in conventional New Zealand identity than any distinct femininities.

While the concept of masculinity is a set of qualities and practices stereotypically associated with men, the general assumption in the field of language and gender is that masculinity is not inherent to men, but is performed, by males or females (and of course trans and intergender people). This performative view of gender (see, for example, Eckert \& McConnell-Ginet, 2003) asserts that certain social practices become associated with men and therefore become seen as masculine, however, Kiesling (2007) points out that a quality or practice need not be done exclusively by men in order to be associated with masculinity. Indeed, women may engage in a practice or quality just as frequently, yet because it is stereotypically associated with men it is either censored or goes unnoticed. Performances of masculinity are perhaps distinct (yet largely unnoticed) in many New 
Zealand women due to their strong identification with stereotypically masculine practices, such as rugby.

Recent research has suggested that young males are using the address term dude to perform a stance of masculine solidarity, yet females have begun to adopt the term in spite of its masculine connotations (Kiesling, 2004). In investigating the indexicality of dude in young American speakers, Kiesling has stressed its function as a marker of 'cool solidarity' - a stance of camaraderie performed in an essentially nonchalant or not-tooenthusiastic way. Although, as Kiesling claims, this stance has traditionally made dude a term used among young men to assert masculinity bonds, he found that its use has expanded and it is increasingly being used by and to both sexes. Indeed, the second most common speaker-addressee dyad in his data after male-male was female-female. Furthermore, Kiesling found that the female-female tokens were not commonly used in simple greetings (e.g. what's up dude?), but almost always in situations where solidarity or camaraderie was intended, suggesting that young female speakers are using dude to index a stance of solidarity, independently of that which it was expected to index, masculinity. Kiesling concludes that the expansion of the use of dude to females is based on its ability to index this solidarity stance, independent of its associations with masculinity.

The data collected in the present study showed that a term's disassociation with its masculine index was a potent motivation for a shift towards gender neutrality, which suggests that Kiesling's (2004) findings are in fact indicative of how conventionally gendered address forms can evolve, i.e. the loss of masculinity as a primary index means a term is perceived as less gendered and therefore more likely to become gender neutral. This sequential development can be markedly observed in the use of man and guys.

Guys appears to have a pervasiveness that is quite probably due to its grammatical function as a second person plural pronoun. Heyd (2010) highlighted how many young speakers are replacing the somewhat ambiguous plural pronoun you with you guys by tracking the development of you guys in the American TV series Friends, over a ten year period. Findings showed that it was the most frequently used second person plural 
pronoun form (accounting for $48 \%$ of usage), and that it had mixed gender referents a majority of the time (67\%). This frequent gender neutral use of guys (of which results from this study echo) demonstrates how, despite a trend to eliminate generic male items (i.e. he and man), historically male forms are entirely capable of obtaining a gender free status. Clancy (1999) has argued that the cognitive model behind the multiple meanings of he and man must still be powerfully active in the minds of English speakers, as the development of guy closely parallels their meanings and functions.

A significant finding in the examination of you guys is how the Friends character's use of the form changed over the ten year time span. Heyd argues that you guys first evolved in emotive contexts, frequently used as a vocative involving the addressees. However, over the decade the form was increasingly used to fulfil more grammatical functions, losing its emotive connotations and functioning more like a regular pronoun form. From this we can see that guys is consistent with the unidirectionality and desemanticisation associated with grammaticalisation, as the developing pronoun appears to be taking prominence, and the semantic bleaching of the [+male] feature has resulted in the meaning of guys changing from gender specific to gender neutral.

Cheshire (2013) has documented the early stages of the grammaticalisation of man as a new first person singular pronoun in Multicultural London English (MLE). The findings showed that the new pronoun was emerging in the speech of males in multi-ethnic adolescent peer groups in inner cities of the United Kingdom. Cheshire argues that the recruitment of man as a pronoun is likely to be prompted by two main sociolinguistics triggers. One is the high frequency with which those same speakers use man as both an address form and a pragmatic marker. She suggests that man in this form is used to engender solidarity and show group affiliation, unlike, Goodwin's (1990) finding in the speech African American children, where it was being used to address someone being treated as a subordinate.

The second sociolinguistic trigger Cheshire (2013) notes is due to a process of group second language acquisition through which children in multicultural urban areas acquire English. Namely, many young children will not learn English until they go to nursery 
school, which results in collective language learning and produces a great deal of linguistic variation from the mix of different varieties of English and different languages spoken at home. Cheshire claims that the pronoun wouldn't have emerged if it wasn't for the extensive variation in the source noun man, as it may be relatively easy to add a further grammatical function (in addition to a singular noun, a plural noun, a pragmatic marker and an address form).

These findings show us how important the sociolinguistic setting is in the development of innovative forms, but may also have significant relevance to language change in New Zealand as (i) results from this study show that man has similarly diverse functions for many young NZE speakers and (ii) a growing urban and multicultural population ${ }^{1}$ may be resulting in a comparable process of group second language acquisition. If this is the case it will be interesting to see if new items begin to appear that are either modifications of well-established forms such as man, or representative of ethnic groups other than European, i.e. non-Pākehā forms.

A trend towards conventionally non-Pākehā forms is of interest given the spread of bro into general NZE. While little research has been done on bro specifically, there is some evidence to indicate that features that are characteristic of Māori English such as the tag particle eh are growing in usage among young Pākehā speakers, suggesting a change from below (Meyerhoff, 1994; Stubbe \& Holmes, 1995). Bell (2007) has claimed that the use of features such as eh by Pākehā speakers may be a stylistic choice made with the intention of promoting solidarity with Māori, which could conceivably be a factor in young Pākehās' adoption of bro.

Although Māori English has been well discussed by linguists (e.g. Bell, 2000; Holmes, 1997, 2005; King, 1999; Vowell, Maclagan, \& King, 2014), address forms associated with the variety, such as bro, don't appear to have been given much specific attention. An exception is Wilson's (2010) research into how address terms function within a New

\footnotetext{
${ }^{1}$ The 2013 Census showed that in the Auckland region $40.7 \%$ of the population belonged to an ethnic group other than European and $30.6 \%$ were either bilingual or multilingual (Statistics New Zealand, n.d).
} 
Zealand rugby team. Wilson examined how various address terms were used by different communities of practice within the rugby team and revealed interesting results regarding terms that are deemed predominantly Māori, such as bro and cuz. Despite over half the team laying claim to Māori identity such terms were surprisingly infrequent, suggesting that in that particular rugby club, the more common norms of address were Pākehā ones. This perhaps represents a shift in community norms from King's (1999) work in which she concluded that use of familial terms of address is a feature of Māori English commonly used by the younger demographic. Since Wilson's rugby players fall into this demographic, this indicates either change in progress, or that younger men orient to different norms in different contexts.

Wilson (2010) found that the term boys was used substantially more than any other familiariser, usually to give encouragement to team mates. While guys was also prevalent, it was used almost exclusively by coaches to give directives. From this we can see that while the terms are ostensibly both candidates for intimate use in addressing one another, in practice, the social and interactional functions of the words differentiate them clearly.

A further instance of address terms being looked at in a specific New Zealand setting is in Bauer \& Bauer's (2002) work on language variation in New Zealand playgrounds. They found that while mate was used in a range of areas, it was not particularly common anywhere, unlike man which occurred with the most frequency. Bro was found to be more common in the North Island and in lower decile schools. Interestingly, guys was found throughout the country with the exception of the central North Island (Waikato, the timber belt, the volcanic plateau, and Taranaki) where bro was prevalent, suggesting that guys and bro were in a sort of parallel distribution. The fact that mate was only found to occur with low frequency in the speech of primary school aged children in the early 2000s is supported by the results from this study that showed its infrequency in NZE speakers in their teens and twenties. Both Wilson's and Bauer \& Bauer's research provided valuable insight into the use of address terms in a New Zealand setting, however, there appears to be a considerable research gap with regards to female speaker's use of gendered address forms. 
As with dude in the U.S., young female speakers renegotiating a conventionally masculine address form has recently been observed in Australia. Of specific relevance to the present study, and indeed one of the key motivations behind it, is Rendle-Short's $(2009,2010)$ work on mate in Australian English (AusE). Rendle-Short (2009) analysed the use of the address form mate, to see how the traditionally masculine term was being used in contemporary Australian society. Findings showed that where mate had traditionally been recognised as a term used by and to males, there seems to be a shift happening, and younger women are using the term with much more frequency. Furthermore, Rendle-Short's (2009) research suggests that young women may be re-defining mate as a term of endearment that can express fun, friendliness and even intimacy.

Further research by Rendle-Short focused on the sequential environment of mate, (e.g. post-positioned hey mate and pre-positioned mate, how are you), and noted how the form can also be interpreted as hostile or antagonistic (Rendle-Short, 2010). This notion is supported in an article by Spry (2005), who argues that mate is frequently being used in an aggressive manner, to belittle or demean. This discussion was provoked by a notice to security guards at Parliament House in Canberra, dissuading them from using informal colloquialisms such as mate. The present study supports the notion that mate can function as a marker of hostility, suggesting that while the term may be evolving in Australia and is potentially stagnant in New Zealand, some of its distinctive interactional functions are, at this point, still aligned in both countries.

Given that Rendle-Short's (2009) research suggests that young Australians are actively renegotiating the term mate with regards to gender, and bearing in mind that mate is often perceived as a quintessentially Australasian term (although Leech, 1999, attributes it to British English), it seemed timely to investigate whether or not a similar shift is happening in NZE. However, while there are some parallels in usage, the term does not appear to be being maintained and renegotiated by young New Zealanders. 


\section{Methods}

This study involves a mixed-methods design, in which qualitative data was analysed with the aim of assisting with the interpretation of the quantitative results (Creswell, 2011). A mixed-methods analysis was chosen in the hope that it would provide a nuanced understanding of how the address terms are being used by speakers in specific interactional contexts. The quantitative data provided solid information on the distribution of the forms, while the qualitative data allowed an assessment of what those distributional patterns show in terms of social function and meaning.

A hermeneutic approach was taken in the analysis of the qualitative data. Situated in the interpretative paradigm, hermeneutic research studies everyday experiences to gain knowledge through describing, illuminating, theorising or seeking meaning (Higgs, 2001). The analysis in this study is essentially based on interpretation, that is, rather than stressing objectivity it emphasises subjective interpretation. The use of this qualitative strategy, focusing on the function and meaning of address terms, aimed to complement the quantitative results that provided concrete information about distribution and usage.

The interpretation of interactions was approached from a socio-pragmatic perspective. An analysis from this perspective was central to this study, as the pragmatic force of address terms was found to be highly relevant, and the interpretation of forms often came down to understanding their meaning in the context of the utterance (what Dascal, 2003, terms utterance meaning), or what the speaker intended to imply by using them (speaker's meaning). Grice's (1981) theory of conversational implicature and Searle's $(1969,1979)$ influential contribution to Speech Act Theory were a valuable starting point in my analysis, and of particular salience was the widely discussed distinction between semantics and pragmatics (e.g. Bianchi, 2004; Stojanovic, 2008; Szabó, 2006), as pragmatic cues were heavily relied upon in the analysis of the address forms' social and interactional functions, while semantic meaning was largely redundant. 


\subsection{Choice of lexemes}

In the preliminary stages of research, the intention was to focus on the use and distribution of mate and bro. There were two reasons for this: first, each is associated with a strong archetype of users of New Zealand English, and second, because research elsewhere (Rendle-Short; Kiesling) has recently highlighted the propensity for terms which start out as primarily masculine address terms to broaden and to encompass women as well. The gendered nature of mate and bro meant that they were obvious candidates to focus on in NZE since both terms are prototypically associated with men's discourse. However, during the initial data collection phase, it became apparent that there was extensive use of man and guys in gender neutral contexts, i.e. unmarked for gender, and being used by and to males, females and mixed gendered interlocutors. As a consequence, it seemed beneficial to complement an investigation of shifts towards gender neutrality with an evaluation of forms that have already achieved gender neutral status (man and guys). Thus, the scope of the study was broadened to incorporate all four address forms. However, the primary focus, and therefore the greater part of this thesis, is concerned with the male gendered address terms mate and bro.

It is also important to address what precisely is meant by 'gendered' terms (or the 'gendered nature' of some terms). Clearly, the core semantics of the forms bro, man and guys historically denoted only a male addressee or reference or group of males. However, at this point in time, the classification of a form as 'male gendered' requires more socially situated considerations than the semantic denotation alone. Specifically, there is a strong tendency for men to be both the speaker and referent/addressee of mate and bro, that is, the data showed that both mate and bro are [+male] with respect to the addressee and the user of the term. Furthermore, as we will see, in the media data there was a strong correlation between the raw frequencies of tokens produced by, and tokens referring to, a specific gender. In the case of both mate and bro the number of female speakers and female referents were aligned. In other words, the users of these words seem to be telling us that in everyday speech there is an alignment between reference and use for these words that takes the notion of them being 'gendered' beyond mere 
semantics. For this reason, I use the term 'male gendered' to refer to the predominance of males as both the addresser and the addressee of the form.

\subsection{Data sources}

Two distinct data sets were analysed in this study. The first, which I have collectively labelled the 'corpus data set' consists of four corpora of NZE speakers. The second, collectively labelled 'media data set' consists of spontaneous and scripted speech collected from a range of New Zealand media broadcasts.

\section{Corpus data set}

The corpora I analysed were previously existing data taken from The Language in the Workplace Project (www.victoria.ac.nz/lwp), The Wellington Corpus of Spoken New Zealand English (Holmes, Vine, \& Johnson, 1998) and The International Corpus of English - The New Zealand Component (Vine, 1999).

The Language in the Workplace Project (LWP) is a unique study by a team at Victoria University of Wellington that has been responsible for cutting edge research in spoken communication in New Zealand workplaces. Volunteers from a variety of organisations recorded everyday work-related meetings or discussions in government policy units, management groups, project teams, factory production teams and small businesses. The LWP has collected approximately two thousand interactions in a variety of workplaces. Data was collected primarily in 1996 and 1997.

This study analysed transcripts of the LWP recordings that contained the forms mate, bro, man and guys. The transcripts were divided into two distinct corpora: the 'blue-collar workplace,' which was data taken solely from one setting - a factory production team, and the 'white-collar workplace,' which was data taken from twelve different white-collar settings - a mixture of government and private organisations. The blue-collar data is estimated to be approximately 250,000 words, and the white-collar data approximately $2,000,000$ words. These corpora were particularly advantageous to this study due to the fact that ample work has been published that refers to specific workplaces and workplace participants from the LWP (e.g. Holmes, 2006a; Holmes, \& Stubbe, 2015; Holmes \& 
Marra, 2002). This meant that I was able to have a foundation of otherwise unattainable qualitative information, which resulted in a more in-depth analysis.

The Wellington Corpus of Spoken New Zealand English (WCS) comprises one million words of speech in a range of contexts - monologues, dialogues, public, private, scripted and unscripted speech. The majority of the data (99\%) was collected between 1990 and 1994. The International Corpus of English (ICE) - The New Zealand Component comprises 600,000 spoken words and was also collected between 1990 and 1994. The New Zealand component of ICE was completed in conjunction with the WSC and the two corpora are closely linked, sharing nine categories. Furthermore, there is an actual overlap of 338,718 words between the two corpora. In order to attain accurate results in token frequency in this study, where tokens were found in speech extracts that were duplicated, they were only counted once, and were attributed to the larger corpus - the WSC.

The corpora were searched for all forms of mate, bro, man and guys. Only tokens relevant to the study were counted and analysed. Thus, terms of address, which Leech (1999) has defined as: a device used to refer to the addressee(s) of an utterance (e.g. hey mate, come on man) were noted and tokens that were terms of reference (e.g. my mate, that man) were disregarded. Tokens of man that were functioning as interjections were also noted, for the purpose of a complete analysis, and as Cheshire (2013) has argued, because they can be linked in the expansion of a form into new address domains.

The corpora were chosen as a source for this study as collectively they contain a vast and comprehensive selection of New Zealand speakers from a range of ages and ethnicities. They provided extensive spontaneous speech in conversation which was invaluable to analysing the interactional functions and indexicalities of the address terms.

\section{Media data set}

The media data set was collected primarily over an eight month period between March and October 2015. Data collection was achieved by viewing and listening to a wide range of broadcasts from the New Zealand media. It is estimated that approximately 175 hours of screened broadcasts were viewed and between 30 and 35 hours of radio broadcasts 
heard. The screened broadcasts focused on 23 of New Zealand's televised programmes, 12 of which were scripted shows and 11 non-scripted, i.e. spontaneous speech. In addition to this a selection of films and an extensive range of television commercials were observed, and any online material available was viewed (e.g. video blogs and video diaries). The media data was searched and relevant tokens were recorded. Where possible the relevant broadcasts were also saved and filed.

Radio shows were chosen with the aim of getting samples from a range of NZE speakers. The focus was on talk back radio, shows that had a large amount of DJ talking time/listeners calling in, and programmes that seemed to be targeted towards younger listeners (e.g. ZM shows Jase \& PJ and Fletch, Vaughan \& Megan), with the purpose of observing trends in young people's speech.

In order to make the media data available for recurring and public observation I set up a YouTube channel, and, after editing the relevant sections (that contained the token/tokens) out of the respective broadcasts, uploaded and published them. I was then able to add hyperlinks to the various video clips into my analysis. The purpose of this was so the reader is provided with the same audio and visual cues that I used to support my analytical discussion.

The media as a data source was chosen for a number of reasons. First and foremost because it was an easily accessible and expansive source of current ${ }^{2}$ speech, which provided both visual and audio information beneficial to an in depth analysis (e.g. contextual information, paralinguistic signals, socio-pragmatic cues). Furthermore, the fact that the broadcasts used in the data collection were all in the public domain (i.e. televised, online, on local and national radio) meant that an extensive amount of data was able to be gathered without ethical limitations. As approximately half of the broadcasts were unscripted the media was a good source for spontaneous natural speech, which provides the most telling information about current language use.

\footnotetext{
${ }^{2}$ The broadcasts screened were either current programs or were aired within the last five years, with two exceptions - The Truth about Teenagers (2008) and Seven Periods with Mr Gormsby (2005-2006).
} 
However, recent studies have also investigated how scripted television may reflect ongoing language change (e.g. Tagliamonte \& Roberts, 2005), illustrating how the media is a valuable source of data in a study such as this one. Moreover, Queen (2015) has noted that narrative audiovisual media involves predictable, recognisable forms that, combined with the intentions of the production team and the response of the audience, form multi-layered representations of social life.

Following the primary media data collection phase, tokens from both data sets were quantified to provide information on: raw token frequency, the structural position of tokens, ethnicity of speakers (primarily in the corpus data) and the distribution of tokens in terms of grammatical category (in the case of man). However, I was also interested in the more qualitative components, for example, indications of speaker's emotional states and interlocutor relationships, in order to make the most informed interpretations of the terms' meaning and function. Thus, I coded my data for any aspects of the interaction that provided cues for these things. In the written corpus data these cues were generally based on surrounding speech, interlocutor response and context where possible.

However, because of the audio and visual information, in the media data there were paralinguistic cues and complete situational context which provided additional shades of meaning (e.g. a hostile or jokey tone, sarcasm). The interactional functions and speaker meanings I coded for then formed the basis of my analytical categories.

\subsection{Data limitations}

Some methodological problems arose during the data collection and data analysis phases. The corpus data set was transcriptions without sound files, therefore paralinguistic cues were not available to help in the interpretation of speakers' meaning, and some forms appeared ambiguous in terms of category, or what part of a clause they were attached to. However, care was taken to address such ambiguities where necessary. A further limitation in the corpus data was caused by, specifically in the blue-collar workplace, the high number of unidentifiable speakers ${ }^{3}$ which meant demographic knowledge was

\footnotetext{
${ }^{3}$ Unidentifiable speakers were represented in the LWP transcriptions by a ?
} 
unavailable for some of the interactions. However, this was due to the nature of the workplace (e.g. loud machinery muffling speech) and was unavoidable.

A somewhat unanticipated issue arose in the media data collection phase in that the address terms were sometimes quite difficult to find tokens of, probably due to them being characteristic of a very informal vernacular. Likewise, it was hoped that a large number of younger NZE speakers would be observed, however, it was often difficult to find broadcasts where young speakers were predominant. An additional limitation of the media data was that, in many cases, I lacked ethnographic knowledge about the speakers. For this reason, some of the contributor's ages and ethnicities in this study were assumed rather than self-reported or reliably documented. However, this was an inevitable outcome by the nature of the data collection and every effort was taken to only make assumptions when there was a level of transparency, such as when someone had a Māori name and used Māori or Māori English, I made the assumption that they were Māori.

The following tables summarise the statistics for both sets of data. The corpora have been divided into workplace data and WSC + ICE data, as the information available regarding speakers differed slightly (no percentage of words spoken statistics were accessible for the workplace data).

Table 1: Size of corpus and speaker information for the workplace data section of the corpora

\begin{tabular}{|l|c|c|c|c|c|c|}
\hline Corpus & $\begin{array}{c}\text { Approximate } \\
\text { no. of words }\end{array}$ & $\begin{array}{c}\text { No. of } \\
\text { male } \\
\text { speakers }\end{array}$ & $\begin{array}{c}\text { No. of } \\
\text { female } \\
\text { speakers }\end{array}$ & $\begin{array}{c}\text { No. of } \\
\text { Māori } \\
\text { speakers }\end{array}$ & $\begin{array}{c}\text { No. of } \\
\text { Pākehā } \\
\text { speakers }\end{array}$ & $\begin{array}{c}\text { No. of } \\
\text { mixed/other } \\
\text { ethnicity } \\
\text { speakers }\end{array}$ \\
\hline $\begin{array}{l}\text { White-collar } \\
\text { workplace }\end{array}$ & $2,000,000$ & 77 & 56 & 26 & 70 & 37 \\
\hline $\begin{array}{l}\text { Blue-collar } \\
\text { workplace }\end{array}$ & 250,000 & 24 & 7 & 5 & 14 & 12 \\
\hline
\end{tabular}


Table 2: Size of corpus and word percentage information for the WSC and ICE sections of the corpora

\begin{tabular}{|l|c|c|c|c|c|c|}
\hline Corpus & $\begin{array}{c}\text { No. of } \\
\text { words }\end{array}$ & $\begin{array}{c}\text { \% of words } \\
\text { by male } \\
\text { speakers }\end{array}$ & $\begin{array}{c}\text { \% of words } \\
\text { by female } \\
\text { speakers }\end{array}$ & $\begin{array}{c}\text { \% of words } \\
\text { by Māori } \\
\text { speakers }\end{array}$ & $\begin{array}{c}\text { \% of words } \\
\text { by Pākehā } \\
\text { speakers }\end{array}$ & $\begin{array}{c}\text { \% of words by } \\
\text { mixed/ other } \\
\text { ethnicity } \\
\text { speakers }\end{array}$ \\
\hline WSC & $1,000,000$ & 48 & 52 & 18 & 76 & 6 \\
\hline ICE $^{4}$ & $600,000^{5}$ & 54 & 46 & 14 & 80 & 6 \\
\hline
\end{tabular}

Table 3: Approximate minutes of speech and words spoken in the media data set

\begin{tabular}{|l|c|c|}
\hline Sex of speaker & $\begin{array}{c}\text { Approximate no. of } \\
\text { minutes of } \text { speech }^{\mathbf{6}}\end{array}$ & $\begin{array}{c}\text { Approximate no. of } \\
\text { words spoken }^{\mathbf{7}}\end{array}$ \\
\hline Male speakers & 5400 & 907,200 \\
\hline Female speakers & 5100 & 856,800 \\
\hline Total & 10,000 & $1,764,000$ \\
\hline
\end{tabular}

Results for all the address terms investigated will be reported as raw frequencies (though the overall size of each corpus will be provided as context for the results). Although it is common to normalise frequencies to some standard measure (e.g. number of tokens per 10,000 words) I have deliberately chosen not to do this for my data set. There are several reasons for this. First, the purpose of the comparisons is to describe general norms for different speaker groups, not provide a quantitative basis for generalisations along the lines of Group X uses mate half as much as Group Y, and so forth. There is a principled reason why these generalisations should not be made: we simply don't know what the envelope of variation is (Labov, 1972; Tagliamonte, 2006) for use of address terms. For example, even ostensibly comparable corpora (such as the respective workplace corpora)

\footnotetext{
${ }^{4}$ Percentages in the ICE corpus are rounded to the nearest whole number.

${ }^{5}$ The official documentation for ICE-NZ describes the spoken part of the corpus as being comprised of 600,000 words. In the course of writing this thesis I have learnt that the precise word count is 316,113 for women and 373,099 for men. In the remainder of the thesis I will refer to the officially documented total of 600,000 words.

${ }^{6}$ This is an estimate based on the hours of media viewed and the ratio of male and female speakers per broadcast.

${ }^{7}$ This is based on an average WPM of 168. This estimate was taken from Robb, Maclagan \& Chen's (2004) findings that NZE speakers spoke on average 12\% faster than AE speakers (NZE 280spm; AE 250spm), and according to the National Center for Voice and Speech the average AE speaker's speech rate is 150 WPM (http://www.ncvs.org/ncvs/tutorials/voiceprod/tutorial/quality.html).
} 
may differ in regards to how often an address form is perceived to be socially appropriate or in the distribution of sub-genres or sub-events that facilitate the use of address terms.

A second practical consideration is that the large corpora, where percentages of spoken words have not previously been calculated (i.e. the white-collar workplace), cannot easily be searched for the sex of the speaker. This means the only way to provide a "word count" for each sex would be to assume that both sexes speak approximately the same amount when they speak within the corpus, and divide the corpus total by the number of male or female speakers. However, this seems hugely problematic, given what we know about the distribution of turns and the length of turns in discourse (e.g. Eckert \& McConnell-Ginet, 2003; Coates, 2013).

I now turn to analysis of each of the four address terms respectively: mate, bro, man and guys. 


\section{Mate}

Recent interest by sociolinguists in the vocative use of mate in Australia (Alimoradian, 2014; Rendle-Short, 2009, 2010) meant that it seemed timely to investigate its corresponding usage in NZE. It was tentatively expected that the results from this study might be consistent with Rendle-Short's findings that mate in AusE is shifting towards gender neutrality. However the lack of tokens referring to/produced by women in the current data collection compared to their frequency in Rendle-Short's data, suggests that there will not be direct parallels in the use of the word in both places.

In this chapter I introduce the claim that mate in NZE is not only heavily gendered, but is in fact intrinsically linked with the image of a stereotypical New Zealand male. This 'Kiwi bloke' image with which mate is associated is a symbolic representation of New Zealand identity, and is often typified by a specific kind of humour. This argument will be discussed in more detail later in the chapter.

I start my discussion of the data by giving a brief overview of the general trends that emerged. I then examine the function of mate in both data sets, in terms of usage. I begin with the corpora, where I discuss the various ways in which mate is used in natural spontaneous speech acts, the functions such uses serve, and any social indexicalities the term possesses. I then present some observations on how the grammatical and structural use of mate correlates with function, before turning to the media data, where I analyse the use of mate in both spontaneous and scripted speech. Finally, I conclude with a discussion of the findings, which includes some comparisons between data sets, and considers the use of mate with specific reference to young NZE speakers.

\subsection{Overall trends in the corpora: frequency of tokens and token function}

The raw frequency of tokens in the corpus data is presented in Table 4. The table makes a distinction between blue and white-collar settings, and divides the WSC and the ICE corpora. 
Table 4: Token frequency of mate in the corpus data

\begin{tabular}{|l|c|c|c|}
\hline Corpus & Total tokens & $\begin{array}{c}\text { Male tokens } \\
\text { (Tokens uttered by men) }\end{array}$ & $\begin{array}{c}\text { Female tokens } \\
\text { (Tokens uttered by women) }\end{array}$ \\
\hline White-collar workplace & 122 & 113 & 9 \\
\hline Blue-collar workplace & 59 & 53 & 6 \\
\hline WSC & 57 & 53 & 4 \\
\hline ICE & 22 & 16 & 6 \\
\hline Total: & 260 & 235 & 25 \\
\hline
\end{tabular}

Note: Corpus sizes are as follows: White-collar workplace (approx. 2,000,000), Blue-collar workplace (approx. 250,000 words), WSC (1,000,000 words), ICE (600,000 words).

As indicated in Table 4, mate tokens occurred with some frequency across all four corpora. The greatest number was found in the white-collar workplace, however this is likely to be a result of the size of the corpus, as at approximately two million words it is substantially larger than the WSC and ICE (at 1,000,000 and 600,000 words respectively), and the blue-collar (approximately 250,000 words).

Relative to the number of words per corpus, the ICE, WSC and white-collar workplace data were fairly consistent in the number of mate tokens from male and female speakers. However it was the blue-collar data that provided the largest percentage of tokens, from both sexes. This is likely to be a result of the typically informal nature of the participant's speech, and associated with a normatively masculine interaction style that typifies the factory production floor (Holmes, 2006a). As we will see shortly, there are strong correlations between mate and masculinity.

As expected, male tokens dominated the data, however female speakers did account for close to $10 \%$ of all tokens (9.2\%). Aside from differences in raw frequency, two main variations were observed between the sexes' use of mate in the data: the speaker's social characteristics, and function.

Across the corpora tokens of mate were found in the speech of males from a variety of ages and ethnicities, resulting in no clear patterns being established with regards to either of those factors. The fact that mate was found to be largely unmarked for age or ethnicity, in male's speech, is one of the first indications that its primary index in NZE is masculinity. In the female speech data however, a distinct trend was observed - the term 
was favoured by young Pākehā, with eight of the fourteen speakers being Pākehā women under thirty.

Specific criteria were employed in the identification and classification of speech acts. For example, a humorous speech act was labelled as such when it was clear, most commonly by the presence of laughter, that a remark was not intended to be taken seriously (e.g. [laughs] it would mate [laughs] sweaty bottom eh - see example 10 below). Similarly, a hostile speech act was identified as such when it was evident that a negative stance was intended (e.g. fucking borrow one of my fuckers mate - see example 17 below).

In terms of function, the clearest patterns were found in the white-collar workplace data. Mate functioned most predominantly in four distinct speech acts, summarised in Table 5.

Table 5: Functions of mate in the white-collar workplace data

\begin{tabular}{|l|c|c|c|}
\hline Type of speech act & Total tokens & $\begin{array}{c}\text { Male tokens } \\
\text { (Tokens uttered by men) }\end{array}$ & $\begin{array}{c}\text { Female tokens } \\
\text { (Tokens uttered by women) }\end{array}$ \\
\hline Humorous speech act & 16 & 16 & 0 \\
\hline Hedged utterance & 12 & 9 & 3 \\
\hline Reported speech & 10 & 8 & 2 \\
\hline Expression of solidarity & 4 & 4 & 0 \\
\hline
\end{tabular}

As Table 5 illustrates, mate occurred most frequently in humorous speech acts, however this was a function utilised exclusively by males. This is potential evidence for a strong correlation between mate and a 'Kiwi bloke' image that is often characterised by humour, a claim I explore in more detail shortly. As female mate tokens were scarce it is difficult to draw any solid conclusions regarding function, however, it is notable that the greatest difference between sexes in function frequency is associated with humorous interactions. The blue-collar data showed a slightly different set of predominant functions.

Table 6: Functions of mate in the blue-collar workplace data

\begin{tabular}{|l|c|c|c|}
\hline Type of speech act & Total tokens & $\begin{array}{c}\text { Male tokens } \\
\text { (Tokens uttered by men) }\end{array}$ & $\begin{array}{c}\text { Female tokens } \\
\text { (Tokens uttered by women) }\end{array}$ \\
\hline Humorous speech act & 6 & 4 & 2 \\
\hline Hostile speech act & 3 & 3 & 0 \\
\hline Directive & 5 & 3 & 2 \\
\hline Expression of solidarity & 6 & 6 & 0 \\
\hline
\end{tabular}


As we can see from Table 6 mate appeared in hostile speech acts in the blue-collar workplace that did not appear in the white-collar data. Directives were also present, where in the white-collar data they were more likely to be interpreted as hedged utterances. As in the white-collar data, tokens in humorous speech acts were dominant, however, in the blue-collar workplace mate was used just as much in expressions of solidarity. This is possibly associated with the factory setting being a community of practice (CofP) where address terms are used to index solidarity and in-group membership, something that we will see more evidence of in the following chapter.

\subsection{Overall trends in spontaneous and scripted speech in the media}

Comparable to the corpus data, mate tokens produced by female speakers in the media data were remarkably infrequent. The raw frequency of tokens is presented in Table 7, and has been divided into spontaneous and scripted speech.

Table 7: Token frequency of mate in the media data

\begin{tabular}{|l|c|c|c|c|c|}
\hline Type of speech & $\begin{array}{c}\text { Total } \\
\text { tokens }\end{array}$ & $\begin{array}{c}\text { Male tokens } \\
\text { (Tokens uttered } \\
\text { by men) }\end{array}$ & $\begin{array}{c}\text { Female tokens } \\
\text { (Tokens uttered } \\
\text { by women) }\end{array}$ & $\begin{array}{c}\text { Male } \\
\text { addressee } \\
\text { (Tokens uttered to } \\
\text { men) }\end{array}$ & $\begin{array}{c}\text { Female } \\
\text { addressee } \\
\text { (Tokens uttered to } \\
\text { women) }\end{array}$ \\
\hline $\begin{array}{l}\text { Spontaneous } \\
\text { speech }\end{array}$ & 49 & 44 & 5 & 42 & 7 \\
\hline Scripted speech & 66 & 62 & 4 & 60 & 6 \\
\hline Total: & 115 & 106 & 9 & 102 & 13 \\
\hline
\end{tabular}

It was anticipated that male tokens would also dominate the media data, based on the conventionally masculine associations with mate. As Table 7 illustrates, female tokens account for just ten of the 116 (8.6\%), making them even less frequent than in the corpora. As we can see, there is a strong correlation between the raw frequencies of tokens produced by, and tokens referring to, the different sexes. Aside from raw frequency, the media data also showed some functional distinctions between the sexes. Tables 8 and 9 present the functional distribution of tokens in spontaneous and scripted speech, in the three speech acts where mate occurred most frequently. 
Table 8: Frequency of functions of mate in spontaneous speech

\begin{tabular}{|l|c|c|c|}
\hline Type of speech act & Total tokens & $\begin{array}{c}\text { Male tokens } \\
\text { (Tokens uttered by men) }\end{array}$ & $\begin{array}{c}\text { Female tokens } \\
\text { (Tokens uttered by women) }\end{array}$ \\
\hline Humorous speech act & 19 & 16 & 3 \\
\hline Expression of solidarity & 14 & 14 & 0 \\
\hline Expressions of hostility & 8 & 8 & 0 \\
\hline
\end{tabular}

Table 9: Frequency of functions of mate in scripted speech

\begin{tabular}{|l|c|c|c|}
\hline Type of speech act & Total tokens & $\begin{array}{c}\text { Male tokens } \\
\text { (Tokens uttered by men) }\end{array}$ & $\begin{array}{c}\text { Female tokens } \\
\text { (Tokens uttered by women) }\end{array}$ \\
\hline Humorous speech act & 11 & 11 & 0 \\
\hline Expressions of solidarity & 30 & 26 & 4 \\
\hline Expressions of hostility & 7 & 7 & 0 \\
\hline
\end{tabular}

The hostile use of mate accounts for the least tokens in both spontaneous and scripted speech, however, the fact that it is entirely absent from the female speech data suggests that the use of mate in expressing hostility is the chief locus of functional difference across the sexes. Although female tokens were scarce, this finding is supported by the corpus data, as no instances of females using mate to express hostility were found there either.

As we can see by comparing Tables 8 and 9, tokens in humorous speech acts dominated spontaneous speech, while tokens in expressions of solidarity characterised scripted speech. However, this is likely to be, in part, a result of the types of media that typified the data collection, i.e. comedic settings were common in broadcasts that provided spontaneous speech, and scripted speech often centred round friendships/familiar relationships, where expressions of solidarity are commonplace.

As in the corpus data, male tokens of mate were found in speakers of a range of ages and ethnicities, further evidence that mate is essentially only marked for masculinity in NZE. However, in the female speech data there appeared to be an interaction between ethnicity and type of speech. Table 10 presents these results.

\footnotetext{
${ }^{8}$ The humorous speech acts here include a jokey/playful manner I analyse later in the female speech data.
} 
Table 10: Ethnicities of the female users of mate in the media data

\begin{tabular}{|l|l|l|}
\hline Token and media origin of token & Type of speech & Ethnicity \\
\hline Token 1 - Word Up & Spontaneous & Pākehā \\
\hline Token 2 - Family Recipes & Spontaneous & Pākehā \\
\hline Token 3 - The Edge & Spontaneous & Pākehā \\
\hline Token 4 - The Block & Spontaneous & Pākehā \\
\hline Token 5 - Motorway Patrol & Spontaneous & Māori/Pasifika \\
\hline Token 6 - Go Girls & Scripted & Māori/Pasifika \\
\hline Token 7 - Go Girls* & Scripted & Māori/Pasifika \\
\hline Token 8 - Coverband & Scripted & Māori/Pasifika \\
\hline Token $9-$ What We Do in the Shadows & Scripted & Russian New Zealander \\
\hline
\end{tabular}

*Tokens 6 \& 7 were produced by the same speaker

What is immediately apparent here is that the spontaneous speech tokens are dominated by Pākehā, while the scripted speech are predominantly Māori/Pasifika. This finding suggests that Māori/Pasifika people are being portrayed as the prototypical user of the term while it may actually be favoured by Pākehā women, raising some significant questions about accuracy and representation in the media. However, the paucity of tokens means that it is not possible to determine whether this is a trend that is likely to be sustained in a larger scale data set. A further exploration of current New Zealand broadcasts would be necessary to validate the inferences drawn from this data collection.

Despite this possible misrepresentation regarding ethnicity, the raw frequency of tokens (both male and female) were similar in spontaneous and scripted speech environments. This suggests that the portrayal of mate in the media, in terms of frequency, is likely to be fairly representative of the current linguistic situation, strengthening the grounds for using media data in this study. This is in contrast to Cheshire's (2013) suggestion that the use of man in London English was inflated by the media, something we will return to in Chapter 8.

\subsection{Interactional functions of mate in the corpora}

The corpus of data examined reveals a range of functions for mate in conversation. In keeping with the fundamentally interactional sociolinguistic nature of this study, the functions that I have identified are labelled in terms of their interactional significance. As we will see, both affiliative moves and distancing moves are associated with the use of mate, rendering it a powerful and polyfunctional tool for speakers of NZE. We will also 
observe how the term is capable of transmitting different meanings, depending on context.

\section{Hedging face-threatening acts}

One of the most common functions observed, specifically in the white-collar workplaces, was that of mate being used to mitigate or hedge a potentially positive face-threatening act. This finding supports previous studies of directives that found that in white-collar settings, indirect forms were often favoured over imperatives as a way of mitigating potential face threats when giving orders or making requests (Holmes \& Stubbe, 2015). The most frequent examples of this mitigating form of mate were found in the speech of people in senior roles speaking to their subordinates, as illustrated in Example 1. Jaeson is the company's General Manager and Brendon is an Account Manager.

\section{Example 1}

1 Jaeson: [laughs] it's what you should be aiming for okay what do you think of that mate

2 Brendon: sounds good

Here Jaeson gives Brendon the directive it's what you should be aiming for, and immediately follows it by asking Brendon's opinion, then ends the turn by calling him mate. Particularly in conjunction with the switch to a request for Brendon's input, it seems reasonable to interpret this use of mate as Jaeson, the boss, softening his instruction to a subordinate with the use of the familiar and informal address term. This can be observed again in Jaeson's interaction with another colleague Paul, a Sales Manager, in example 2.

\section{Example 2}

1 Jaeson: you know so there's all these sorts of things and it's the brief still has to be perfect mate

2 Paul: [phone rings] yeah

3 Jaeson: because it's um you know why it has to be perfect

4 Paul: yeah 
Once again Jaeson is instructing his colleague on how a task should be performed, and ending his turn by addressing him as mate. In both example 1 and 2, Jaeson appears to be correcting the person's previous action, suggesting his use of mate is not merely mitigating a directive but softening a corrective action they are being directed to take. In his role as team leader, Jaeson is using the familiariser to attend to his subordinate's positive face.

A slightly different instantiation of this function can be observed in the following example, involving two younger (25-29) participants from a government organisation. Heke, in the senior role, is a Policy Manager and Merimeri is a Policy Analyst.

\section{Example 3}

1 Merimeri: and in the meantime should I draft up a brief

2 Heke: yeah you could make a start on that brief mate

Unlike in examples 1 and 2, in example 3, the speaker in the subordinate position prompts the directive. Although Merimeri has initiated the task, Heke softens his instruction with the modal could and a clause final mate. This is quite possibly evidence of a familiar relationship between the two speakers. Worth noting in this interaction is the gender relationship. Unlike the other exchanges which are male-male, here it is a male addressing a female as mate. This example is anomalous as males generally only addressed other males as mate in the workplace data. This anomaly may be associated with ethnicity, as both Merimeri and Heke are young Māori speakers. While mate in the workplace data primarily indexes gender, it is possible that in this case ethnicity is overriding that primary index. As we saw in Table 10, it appears that the mate in the media is perceived to be ethnically marked.

The use of mate to lessen the impact of a directive is arguably a tool used in the workplace to improve productivity and maintain collegiality. Although using hedges and mitigation to give downwards directives is often considered a feminine style of leadership (Holmes, 2006a) these examples show that it is also a strategy used by males in 
leadership roles in the white-collar setting. This suggests that indirect forms are normative in their workplace culture, and contextual factors are overriding conventionally gendered leadership styles. This will be observed again below in the bluecollar setting, where direct forms are the workplace norm.

We have seen that mitigating directives can be beneficial to workplace collegiality, however, outside of the workplace it can serve a similar function. Example 4 is taken from a teacher monologue, addressing a classroom of children at sharing time.

\section{Example 4}

1 Teacher: I expect you to be sitting with your legs crossed and your arms folded

$2 \quad$ Peter has only been here a short while

$3 \quad$ look at the way he's sitting

$4 \quad$ that's what I expect from you

5 Aaron you need to be close mate just up in there's a nice space for you okay

6 sit like Felix and like um Tom

The teacher uses a series of directives and imperative statements to communicate to his students how he wants them to behave. When he addresses the class as a whole he uses direct language and clearly states his expectations, his authoritative status is evident in his speech. However when he speaks to Aaron individually, he softens the directive by addressing him as mate, offering him a nice space and checks his understanding with okay? The teacher modifies the speech act in order to reduce the impact of the directive, and the inclusion of mate plays a key role in achieving this.

In addition to reducing the impact of directives, mate is also used to hedge other facethreatening acts such as disagreeing, correcting or expressing a differing of opinion. Instances of which are illustrated in the following examples. 


\section{Example 5}

1 Vince: we are a government organisation we should be funding shit like this eh

2 Aidan: in reality though mate there's um so few [type] organisations that are onto it that are really onto it

Vince makes a work related complaint that Aidan challenges. His remark, in reality though, is a response to Aiden's counterfactual statement beginning we should. However the addition of mate, followed by the pause filler um, seems to abate the force of the challenge. As highlighted in previous examples this form of hedging is common in workplace scenarios, yet it also appears in informal interactions between friends. In example 6, two young males discuss a rugby league player turning down an overseas job offer.

\section{Example 6}
1 S1: I reckon I reckon he should have taken it
2 S2: nah too far away from home eh
3 S1: it's a million bucks he could take his family there with him
$4 \quad$ S2: obviously his family comes first mate

In his first turn speaker 1 offers his opinion with I reckon, and speaker 2 disagrees, beginning his turn with the negative nah, before giving an explanation. Speaker 1 strengthens his argument with further information and again speaker 2 disagrees. In his second turn however, speaker 2 uses the potentially face-threatening word obviously, but then follows it by addressing his friend as mate. He has chosen to counter his friend's argument while hedging or mitigating the face threat by signifying their familiar relationship.

An additional situation where the inclusion of mate aids in hedging an utterance is when it forms part of an apology. The following example is a sequence from a broadcast discussion about the budget, between a journalist and a political commentator. 


\section{Example 7}

1 Com: we have to face some economic realities

2 we've got a social welfare bill of eleven billion dollars

3 Journ: quick rap

4

sorry mate

5

quick rap quick rap

Here the journalist signals that the commentator needs to end his turn, presumably because they're out of time. He quickly follows this with an apology, paired with the familiariser. Sorry mate mitigates the face threat of the interruption and instruction that the commentator has to stop talking, by both apologising, (i.e. recognising there is a threat to the other person) (Brown \& Levinson, 1987) and by addressing him as mate (i.e. recognising him as an in-group member). He then reinforces the directive by repeating it a further two times, perhaps to stress, despite the apology, the urgency of the instruction.

As is illustrated in these examples from a variety of interactions, mate is often found in hedged contexts. It can function as a familiar and amiable way to reduce the impact of a potentially positive face-threatening act. A further observation regarding the use of mate in hedged structures was its prevalence in the white-collar workplace data compared to the blue-collar. Indeed, there was a complete absence of it in the factory data, the textbook blue-collar setting. This supports Holmes and Stubbe's (2015) argument that more direct forms of speech are employed in a factory setting, due to that workplace being organised around more routine tasks that require less mitigation, and where there are clear, uncontested power relationships. This suggests that the use of address terms to mitigate can be understood on a scale of sorts, i.e. uncommon in archetypal blue-collar settings (e.g. factory), potentially more common in other blue-collar settings, and most common in white-collar workplaces. However, as we will see shortly in the analysis of bro, it is also possible for forms of address to be used to mitigate in some instances in the blue-collar workplace. 


\section{Building interpersonal rapport}

A further function that correlates with the above mentioned collegiality, is mate being used to help build interpersonal rapport. This was observed in several instances in the white-collar workplace between a boss and their subordinate, such as in the following example, between the Chief Executive of a company and one of his managers.

\section{Example 8}

1 Caleb: um are you still happy with me to do sponsorship or do you want me to share it with Steve or anything like that

2 Daniel: no I want you to do it

3 Caleb: okay cool

4 Daniel: yep

5 Caleb: [very quietly] okay it's just so I can direct um cos everyone gets asked so I might just say

6 Daniel: yeah

7 so

8 oh no it should go through you mate

9 Caleb: okay

Caleb appears to approach the topic with uncertainty but is reassured by Daniel, the CE, who ends his turn in line 8 by addressing Caleb as mate. The use of mate in what is likely a discreet, inclusive conversation seems likely to be a rapport building device. Daniel is encouraging towards his subordinate while taking a solidarity stance, indexed by his use of a casual familiariser. Caleb can infer from Daniel's usage that the two share a kind of affiliation and rapport.

A similar construction can be observed below, this time to create a kind of shared exclusivity between speakers. Example 9 is once again between Jaeson (the GM) and Paul, the Sales Manager. 


\section{Example 9}

1 Jaeson: so um yeah mate we'll just do our own little thing that's what we've always done eh

2 Paul: yep

Jaeson's language here, our own little thing, what we've always done along with addressing him as mate constructs a kind of private alliance, which is quite feasibly designed to build rapport. In this instance we see how building rapport can be constructive and inclusive, while simultaneously being a potentially divisive exclusion tactic.

It has been widely noted that humour plays a key role in workplace interaction (Brown \& Keegan, 1999; Holmes, 2006b; Holmes \& Marra, 2002; Koester, 2010) and building rapport amongst colleagues is one of its many functions. Humour is a particularly salient factor in the discussion of mate, as it is arguable that the quintessential 'Kiwi bloke' mentioned above is often characterised by a particular kind of dry, laconic humour. This humour, often defined by ironic, deadpan or sarcastic speech is exemplified in infamous New Zealand beer ad campaigns and is enormously gendered.

The inclusion of mate in jocular sequences was observed numerous times in both the white and blue-collar workplaces, and in casual conversation between friends and acquaintances. Koester (2010) identifies solidarity humour as a method of showing convergence, an example of which can be observed below in a casual interaction between two young males. Speaker 2 has just recalled a story where he encountered a man with a gun.

\section{Example 10}

1 S1: that' $d$ be quite a buttock clenching moment wouldn't it

2 S2: [laughs] oh yeah [laughs]

3 S1: [laughs] it would mate [laughs] sweaty bottom eh 
This sequence contains several displays of solidarity: agreement, appreciative laughter and the inclusion of a friendly term of address. While solidarity could still be achieved without the address term, the inclusion of mate emphasises the amiable condition constructed by Speaker 1's quip.

Koester (2010) also identifies teasing as a form of solidarity humour, as it is a way of expressing the closeness of a relationship. A tease has been defined as an intentional provocation accompanied by playful off-record markers, which comment on something relevant to the target (Keltner, Capps, Kring, Young, \& Heerey, 2001). While various other definitions have been offered, most scholars agree that teasing incorporates prosocial behaviours, most typically humour and play (Keltner et al., 2001). Mate tokens were found in what I have termed 'teasing sequences,' examples of which can be observed in both white-collar and blue-collar settings respectively.

\section{Example 11}

$1 \quad$ Harry: $\quad$ god it'll start me growing big ears and buck teeth

2 Veronica: [laughs] [laughs]

3 Evan: come on mate you're growing a pot belly more like it

4 Harry: [laughs]

Although Evan is teasing Harry about this weight, he first addresses him as mate, possibly to signal that the comment is just office banter, and shouldn't be taken seriously. The use of mate implies that he is socially licensed (in their relationship) to tease Harry. Evan's speech act is successful, as Harry laughs, indicating he has not taken offense and that he has correctly inferred that the teasing comment was intended playfully. A similar example of this can be observed in an interaction in the blue-collar workplace.

\section{Example 12}

$[\mathrm{X}=$ unidentifiable participant $]$

$1 \quad \mathrm{X}$ : $\quad$ you sure you and Vicky haven't been together

2 Simon: why

$3 \quad \mathrm{X}: \quad$ I seen she's got a bit of a bit of a cut out of her nose [laughs] eh eh 


\section{Simon: you can fuck off mate \\ $5 \quad \mathrm{X}: \quad$ [laughs]}

Here it is the recipient of the gibe that uses mate, however it is potentially functioning in the same way as in the previous example, to couch his insult fuck off in a frame of good humour rather than a genuine face attack. Again, Speaker 1's laughter suggests that the playful provocation is not serious. Example 12 could also be interpreted as including an exaggerated comment, bit of a cut out of her nose, something that is further associated with off-record markers (Charpentier, 2006).

The addition of mate in these sequences seems to consolidate other cues, such as offrecord markers, that these are teases rather than serious put downs. As we recognise teasing as a speech act that is capable of indexing affection, it seems reasonable to assume that the sequences here are a form of solidarity humour, and that the cooccurrence of mate with teasing, in these cases, is functioning as a marker of this.

Holmes (2006b) has examined how spontaneous, collaborative humour can help construct and maintain social relationships in the workplace. Example 13 demonstrates how mate can be used to support this kind of conjoint humour.

\section{Example 13}

$[\mathrm{X}=$ unidentifiable participants $]$

1 RW: well I've already asked the question if you don't have travel budget and you're on budget you don't have any travel budget there is none someone's gonna have to pay for it aren't they

$2 \quad \mathrm{X}: \quad$ cover it out of my underspent wages mate [laughs]

$3 \quad \mathrm{X}: \quad$ that's it mate same

$4 \quad$ RW: well I'm sure the [company] might have another view on it

$5 \quad \mathrm{X}: \quad$ I don't have a budget centre

$6 \quad \mathrm{X}: \quad$ just ask one of you guys to take a week without pay mate you're in 
This is a jointly constructed sequence that several of the participants are contributing to, and in each of the turns that include a humorous remark, the speaker uses mate. Although a critical attitude to an absent party (the boss or the company) can be inferred by their comments, the humour is supportive, as they are contributing to the sequence in order to emphasise a point - the joke that their own money should be used for the travel budget. The mate tokens here seem to be serving two functions concurrently: indicating that their comments are sarcastic and should not be taken seriously (which we will observe again in examples 14 and 15), and echoing each other's usage, which further supports the jointly constructed humour.

The use of sarcasm is significant in this analysis, as the data revealed numerous interactions where mate was used to support the kind of dry humour I claim is often associated with the 'Kiwi bloke' image. The following interaction, from the same male participants already encountered in Example 11, exhibits such humour.

\section{Example 14}

1 Evan: so obviously when [franchise] [city] comes in from a production perspective Harry you know where it goes

2 Harry: no worries mate

3 Evan: top of the pile mate

[laughter and comments - hard to hear]

Harry and Evan are both indicating that when work from another branch of the company comes in, it will not be going to the 'top of the pile.' This example demonstrates how the addition of mate - arguably a term representative of the stereotypical New Zealand 'bloke,' to the sarcastic remark (top of the pile) reinforces this 'blokey' stereotype that is often characterised by humour. As mentioned above, evidence of this sarcastic, essentially masculine humour can be found in a number of New Zealand advertising campaigns, specifically in beer commercials. For example, Tui beer's 'yeah right' billboard campaign, which has been running successfully for over two decades, is exemplified by humour that is decidedly masculine in terms of content (e.g. It actually makes your bum look small - yeah right.; Mate, you can't fix that with Duct tape - yeah right.). This type of 
advertising is unsurprising in the national media, as there is an explicit connection between beer and a set of New Zealand ideas about masculinity (Honeyfield, 1997). Masculinity being representative of New Zealand's national identity is a notion that will be discussed in more detail in Chapter 8.

Despite its strong associations with masculinity, this sarcastic or ironic use of mate is not exclusive to males, as illustrated in the following jocular sequence between two teenage females, discussing bad make up.

\title{
Example 15
}

\author{
$1 \quad$ S1: $\quad$ lots of blush \\ 2 S2: blue and pink probably \\ 3 S1: $\quad$ yeah half and half with heaps of rouge frosted pink lipstick \\ 4 S2: $\quad$ [laughs] [groans] \\ $5 \quad$ S1: $\quad$ you'd look great mate in fact that's what you're getting for your \\ birthday \\ $6 \quad$ S2: $\quad$ nice one of those little compacts with the blue and pink
}

In much the same way as in the previous example, in line 5 Speaker 1 makes a nonserious remark and punctuates it with mate. It is possible here that the speaker is using the term precisely because her remark is in jest, i.e. she is using mate in an ironic sense as part of their jointly constructed 'joke.' Although the topic of conversation here is a conventionally feminine one, it is possible that speaker 1 is using mate in this type of exchange because of its associations with the sort of sarcastic humour discussed above. This suggests that this usage can index a type of comic quality that dominates the primary index of gender seen in example 14.

\section{Expressing hostility}

It has been claimed that in AusE, in addition to marking friendship and solidarity, mate can also be used antagonistically (Rendle-Short, 2010; Spry, 2005). As we have seen in examples 12, 13 and 14, mate is entirely capable of being used in an ironic sense, however Spry (2005) further notes that the familiariser can be 'hypocritical,' in that the 
speaker is aware that the person in question is not in any real sense a 'mate.' This hostile use of mate has been evident in NZE for some time, an example of which is illustrated by Barry Crump's 1961 novel Hang on a Minute Mate, a phrase that is conventionally associated with taking a conversational partner to task, or disagreeing with them. In the 1982 film adaptation of Hang on a Minute Mate, the first instance of the phrase is used by the protagonist to a police officer (Lindsay, 1982), and is an objection that, (as well as making his disdain for the policeman's institutional power role evident) is clearly antagonistic in tone. Evidence of mate functioning in a similar way was observed in the data. The following interaction is between participants in the blue-collar workplace.

\section{Example 16}

1 Simon: start it again [name] start up

2 Christian: yes sir

3 Simon: thank you

4 Christian: next time mate try saying please

5 Simon: please may you start the fucking machine now

While this could conceivably be a humorous sequence (a lack of audio means paralinguistic cues cannot provide additional information) like those discussed previously, it seems more likely to me that mate is functioning here primarily as a marker of contention, as it is used directly in the middle of a strong imperative and corrective statement. This usage can be interpreted as signalling the same kind of objection we saw in Crump's use of mate above. Perhaps notable here is the power relationship as Christian is Simon's superior. This potentially indicates that both his sarcastic remark yes sir, and his use of mate are warning signals that Simon's behaviour is inappropriate.

The following example is less ambiguous with regards to the content being hostile, yet what is interesting about this example is that the hostility is not directed at the addressee (as in example 16) but rather serves as a resource for the speaker to co-construct a stance of hostility towards out-group referents. 


\section{Example 17}

[X = unidentifiable participants $]$

$1 \quad \mathrm{X}$ : they come on fucking site twice our fucking hourly rate and borrow your fucking tools

2 X: fucking borrow one of my fuckers mate

3 Simon: [name] [deep voice] [name]

$4 \quad \mathrm{X}$ : fucking bludgers

Here it seems likely that, rather than the speaker addressing their interlocutor, mate is being used to emphasise the hostility felt towards the subjects of the conversation. On the basis of that interpretation mate is functioning here as a negative exclamation, in much the same way as man could. Furthermore, this example demonstrates how the term can function simultaneously as both a marker of hostility, and as something that helps build on inclusiveness and in-group membership - the shared criticism creates the same sort of exclusivity and divisiveness discussed in examples 8 and 9 above.

Up until now we have seen mate used in interactions where the force of the utterance is positive, and the term is functioning as an index of familiarity. In these hostile examples however, we begin to see how multidimensional mate is in terms of meaning. Despite its original 'friendship' or 'mateship' abstract semantics, it can quite easily carry negative meaning that is both implied by the speaker and understood by the hearer. The hearer is expected to know that mate is not being used in the conventional sense, and must rely on their socio-pragmatic ability to interpret it as such. We will see further evidence of this in the media data analysis shortly.

\section{Reported speech (constructed dialogue)}

Tannen (2007) argues that 'reported speech' is in fact not reported, but creatively constructed by a current speaker in a current situation. The reported speech found in the data was quite feasibly recreated by the current speaker, therefore 'constructed dialogue' (Tannen, 2007) is perhaps a more accurate term to employ. The overwhelming majority of instances of mate found in constructed dialogue were from participants 
recounting their own speech within a narrative. The primary functions this appears to serve are to index the speaker's attitude, and portray themself in a favourable light. Examples 18 and 19 are from white-collar workplace settings.

\section{Example 18}

1 Theo: and he rang me today and and discussed a number of issues about the the latest er sample format um now it would have been very good and I said to him look mate you've [laughs] got to go you've got to be there

\section{Example 19}

1 William: okay so it's a question of well what can we do and I said to him look mate I don't care if we have to run jumping wires across there now

Both William and Theo declare I said to him look mate when recounting a prior interaction to a third party. While it's possible that they believe they're repeating the conversation verbatim, it is more likely, as Tannen argues, that they're reconstructing their own speech. Whether or not the original utterance included the address term, the report of it with the inclusion of mate, seems to be in an effort to appear more amiable, as in example 19 , or as in 18 , to express attitude.

Notably, both of these constructions occur in the same kind of corrective contexts we have observed in both mitigating (e.g. examples 1 and 2) and hostile speech acts (e.g. example 16). That is, when one interlocutor is telling the other to do something that deviates from what they have done, or plan to do. It seems likely that there is a correlation here - where the speaker is attempting to portray themselves favourably they portray their use of mate with a mitigating function, and where the speaker's primary aim is to express attitude, they portray themselves as using mate in a way that corresponds more to the hostile use.

Rendle-Short (2010) points out that when used in reported speech, mate can have the function of revealing information about the speaker's attitude towards the other person. 
The following interaction, once again between Jaeson and Paul, provides information about Jaeson's attitude towards the subject of their conversation.

\section{Example 20}

1 Jaeson: he shouldn't be embarrassed about it

2 Paul: no he shouldn't be

3 Jaeson: he can do what he likes mate

4 Paul: well exactly and and [company] er really do look after him

5 Jaeson: yeah

6 Paul: you know and

7 Jaeson: I keep telling him you should be doing more mate you you own a huge company you know like you know like he doesn't actually live like he owns a huge company does he

8 Paul: no

9 Jaeson: he he could be doing a lot more mate but he he says oh no no no plenty of time to do that later on you know

In this example both Jaeson and Paul are being somewhat critical of the person they are discussing. Jaeson addresses Paul as mate twice (line 3 , line 9) but also uses the term to the subject of the conversation, when he is constructing his own previous dialogue (line 7). Based on what we have seen of the use of mate as a direct term of address in conversation already, it seems reasonable to interpret it in this token of reported speech as conveying that despite Jaeson being critical of the person he's talking about, he feels fondness towards him. Notice that by virtue of the distance between Jaeson and the third party referent, this use of mate also helps portray Jaeson in a positive light. Here, we see the potential polyfunctionality of mate, it may serve both of these functions concurrently.

Having reviewed several interactional and pragmatic functions of mate, we turn now to a consideration of structural factors associated with its distribution. As we will see, the structural correlates of mate in NZE are rather more clear cut than the functional ones. 


\subsection{Structural considerations}

Structural considerations were necessary in this analysis, as the corpus data revealed some interesting observations on how mate functions, depending on its syntactic environment. In the overwhelming majority of instances it is used in clause-final position, with only a small number of tokens found in either clause-initial or medial environments. This finding supports previous analyses of the syntactic positioning of vocatives (Leech, 1999; Rendle-Short, 2010). Rendle-Short's analysis found that when mate occurs as the first word in a turn construction unit it can be used to draw or direct attention.

Some instances of clause-initial mate in the NZE corpora appeared to be functioning simultaneously as both address term and interjection, i.e. fulfilling the functions associated with quite different syntactic environments in Rendle-Short's work. Furthermore, mate tokens that occurred in stand alone position, i.e. not attached to any other lexical items, were capable of acting as markers of agreement. Table 11 is an exhaustive list of mate tokens in the data that occurred in clause initial, or stand alone position.

Table 11: Mate tokens in atypical structural positions

\begin{tabular}{|c|c|c|c|}
\hline Structural position & Example & Corpus & Function \\
\hline Clause initial & mate fuckin' rude & Blue-collar & Exclamation \\
\hline Clause initial & mate that was boring as & ICE & Exclamation \\
\hline Clause initial & mate oh good skills & ICE & Exclamation \\
\hline Clause initial & mate can you just... & Blue-collar & Attention director \\
\hline Clause initial & mate it don't worry you... & White-collar & Attention director \\
\hline Stand alone & $\begin{array}{l}\text { S1: mate } \\
\text { S2: yeah }\end{array}$ & Blue-collar & Attention director \\
\hline Stand alone & $\begin{array}{l}\text { S1: I felt like saying you were } \\
\text { supposed to tell us that } \\
\text { S2: mate }\end{array}$ & White-collar & Agreement \\
\hline Stand alone & $\begin{array}{l}\text { S1: that was so neat } \\
\text { S2: mate }\end{array}$ & ICE & Agreement \\
\hline
\end{tabular}

As Table 11 demonstrates, both clause initial and stand alone mate can be used to draw attention to the speaker. The clause initial exclamative mate is also being used as a highlighting device, and is performing a more grammatical function than in previous examples (as we will see man do in Chapter 6). The following examples show these 
functions being used in more context. Example 21 is an extract from a brief team meeting in the factory data.

\section{Example 21}

1 Colin: yeah fuckin' [stores] didn't get a mention I noticed I noticed fuckin' Owen got a mention the engineers got a mention Russell got a mention [stores] didn't get a mention

2 Ginette: thanks Col

[others laugh] [others laugh]

3 Ginette: thanks Col [laughs]

4 Colin: mate fuckin' rude

5 Ginette: right let's go

As there are several team members present in this setting it is likely that the use of mate here is not so much addressing an individual as an interjection used to express sentiment, in much the same way as man (that's) fuckin' rude might function. The clause-initial position of mate acts as a highlighting and focusing device which adds emphasis to the phrasal exclamation.

Example 22 demonstrates, in more context, how stand alone mate can act as a marker of agreement. The following extract is from a conversation between two young female friends.

\section{Example 22}

$\begin{array}{lll}1 & \text { S1: } & \text { oh Molly's party } \\ 2 & & \text { that was a crack up } \\ 3 & \text { S2: } & \text { [drawls] yeah [drawls] } \\ 4 & \text { S1: } & \text { yeah } \\ 5 & \text { S2: } & \text { that was so neat } \\ 6 & \text { S1: } & \text { mate }\end{array}$


The mate in this example is a stand-alone utterance that continues the agreement sequence both speakers are contributing to. It is performing in much the same way as yeah mate might. This usage aptly demonstrates how salient pragmatic competence is in an interaction. The hearer needs to (and presumably does) infer that the speaker is using mate to express agreement and not as a form of address (or anything else). If the hearer fails to understand the implicature, confusion would likely ensue.

The solitary use of mate in NZE is by no means restricted to agreement however, and can in fact communicate a number of different meanings depending on its stress, intonation and context. This is exemplified in a New Zealand anti-drink driving advertisement, which will be discussed in more detail below.

As illustrated by the above examples taken from across the corpora, at the time these data were collected, mate was being used to serve a variety of functions, and impart several different meanings, both inside and outside of the workplace.

\subsection{Functions of mate in the media data}

The media data collected reveals a similar range of affiliative and distancing functions we have seen produced in the corpora, demonstrating that mate is still polyfunctional in present-day NZE. While there was a large gender discrepancy in terms of frequency, notable functional distinctions were revealed between the sexes. For this reason, the analysis of male and female tokens in the media data have been divided.

\section{Female tokens: spontaneous speech}

Remarkably few female speakers produced tokens of mate in spontaneous speech environments, however, an interesting trend was observed in the female tokens that did occur. Almost all (4 of the 5) instances of mate were found in the speech of Pākehā women aged roughly between $30-45$. Furthermore, unlike in the corpus data where a number of the tokens of mate produced by female speakers were tokens uttered in female-female contexts, in the media data eight of the nine women's tokens were used to address a male, and all of the spontaneous speech tokens were female-male. The following examples of spontaneous speech are taken from three different media 
environments, TV cooking show Family Recipes, a radio show interview on The Edge, and television game show Word up.

\section{Example 23: Family Recipes ${ }^{9}$}

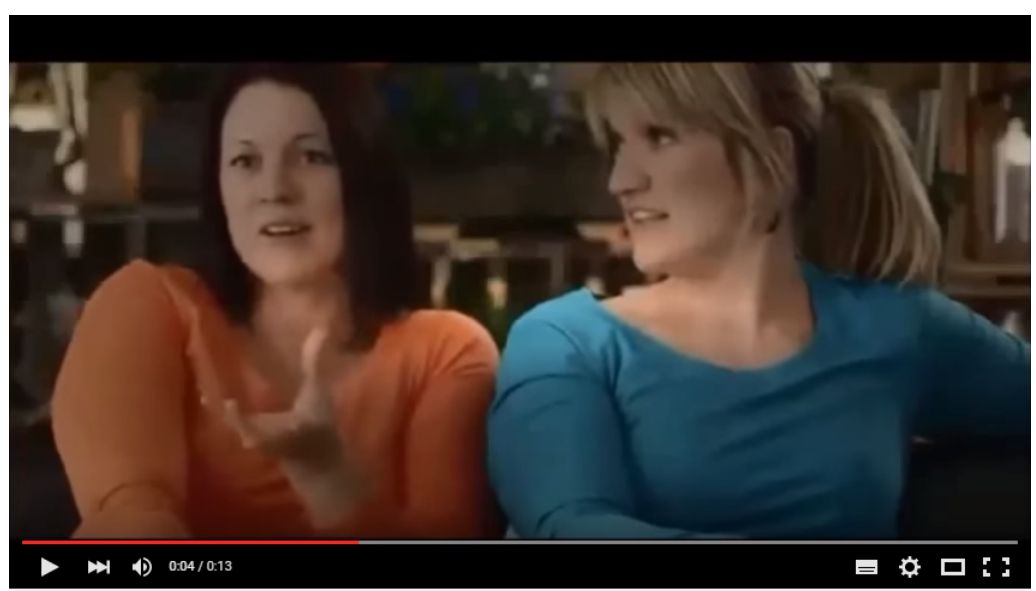

\section{Example 24: The Edge (1)}

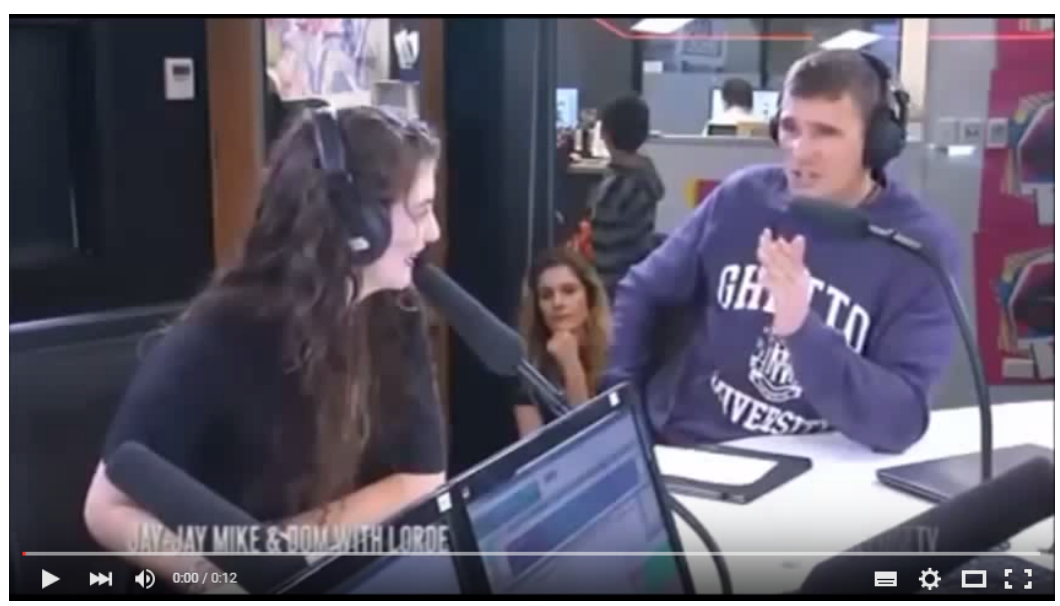

Example 25: Word Up ${ }^{10}$

1 Jaquie: what did a tornado do to some chickens in Kansas in 1928?

2 Cont: ah plucked them, ripped all their feathers off

3 Jaquie: oh mate! this is absolutely one hundred percent correct

\footnotetext{
${ }^{9}$ Transcripts of all media clips can be found in the appendix.

${ }^{10}$ Due to copyright issues this clip was not able to be shown and has been transcribed.
} 
As noted above, significant trends can be seen in these examples. All three women are heterosexual ${ }^{11}$ Pākehā women in their thirties or early forties, speaking to Pākehā males of a similar age. The familiariser itself is used in slightly differing ways in each example however. In example 23 the speaker, food blogger Ingrid Opera, addresses the celebrity chef as mate during part of a playful interaction between the three participants. Her comment you're in trouble mate is clearly meant in jest, and contributes to the humour sequence constructed by the two women. In example 25, Jaquie Brown, a well-known television presenter, uses oh mate in an exclamatory manner following the contestant's accurate answer. The term is somewhat exaggerated here which could suggest it's being used semi-ironically, however the amplification is also keeping with the convivial nature of the show. Unlike in examples 23 and 25 where the interlocutors presumably aren't in an intimate relationship, the mate in example 24 occurs between spouses. Here radio host Jay-Jay Harvey's use of mate functions as a kind of mock protest (hey mate you might not be busy but I've got appointments) in response to her husband and co-host's remark.

A common factor shared by each of these tokens is that they occur in jovial environments, where the female speaker is using the term in a distinctly playful manner towards the man. It is conceivable that the women's use of this typically masculine term is indexing a stance of solidarity with their male interlocutor, through humour. Parallels can be drawn between this and the 'cool solidarity' stance that Kiesling (2004) found dude was indexing. He suggests that the expansion of the use of dude to females is based on the term indexing the solidarity stance separate from its associations with masculinity. Perhaps we are seeing something similar to this in the women's use of mate.

\section{Female tokens: scripted speech}

The media data revealed even fewer female tokens in scripted speech than were found in naturalistic environments. Furthermore, in those instances where mate did occur, it was

\footnotetext{
${ }^{11}$ Sexualities here are assumed, based on information gathered from public media sources, i.e. all three women are currently in heterosexual marriages.
} 
produced by a character that, in some respects, displayed normatively masculine qualities. Example 26 is taken from the television series Go Girls.

\section{Example 26: Go Girls (1)}

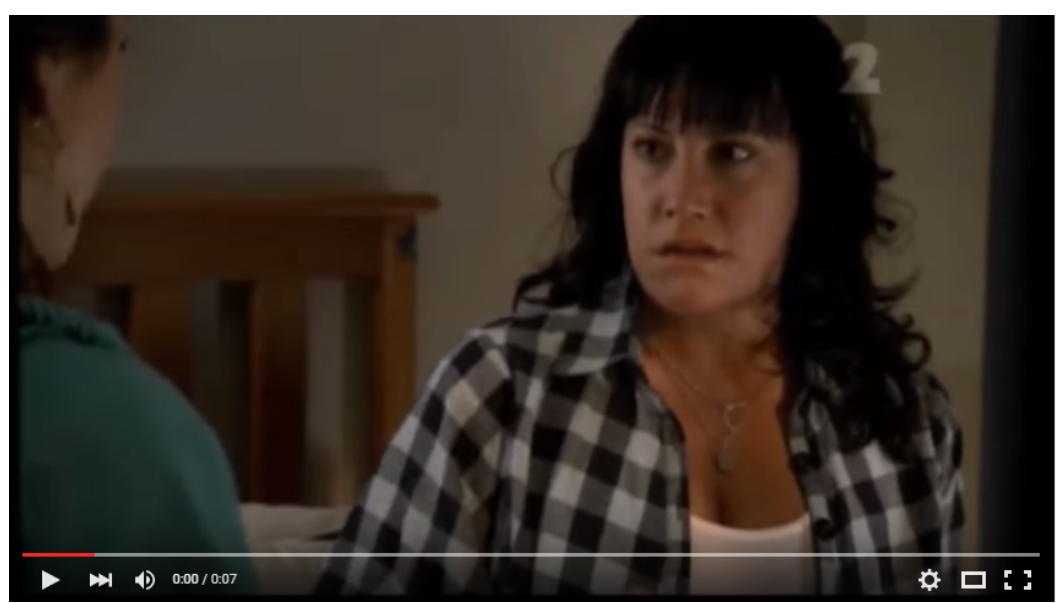

The character 'Cody' in this example is responsible for 2 of the 4 female scripted speech tokens, and is portrayed in Go Girls as the tomboy of the group. In the opening of this episode the narrator's description of her is explicit: Cody-best mate, can drink the boys under the table, knows her rugby, and handy in a fight. Due to the paucity of tokens elsewhere in the scripted data, it seems reasonable to assume that Cody's use of mate is associated with the masculine attributes assigned to her character. In the following example, from comedy series Coverband, we see a more subtle reference to masculinity. 


\section{Example 27: Coverband (1)}

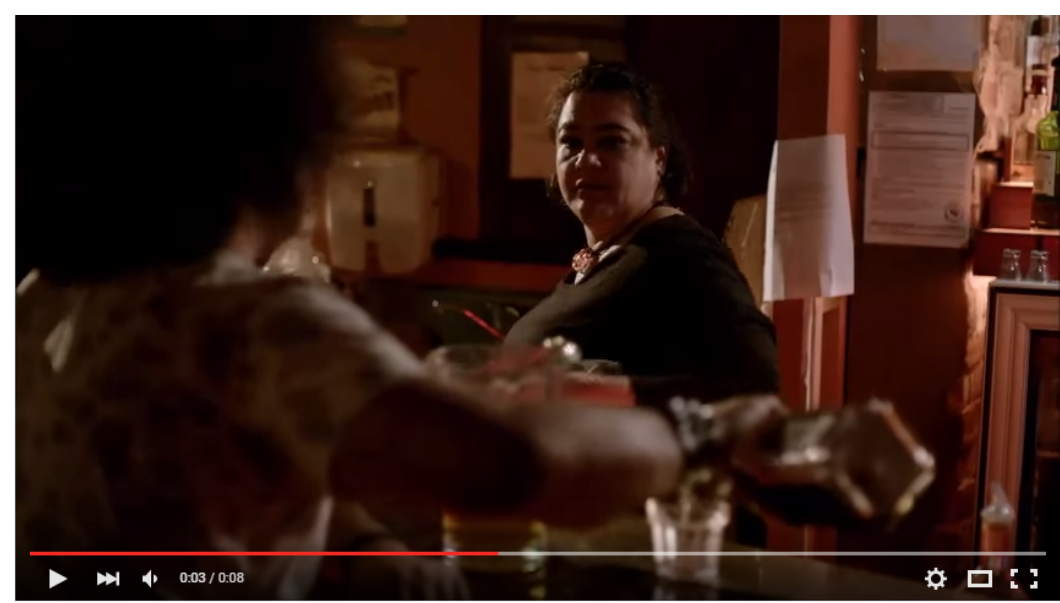

In this example the masculinity is not so much attributed to the character's personal qualities, but the fact that she is a bartender in a somewhat masculine environment - a rough inner city bar. The character's hey mate is potentially an index of a normatively masculine interactional style that is compatible with the bar setting. Notably, the female characters here, unlike in the spontaneous speech examples, are Māori/Pasifika. The representation of masculinised femininities that we have seen in these examples, and the trend observed regarding speaker ethnicity that we saw in Table 10 above, are indications that mate is being used to construct social identities and represent gender ideologies in contemporary mainstream media.

\section{Male tokens: spontaneous speech}

Male-male tokens, easily the most prevalent in the data, were found in a number of spontaneous speech environments. Unsurprisingly, tokens were commonplace in television programs with typically masculine content such as sports, and in situations where a majority of the interactions were male-male, such as police-based reality TV shows. A number of the tokens observed appeared to serve much the same affiliative functions as those discussed in the corpus data analysis, such as mitigation and solidarity. However there were also prominent examples of mate being used in a distinctly negative manner. The following examples, from reality TV show Motorway Patrol, show explicit use of mate functioning as a marker of hostility, as introduced in the corpus data analysis. 
Example 28: Motorway Patrol (1)

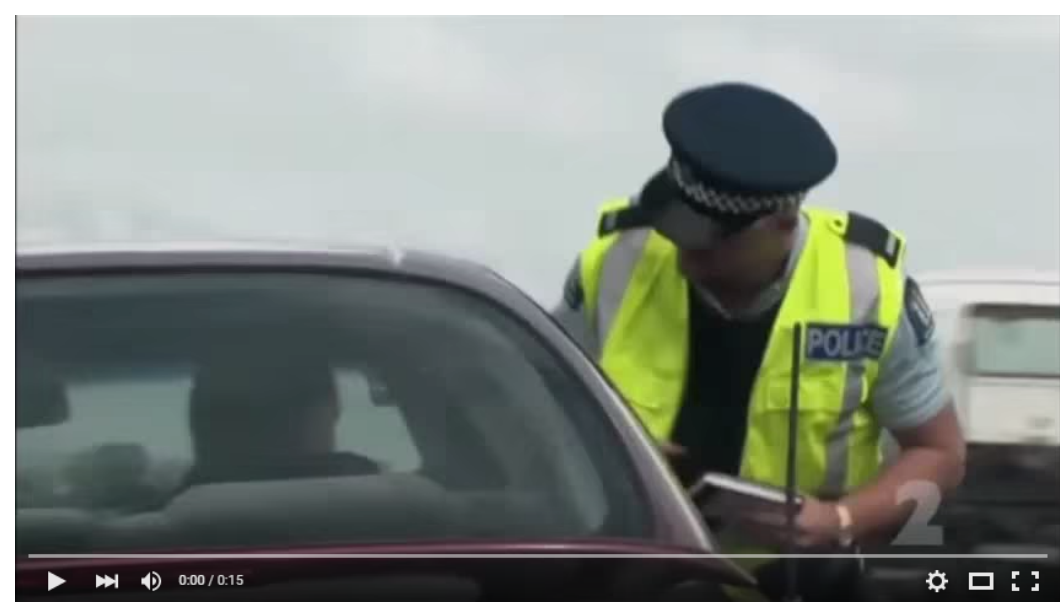

Example 29: Motorway Patrol (2)

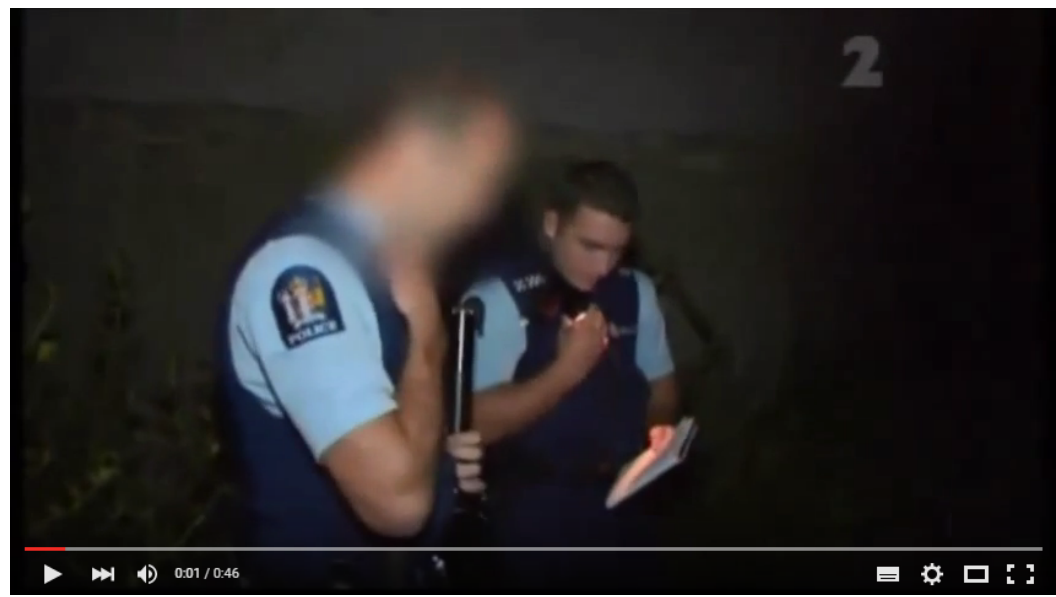




\section{Example 30: Motorway Patrol (3)}

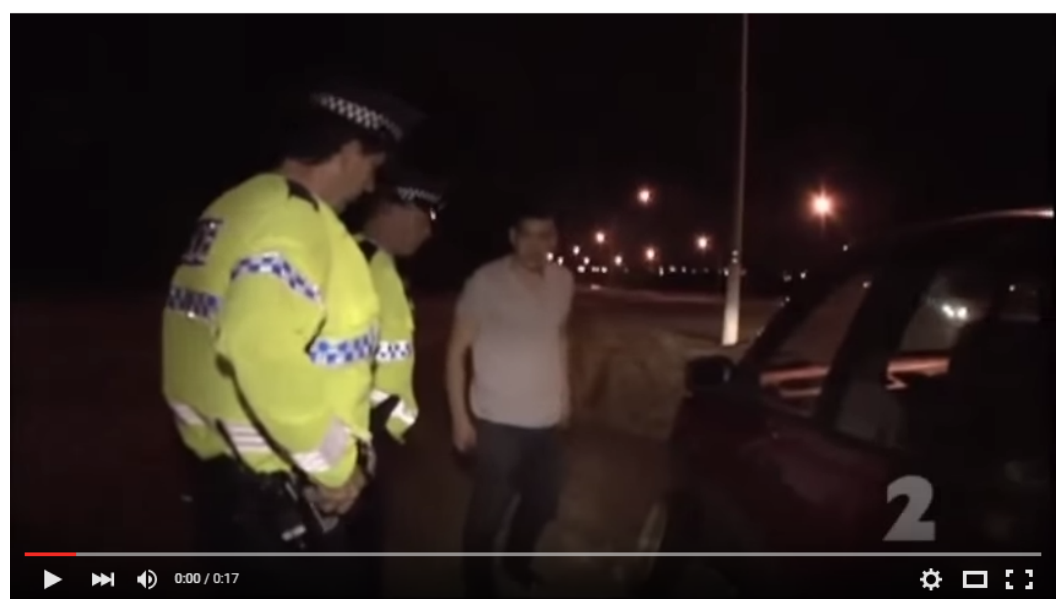

The driver in example 28 and the injured offender in 29 are quite clearly expressing a combative attitude towards the police officers (mate, you bored or something, l'll talk to my lawyer mate), reinforcing the fact that mate is being used contentiously. These tokens aptly demonstrate how mate can imply quite the opposite of the 'friendship' label with which it is often associated. Taking into account the clear power relationship in these interactions, this hostile use supports Spry's (2005) argument that mate can be an aggressive term, intended to disabuse someone of the view that they are in any way superior. In this sense mate is being used to level down, or force level-status in contexts where one of the interlocutors, namely the policeman, is institutionally powerful. Parallels can be drawn between this and the hostility we saw in example 17, when a factory worker is discussing out-group referents (they come on fucking site twice our fucking hourly rate borrow your fucking tools, borrow one of my fuckers mate). As 'they' are on a higher pay grade, and are therefore in some way potentially higher in status, the mate can be interpreted as levelling down the absent referents.

Although not as outwardly hostile, the police officer in example 30, (you've got the tyre round the wrong way too mate) is also using the familiariser in a way that is clearly not signalling a positive relationship towards the drunk driver. Here, however, mate is potentially also used to keep the interaction informal and non-threatening, as it has not yet been confirmed that there has been an actual offence. 
Unlike in the antagonistic speech of both the police officer and the offenders however, the mate tokens spoken by the paramedic in example 29 appear to be serving a different function. In mate, you've just been a hell of a fall, mate is functioning as an attention focusing device (as we have seen clause-initial tokens often do), signalling the importance of the information the paramedic is about to impart. His next use of the term, that's what we're trying to take care of mate is, although firm, arguably more an attempt at solidarity, as he attempts to reason with the man.

Mirroring results from the corpus data, the prevailing use of mate in spontaneous male speech was found in humorous speech acts (see Table 8). Tokens were frequent in settings where discourse was primarily intended to amuse, such as comedy based game and panel shows. These tokens, occurring in jokey sequences predominantly between males, tend to exemplify the 'Kiwi humour' I argue is inherently linked with NZ identity. The following examples are taken from comedy game show 7 Days.

\section{Example 31: 7 Days (1)}

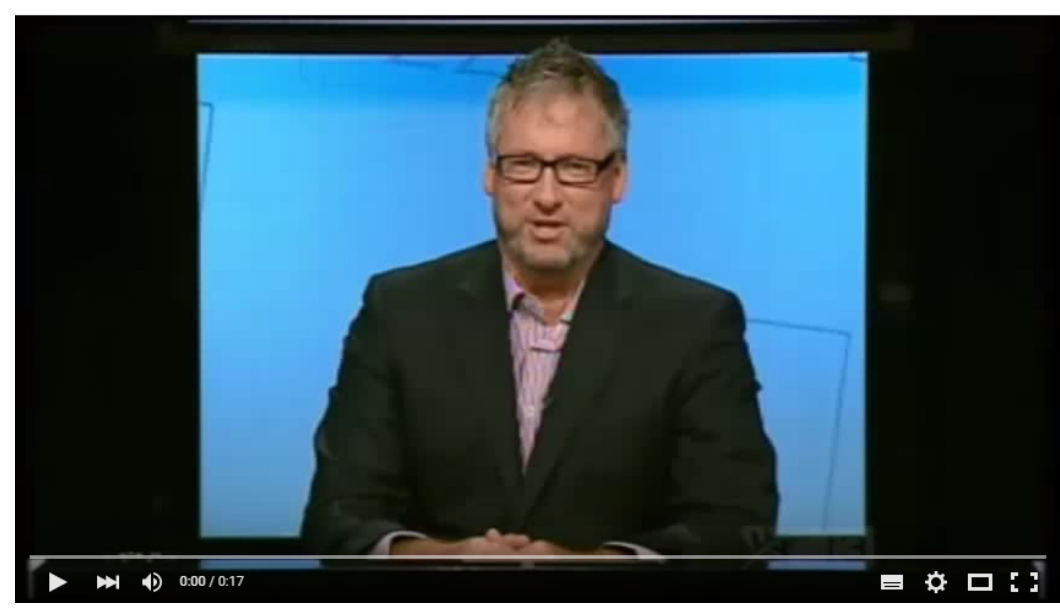




\section{Example 32: 7 Days (2)}

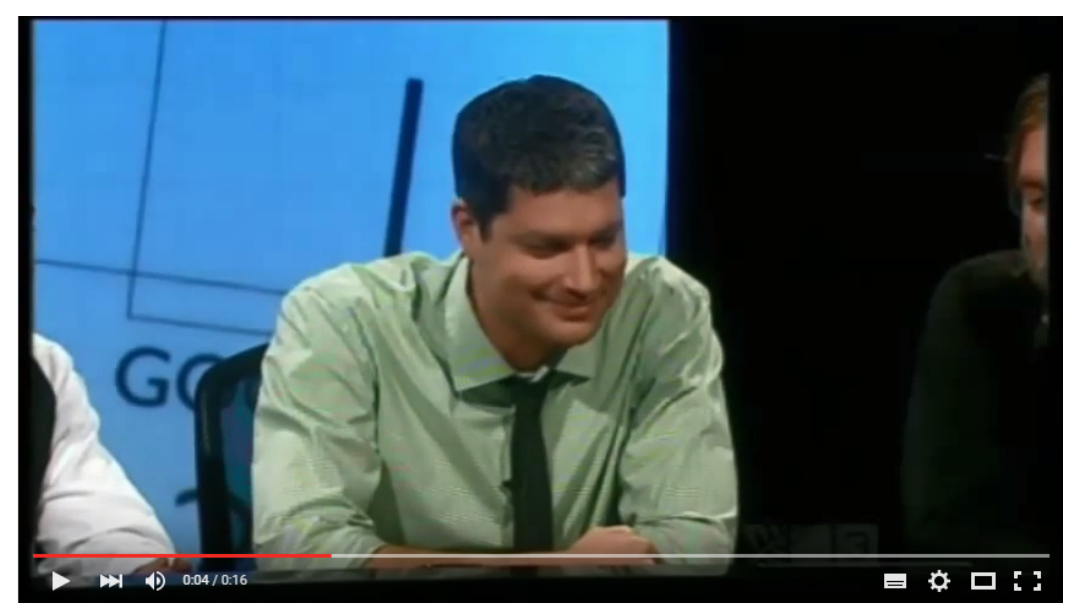

These speech acts are much the same as those found in the 'teasing' sequences discussed in the corpus data. Despite the content of the speech being potentially offensive (namely, a comment on someone's weight, a suggestion of incest), the remarks are obviously meant in good humour and comply with the program's playful atmosphere. These examples can be interpreted as displaying stereotypical qualities of New Zealand humour. Example 31, it'll take more than that mate [to cut down your waistline], is prototypical of the laconic, deadpan humour with which New Zealanders are often associated. In example 32, following a rude remark from the host, comedian Dai Henwood provides a good-humoured response that is both sarcastic and self-deprecating, further characteristics associated with Kiwi humour (Harker, 2013). The correlation between humour and the 'Kiwi bloke' has been identified by Law, Campbell and Dolan (1999), who note that the comedic tradition has lovingly preserved the Kiwi bloke as a stock-in-trade figure (e.g. Fred Dagg, Wal Footrot). This 'blokeish' character, perhaps most notably defined in Phillip's $(1987,1996)$ work on Pākehā masculinity will be considered in more depth below.

As noted, the use of mate to express solidarity and humour, but also hostility, is evident in male-male interactions across the data. A different function however, was observed in the male-female exchanges in the media data, where the term occurred in speech acts associated with praise. The following examples are taken from the competitive cooking show Masterchef, and talent show New Zealand's Got Talent. 


\section{Example 33: Masterchef (1)}

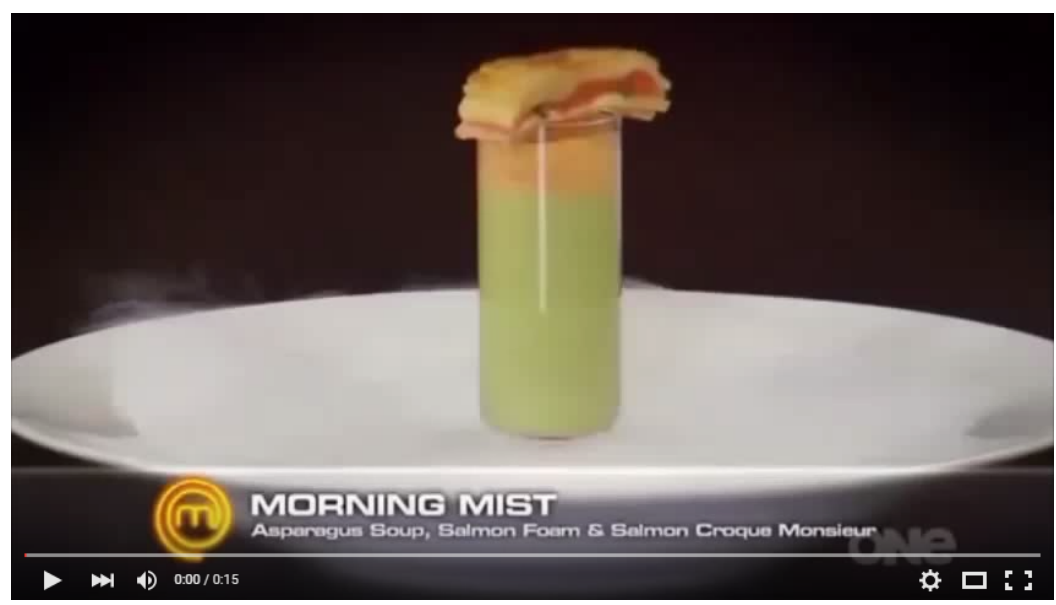

\section{Example 34: New Zealand's Got Talent}

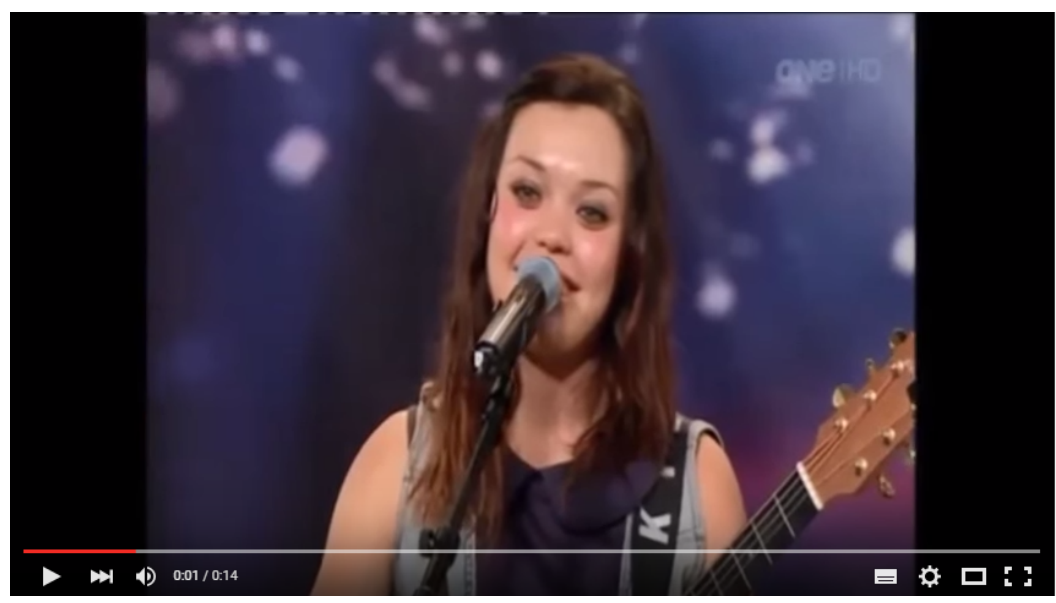

In contrast to the female-male interactions above where mate aided in constructing humorous speech acts, here the term occurs in a quite different environment. In both instances the male speaker is expressing approval and applauding the female's performance. Perhaps significant is the competitive nature of the respective shows, and the relationship between the male as judge, and female as contestant. It is arguable that the use of mate is an attempt to put the contestant at ease by suggesting familiarity, in a potentially stressful situation. It is also feasible that, while they may not typically use the term to address a female, in giving praise, the male speakers select a term they associate with peer affiliation - the praiseworthy performance motivates them to reduce the distance created by the power roles (of judge and contestant) and their respective genders. 


\section{Male tokens: scripted speech}

The claim made above, that the 'Kiwi bloke' is often represented in a comedic context, is nicely illustrated in the first example here, which can be viewed as a stereotypical portrayal of the archetypal New Zealand man. Example 35 is a television advertisement for hardware store Mitre 10.

\section{Example 35: Mitre 10}

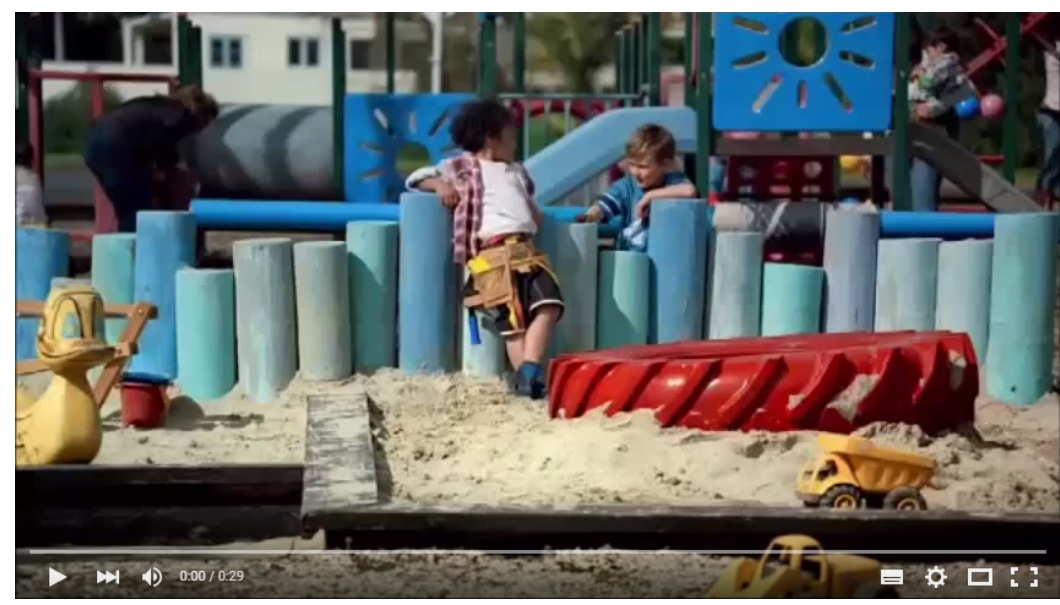

Here we see the 'characters' feeding off strong national stereotypes, i.e. the Kiwi man as a DIY enthusiast always ready to help out a friend, casual, macho, and scornful of Australians. Both the New Zealander and the Australian kids use mate, illustrating how the term is indicative of both nationalities concurrently, even when, as in this case, the intention is to highlight division between the countries. However, the line oh come on mate, do it yourself is a distinct reference to a particular kind of masculine New Zealand identity. The implicature is clear - the Kiwi kid thinks that his 'mate' should exercise his DIY skills rather than 'get a bloke in.' The advertisement is promoting the relationship between DIY and New Zealand identity, transparent in their slogan DIY, it's in our DNA.

As in the spontaneous speech data, male-male instances of mate were fairly frequent in scripted speech environments, however there was less diversity in terms of function. An overwhelming majority of the tokens were used to express friendship or familiarity between male characters. Several tokens were found in father-son interactions or where an older male addressed a younger, often to enhance solidarity or as part of a directive. 
An example of this can be observed in the following clip, taken from drama series Brokenwood Mysteries.

\section{Example 36: Brokenwood (1)}

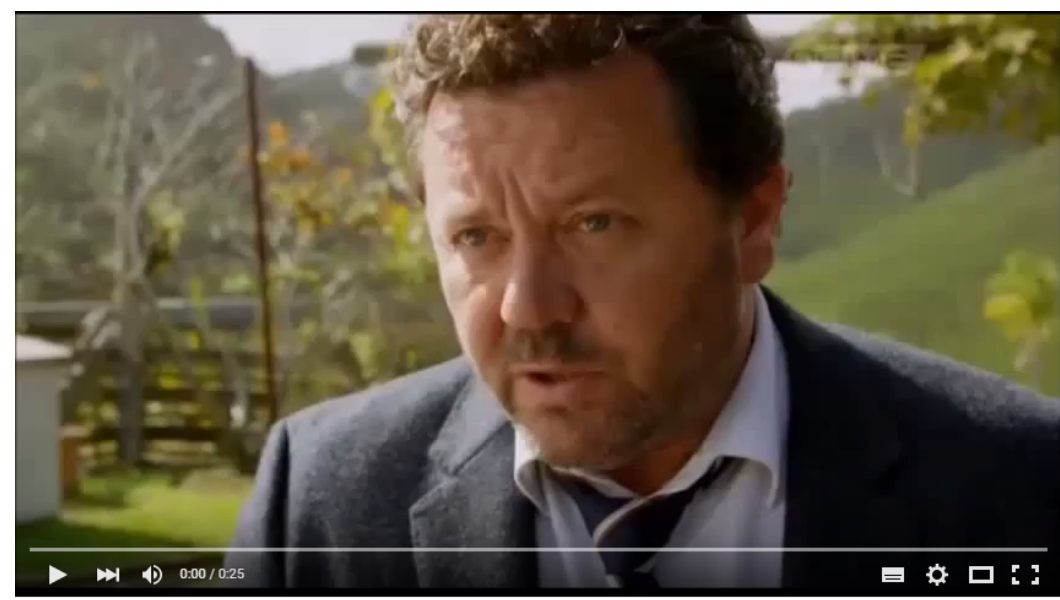

Similar to the paramedic's use in example 29 , here the older man uses mate in a speech act designed to reason with the other person. Here the detective is both issuing a directive and making an appeal to reason and emotion. By including the familiariser in how's that work for you mate?, spoken with an almost fatherly tone, he is attempting a stance of solidarity in order to negotiate with the armed man. An explicit fatherly usage is demonstrated in example 37, an extract from comedy/drama Nothing Trivial.

\section{Example 37: Nothing Trivial}

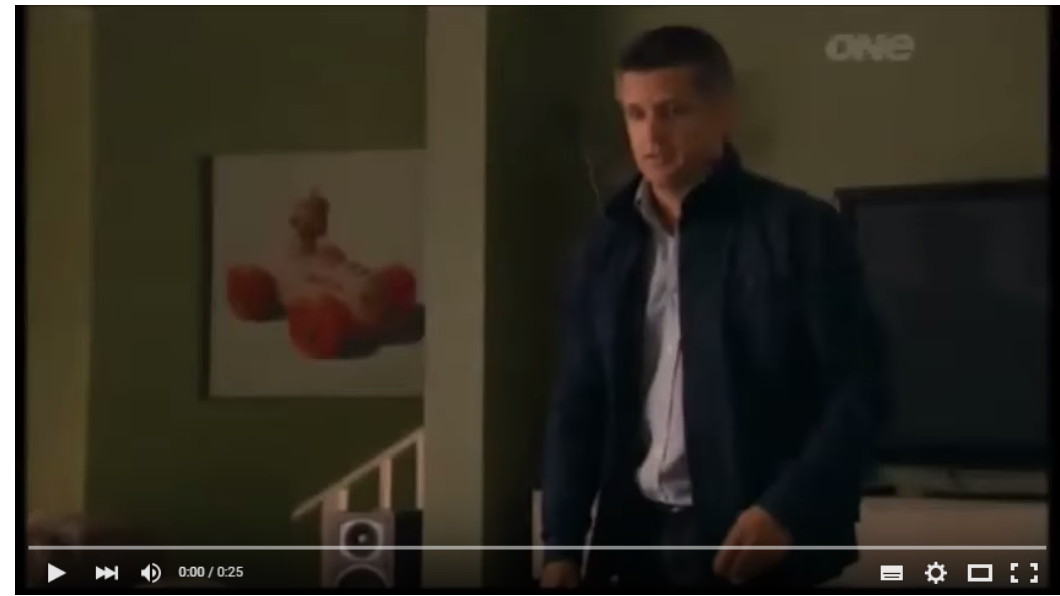

While these tokens display parental warmth from a father to his sons, this example, along with example 36, show how mate can occur in an opposite hierarchical structure to that 
in the Motorway Patrol examples $(28,29)$. Instead of mate functioning as a marker of contempt towards an authority figure, in these examples we see someone in a senior role (in both age and position) use mate in a way that signals affection, to someone younger and of lower status. This further demonstrates how mate, for speakers of NZE, is both polyfunctional and polysemous.

A further function that was observed in the fictional data was once again mate being used to express hostility. The following example, again from Brokenwood Mysteries, contains tokens from two different male characters.

\section{Example 38: Brokenwood (2)}

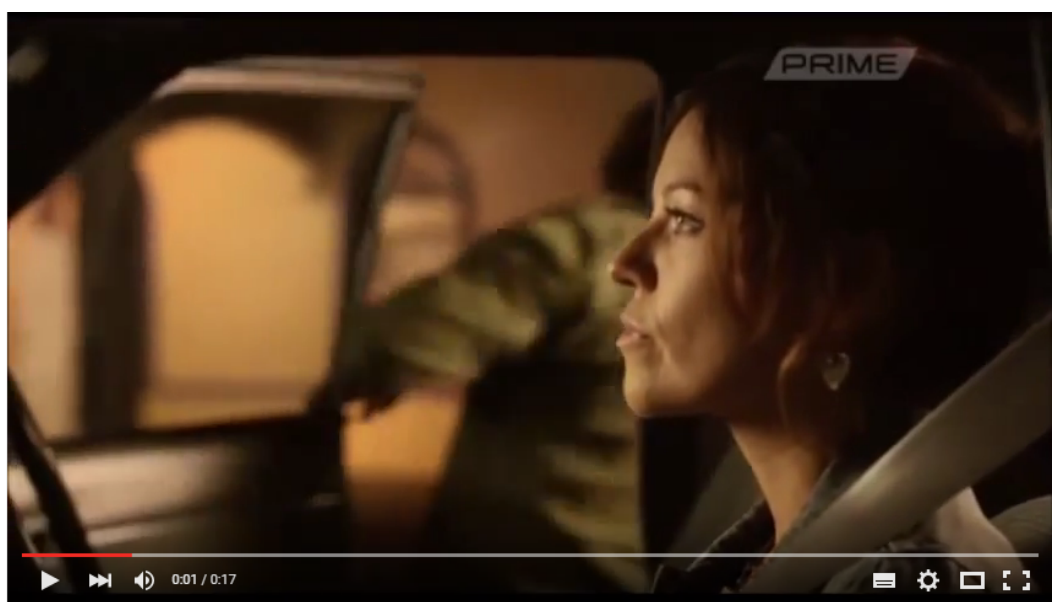

Both instances of mate in this example form part of an obviously hostile speech act. The presence of this hostile use, coming from characters that can be seen as typifying the 'Kiwi bloke' - rural and Pākehā (Law et al., 1999; Perry, 2013; Phillips, 1987), suggests it is commonplace enough to be associated with this image. That is to say, that the hostile use is widespread enough to be written into the dialogues of the stereotypical users of the term.

As illustrated by the above examples, mate occurs in a range of speech acts, yet while it is used on occasion by female speakers it remains a predominantly male term. While still very gendered, mate is able to perform a variety of functions depending on speech style and context, similar to Kiesling's (2004) findings with regards to dude. The final example in this section, although somewhat exaggerated in nature, aptly illustrates how versatile 
the term mate really is. Example 39 is anti-drink driving advertisement from the New Zealand Police.

\section{Example 39: NZ Police (1)}

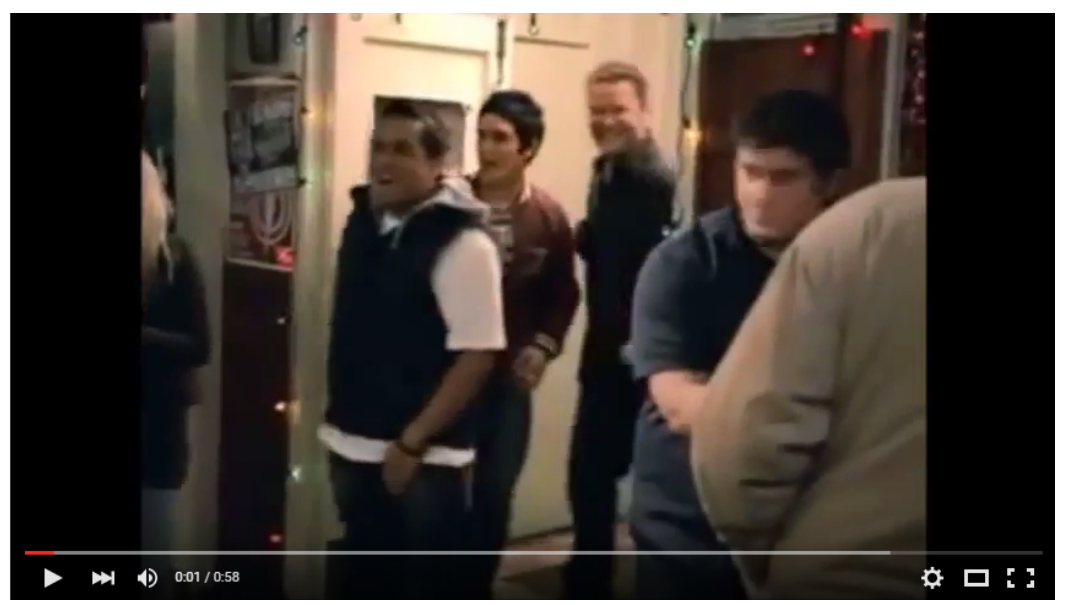

A wide range of meanings can be interpreted from the extensive use of mate here, including its use as an attention grabbing device, to express approval, as a warning and as an expression of disbelief. Overall however the term is used to convey friendship and camaraderie, and the membership of an in-group, which the crucial final switch from mate to Dave (proper name) indicates the drunk driver is no longer a part of. The advertisement therefore represents both the flexibility and polysemy of the term mate, and its role as a quintessential expression of solidarity amongst New Zealand males.

\subsection{Discussion}

As we have seen, the familiariser mate functions in range of speech acts and is capable of communicating different kinds of pragmatic force depending on context and setting.

It is in some respects problematic to compare the two data sets, being that they are of a different medium, and the corpora is much more comprehensive than the media data (e.g. it was not possible to collect current data from such a large range of natural speech environments). However it seems noteworthy to address some disparities, particularly with regards to gender. While tokens produced by female speakers were low frequency

\footnotetext{
12 Due to the repetitive and almost exclusive use of mate in this clip it is the only media example not to be transcribed in the appendix.
} 
in the corpus data, in the media data they were remarkably scarce. Although it is plausible that a larger scale media data set may show different trends emerging, my speculation is that a disparity in token frequency between the sexes would remain vast. Considering that the corpora are taken from the mid-nineties and the media data is current, it seems altogether possible that the difference in female tokens in the data sets is evidence that a shift towards gender neutrality is not taking place, contra RendleShort's (2009) findings in Australia. Ideally, we would like to see whether a current corpus of similar size and content would produce results that support or invalidate the inferences drawn from the media data.

A further disparity was observed with regards to the age groups of female speakers. In the corpora, a majority of the mate tokens came from younger speakers. In the whitecollar workplace data five of the seven speakers were in the 25-29 age bracket, and in the ICE and WSC data sets every user of mate was in either the 16-19 or the 20-24 range. In contrast, the majority of users in the media data were aged approximately $30-45$. Once again a larger sample would be necessary to draw any reliable conclusions, yet it is worth noting that those younger speakers from the corpora would now be in their late thirties to mid-forties. This could potentially indicate that the female use of mate is directly linked to their generation of speakers. That is, the type of younger women who were using the term in the 1990s are still using it in their forties.

Despite these notable differences in the nature of the female speakers, the two data sets shared much in common with regards to the social indexicalities that mate possesses. The way mate is used suggests that it is a predominantly masculine term, and the particular kind of masculinity it indexes is one of mateship, solidarity, camaraderie, and intimacy among friends.

A less predictable pattern that appeared consistently throughout both sets of data was mate being used in hostile speech acts, primarily by men. This appears to mirror the antagonistic use of mate in AusE, widely discussed in the Australian media following an incident in 2005 that saw security guards at Parliament House warned over their use of the term (“Parliament guards told no more 'mate,'” 2005). Although other address terms 
such as man and dude can be used to express negative reactions (Kiesling, 2004), they tend to occur in exclamative speech acts. Mate however has the ability to act as explicitly hostile towards a recipient, often in direct opposition to its original semantics. Taking into account its frequent use as a term of reference free of negative connotations, as in $m y$ mate, it is somewhat strange that as an address term it can act contentiously. An interesting point to consider is whether mate is capable of being semantically antagonistic because of, or despite, its friendly counterpart. I will return to this discussion in more detail in Chapter 8.

As young people are often the agents of linguistic change, it seems important to consider the use of mate with specific reference to young New Zealanders. Although a current, large scale corpus of young NZE speakers would be necessary to form any reliable conclusions, the data collected suggests that mate has declined considerably in young people's speech since the nineties. Although by the nature of the media data the age of speakers was often assumed, mate tokens were not common in broadcasts marketed towards younger viewers, and tokens found in male speakers estimated to be under 25 were infrequent (a deviation from the other terms analysed, as we will see in following chapters). Furthermore, with no tokens in the media data produced by young female speakers, it seems reasonable to suggest it is not following the same shift towards gender neutrality that Rendle-Short (2009) found is occurring in Australia. Assuming such conjectures are correct and mate is in fact dying out as a term popular with young speakers, it is surely a compelling question as to why this is. The claim made above that mate can be perceived as being inherently linked with a specific type of New Zealand identity is perhaps significant.

The 'Kiwi bloke' image personified by the likes of Barry Crump and 'Fred Dagg' may well have strong links to national identity, but in reality isn't particularly representative, or indeed relevant to, a majority of young New Zealanders today. With an ever-growing urban population, New Zealand's increasing multi-culturalism and of course the fact that approximately half the country are female, it may be the case that the rugged, rural, Pākehā male icon is becoming increasingly dated. It is possible that as an address term 
mate is too closely connected to this 'Kiwi bloke' image, a stereotype that young New Zealanders don't really associate with, hence the decline in usage.

It is also perhaps salient here to consider mate's strong ties to Australian identity. Young New Zealanders may also consider mate to be more representative of Australian identity than their own, potentially leading to a disassociation with the term. However a selfreport/attitudes study of young NZE speakers would be necessary in order to draw any reliable conclusions regarding this.

Rendle-Short's (2009) findings suggest that young Australians are renegotiating the term mate with regards to gender, and are therefore allowing it to evolve and remain relevant in a way that doesn't appear to be happening in NZE. The notion that mate is losing its relevance and therefore dying out in younger speaker's vernacular is likely to be caused by a number of factors, one of which is quite possibly associated with the lack of a shift towards gender neutrality. It has been widely noted that young women are often the innovators of linguistic change (e.g. Tagliamonte \& D'Arcy, 2009), which may suggest the lack of female users is in fact the leading edge of a loss of mate in youth speech more generally. If, as the data suggests, very few young New Zealanders of either sex are using mate, it seems unlikely that it will progress in the same way that Rendle-Short has reported happening in Australia. 


\section{Bro}

The use of bro in New Zealand is closely associated with Māori speakers, so much so that some refer to Māori English as 'bro talk' (King, 1999). As the term clearly originates from an abbreviated form of brother it is not only marked for Māori ethnicity but also distinctly gendered. Despite its association with Māori English, this chapter will show that it is present in the speech of Pākehā males and its usage among them is quite possibly increasing. Furthermore, there is some evidence that suggests that the term bro may be emerging as a candidate for gender neutral address and reference, despite its historically masculine semantics. This chapter examines the usage of bro in both the corpus and media data sets.

I begin my discussion of the data by presenting an overview of the general trends that were observed, before examining the functional use of bro in both data sets. As with mate, I begin with the corpora, then turn to the media data where I again analyse bro in both spontaneous and scripted speech. Finally I conclude with a brief discussion of the findings.

\subsection{Overall trends of token frequency and function in the corpus data}

Unlike in the previous chapter, where we saw the distribution of mate was fairly consistent across the respective corpora, the distribution of bro tokens in the corpus data was skewed. Table 12 presents the frequency of tokens across the four corpora.

Table 12: Token frequency of bro in the corpus data

\begin{tabular}{|l|c|c|c|}
\hline Corpus & Total tokens & $\begin{array}{c}\text { Male tokens } \\
\text { (Tokens uttered by men) }\end{array}$ & $\begin{array}{c}\text { Female tokens } \\
\text { (Tokens uttered by } \\
\text { women) }\end{array}$ \\
\hline White-collar workplace & 26 & 25 & 1 \\
\hline Blue-collar workplace & 281 & 262 & 19 \\
\hline WSC & 9 & 7 & 2 \\
\hline ICE & 1 & 1 & 0 \\
\hline Total: & 317 & 295 & 22 \\
\hline
\end{tabular}

Note: Corpus sizes are as follows: White-collar workplace (approx. 2,000,000), Blue-collar workplace (approx. 250,000 words), WSC (1,000,000 words), ICE (600,000 words).

What is immediately apparent here is that the overwhelming majority of bro tokens were found in the blue-collar workplace corpus (89.2\%). There seems to be quite a high 
frequency of bro used among women in the blue-collar data set, however, it is important to note that all nineteen tokens were produced by one speaker, who will be discussed in some detail shortly. Also notable here is that the single female token in the white-collar data occurred in reported speech, as did the single male token in the ICE corpus. That is they were attributions of use rather than spontaneous use in action. Furthermore, of the two female tokens in the WSC, one appears to be addressing the speaker's brother (i.e. the token represented bro's historic semantics), and one was echoing another speaker (i.e. a case of mention more than use, Sperber \& Wilson, 1981).

In terms of function, as result of the high token frequency, the blue-collar corpus revealed the most significant variety of functions. The results from both the blue-collar and white-collar workplaces are presented in Table 13 and Table 14.

Table 13: Functions of bro in the blue-collar data

\begin{tabular}{|c|c|}
\hline Type of speech act & Total tokens \\
\hline Humorous speech act ${ }^{13}$ & 25 \\
\hline Affectionate speech act ${ }^{14}$ & 9 \\
\hline Acknowledgement of information & 30 \\
\hline Please + thank you utterances & 26 \\
\hline Hedged utterance & 6 \\
\hline
\end{tabular}

Table 14: Functions of bro in the white-collar data

\begin{tabular}{|l|c|}
\hline Type of speech act & Total tokens \\
\hline Humorous speech act & 3 \\
\hline Affectionate speech act & 5 \\
\hline Reported speech & 4 \\
\hline
\end{tabular}

As we can see from Table 13, bro occurred most frequently in interactions that involved the acknowledgement of information, however this is presumably directly related to the factory setting - a goal-orientated workplace where the transmitting of information is frequent and direct. This kind of discourse is also likely to be responsible for the high token frequency in please and thank you utterances, as they often occurred in exchanges

\footnotetext{
${ }^{13}$ Humorous speech acts here include mock insults that I have interpreted as having humorous intent.

${ }^{14}$ Affectionate speech acts are those that express affection (e.g. praise, solidarity) but have not been interpreted as humour or mitigation.
} 
where information was imparted, directives given etc. The other interaction where bro tokens were commonplace was in humorous speech acts, a trend we have also observed in the mate analysis.

The low token frequency in the white-collar data meant that no real patterns emerged in terms of function, however, it was used most between Māori speakers in affectionate speech acts, suggesting those speakers were using the term as a kind of ethnic solidarity stance, in a setting where Pākehā norms are standard. This stance will be looked at in more detail below.

Due to bro being closely associated with Māori English, and the factory participants being almost equally divided between Pākehā and non-Pākehā (13 Pākehā, 14 non-Pākehā, 3 ethnicity unknown), the ethnicity of bro users, particularly in the blue-collar data, was meaningful. Table 15 and 16 present the token distribution by ethnicity, in the blue-collar and white-collar workplaces.

Table 15: Ethnicity of bro users in the blue-collar data

\begin{tabular}{|l|c|c|}
\hline Ethnicity of speaker & Number of distinct users & Total tokens $^{\mathbf{1 5}}$ \\
\hline Māori & 3 & 60 \\
\hline Pākehā & 4 & 11 \\
\hline Pasifika & 6 & 117 \\
\hline Unknown $^{\mathbf{1 6}}$ & - & 17 \\
\hline
\end{tabular}

Table 16: Ethnicity of bro users in the white-collar data

\begin{tabular}{|c|c|c|}
\hline Ethnicity of speaker & Number of distinct users & Total tokens \\
\hline Māori & 2 & 11 \\
\hline Pākehā & 1 & 1 \\
\hline Mixed ethnicity ${ }^{17}$ & 2 & 9 \\
\hline Unknown & - & 5 \\
\hline
\end{tabular}

\footnotetext{
${ }^{15}$ The remaining 76 tokens were produced by unidentifiable speakers, indicated by a ? in the LWP transcription.

${ }^{16}$ One speaker's ethnicity was not provided in the factory participant information.

${ }^{17}$ One speaker identified as Māori/Pākehā/Chinese, and one as Māori/Pākehā/Cook Island Māori.
} 
Notable in Table 15 is that while token frequency in the Māori and Pasifika speakers was high, a considerable number of tokens were produced by just a few speakers. For example, one participant (Lesia) was responsible for 31 of the 117 Pasifika tokens, and an overwhelming 50 of the 60 tokens from Māori speakers were produced by just one person (Simon). While Pākehā speakers account for a small minority of the tokens, we can see that there are four distinct users of the term, revealing that within the blue-collar workplace, Pākehā are using a form that is predominantly associated with non-Pākehā speakers. As we can see in Table 16, this trend was not found in the white-collar data set, where only one token of bro was spoken by a Pākehā (in reported speech). Indeed, relative to the size of the corpus (approx. $2,000,000$ words), we can see that the frequency of bro tokens in general is remarkably low.

\subsection{Overall trends of token and function frequency in the media data}

We saw in the mate analysis that tokens produced by female speakers in the media data were scarce, however bro tokens were even more infrequent, as Table 17 shows.

Table 17: Token frequency of bro in the media data

\begin{tabular}{|l|c|c|c|c|c|}
\hline Type of speech & $\begin{array}{c}\text { Total } \\
\text { tokens }\end{array}$ & $\begin{array}{c}\text { Male tokens } \\
\text { (Tokens uttered } \\
\text { by men) }\end{array}$ & $\begin{array}{c}\text { Female tokens } \\
\text { (Tokens uttered } \\
\text { by women) }\end{array}$ & $\begin{array}{c}\text { Male } \\
\text { addressee } \\
\text { (Tokens uttered to } \\
\text { men) }\end{array}$ & $\begin{array}{c}\text { Female } \\
\text { addressee } \\
\text { (Tokens uttered to } \\
\text { women) }\end{array}$ \\
\hline $\begin{array}{l}\text { Spontaneous } \\
\text { speech }\end{array}$ & 43 & 40 & 3 & 41 & 2 \\
\hline Scripted speech & 39 & 39 & 0 & 38 & 1 \\
\hline Total: & 82 & 79 & 3 & 79 & 3 \\
\hline
\end{tabular}

The distribution of tokens in spontaneous and scripted male speech is similar, suggesting that, like mate, the frequency of usage of bro in the media is fairly accurate. Again, we can see that there is a strong correlation between the raw frequencies of tokens produced by, and tokens referring to, the different sexes. The paucity of female tokens of bro in spontaneous speech and their complete lack in scripted speech means that it is difficult to observe any trends regarding function. For this reason Table 18, which illustrates the frequency of functions in the data, shows only the functions of bro in male speech. Bro tokens were found in three distinct speech acts. 
Table 18: Functions of bro in the media data

\begin{tabular}{|c|c|c|}
\hline Type of speech act & Spontaneous speech & Scripted speech \\
\hline Expressions of solidarity ${ }^{18}$ & 29 & 22 \\
\hline Expressions of hostility & 6 & 0 \\
\hline Indexing ethnicity ${ }^{19}$ & 2 & 11 \\
\hline
\end{tabular}

As Table 18 shows, bro occurred most frequently in expressions of solidarity, in both spontaneous and scripted speech. Interestingly, and in contrast to the mate data, the term functioned as a marker of hostility in spontaneous speech environments but not in scripted speech, suggesting that this usage is not nearly as widespread as the antagonistic use of mate. The use of bro to represent ethnicity (specifically Māori) was common in fictional broadcasts, and will be discussed in more detail below.

\subsection{Functions of bro in the corpora}

As we will see, bro contrasts with mate in both its functions and its distribution. Mate tokens were found regularly throughout all four corpora, but as we have seen, the distribution of bro was much more unbalanced. As a result of this imbalance this section will predominantly focus on discourse from the factory production team, a (CofP) that bro has quite distinct social and interactional functions within.

In addition to producing a substantial number of tokens (281 in total), the factory data provided some significant information regarding gender. The most revealing data came from one participant in particular, the factory production team manager, Ginette.

Ginette, a Pasifika woman in the 30-34 age bracket, was responsible for 19 tokens of bro. Such tokens occur in various speech acts and, as we will see, aid in Ginette constructing her identity as the team leader. Ginette's leadership style seems to differs from Jaeson's, who we encountered using mate as a leader in his white-collar workplace. Like Jaeson, there were occasions where Ginette used a familiariser to mitigate and soften directives, however, I argue that Ginette's usage is more often a solidarity stance that signals a close and informal relationship with her subordinates, than a tool for mitigating potential face

\footnotetext{
${ }^{18}$ I use this term here to cover a range of different solidarity stances (e.g. ethnic solidarity, peer solidarity)

${ }^{19}$ Although some expressions of solidarity also index ethnicity, this function relates to the use of bro to index a character's Māori identity, and will be discussed in the analysis of the scripted speech data.
} 
threats. Although there is only a subtle distinction between these functions, I have interpreted them as distinct based on the kind of speech acts that the familiariser tends to occur in - Jaeson's were characterised by directive and corrective statements, while Ginette's use of bro occurred more often when the utterance was more akin to 'office banter,' as we will see demonstrated in example 40 below.

Although Ginette is a direct and authoritative manager (Holmes, 2006a) she uses extremely informal language with her co-workers, and participates in humorous exchanges that in other workplaces might be deemed inappropriate. The following example is an interaction between Ginette and Simon, one of the packing line workers.

\section{Example 40}

1 Ginette: [to radio]: and you can get your sorry ass over there and help Rick get that two kilo going

2 Simon: [via radio]: could you go along to weight watchers please

3 Ginette: [to radio]: been there bro they gave me the boot

Here Ginette not only accepts the gibe about her weight but contributes to the joke further, demonstrating the informality of their relationship. Holmes (2006b) notes that jointly constructed humour tends to develop between people who know each other well, and are familiar with each other's sense of humour, therefore building on one another's humorous remarks. Ginette's use of this conjoint humour, with the addition of bro, affirms her identity as not just the boss but part of the team.

The contestive nature of this sequence exhibits a competitive humour that has been associated with predominantly male groups (Holmes, 2006b). Kiesling (2005) has examined how fraternity brothers balance competing scripts of male solidarity and heterosexuality through ritual insults, routines he characterises as a form of competitive collaborativeness. He notes how the competitive nature of the discourse seems to allow, and masculinise, stereotypically feminine ways of conversing, i.e. supportive and collaborative moves within the fraternity. Kiesling's observation gives insight to this type of interaction style on the factory floor, where like a fraternity, the environment is 
particularly masculine. Ginette's contribution to this kind of competitive, conjoint humour is simultaneously performing her normatively masculine interactional style (Holmes, 2006a) which is compatible with the male-dominated CofP, and supporting a kind of humour that contributes to the solidarity of the group (Holmes, 2006b).

Ginette's directives are typically frank with little or no mitigating features, yet despite not using conventional politeness strategies, on a number of occasions she follows an instruction with praise or thanks, and the use of bro. Example 41 is between Ginette and Bert, a factory manufacturer.

\section{Example 41}

1 Ginette: copy mister Kingston

2 Bert: go ahead copy

3 Ginette: can we have er five hundred kilos out of bin thirty into line three please hold onto the rest we'll get back to you

4 Bert: sweet

5 Ginette: oh you're the bomb bro

6 Bert: yeah we know

Ginette follows her directives with the praise you're the bomb $b^{20}$ and the familiariser bro. This use of bro as part of a speech act intended to praise is further evidence that Ginette's usage can index a stance of solidarity. This index is quite possibly pervasive in the CofP, as bro appeared frequently in please and thank you statements throughout the factory data. An observation that will be discussed in more detail below.

In addition to Ginette using the term with some frequency, she is also addressed as bro on several occasions, by at least two of her male co-workers. This is also telling evidence that the form is relatively bleached of its semantics (at least in this CofP) and serves other functions than simply to pick out an addressee. The following example demonstrates this,

\footnotetext{
${ }^{20}$ It seems likely that this was actually something like you da bomb, however I have kept it as it was transcribed.
} 
and simultaneously illustrates how the term can play a role in the very goal-orientated factory discourse.

\section{Example 42}

1 Ginette: then we are on [product name] for the line one [product name] we need two hundred and fifty six tonnes two five six

2 Robert: yo bro

3 Ginette: [product name] for the line three [machine] we need one five tonnes one five

4 Robert: yeah bro

5 Ginette: for the line two I don't know l'll get back to you later okay bye see you later

Both Ginette and Robert here use direct forms of speech that reflect the goal-orientated culture of the factory, Ginette by concisely imparting information and Robert by giving brief responses to acknowledge he has received it. The function of bro in these responses is multifarious: it both acts as a term of address as yes Ginette would, and it functions as an interjection, much the same way as yeah man might. Additionally, it seems to tone down the seriousness of an exchange which is essentially just a series of directives. What is clear here is that Robert's responses are unsurprising and satisfactory to Ginette, evidence that her being addressed as bro is completely acceptable. This suggests that in this particular CofP, bro is free of the gender constraints we'd perhaps expect to see in other workplaces, and that, in terms of meaning, it is understood by both speaker and hearer as free of the gendered component of its original semantics.

As the above examples illustrate, the term is linked with familiar and informal speech and therefore functions as a kind of bonding device within the factory CofP, which seems to be free (for both addresser and addressee) of the gendered quality it can carry elsewhere. ${ }^{21}$ In this case instead of gender it indexes a closeness and solidarity with fellow workers. This unifying social function can also be observed is further demonstrated

\footnotetext{
${ }^{21}$ There was also an instance of it being used by a male speaker to address one other female in the bluecollar data.
} 
in the following interaction between Simon, a Māori, and another packing line worker Lesia, who is Samoan.

\section{Example 43}

1 Lesia: those are real bad eh

2 Simon: yeah

3 Lesia: nearly half a pallet might be the Mãori guys did that

4 Simon: eh?

5 Lesia: your people

6 Simon: nah your Samoan brothers did that bro

7 Lesia: [laughs]

In what is presumably a light-hearted exchange, both Lesia and Simon attribute the bad work to each other's ethnic groups. However Simon, at the same time as drawing attention to their difference in ethnicity, is using the term that signals solidarity within their CofP. He uses brothers to refer exclusively to the Samoans, and then bro to refer to Lesia, suggesting that bro here does not index ethnicity so much as rapport among colleagues.

A common environment for bro to occur was following an interjection, most typically in please and thank you statements (e.g. please bro, thanks bro) and when receiving information over the radio (e.g. copy bro). This is perhaps interesting in that although the factory discourse is not conventionally polite, the use of the familiariser with such utterances seems to make them more amiable. While brief, direct, goal-orientated discourse is often necessary for the factory environment, the addition of bro to a request, acknowledgement or expression of gratitude efficiently communicates a kind of attentiveness towards the referent. Example 44 is between Simon and another packing line worker Russell, and example 45 is Ginette and an unidentifiable speaker. 


\section{Example 44}

1 Russell: can you have a look at our um

2 Simon: eh

3 Russell: at our line one please bro

4 Simon: at what

5 Russell: at our line one please

6 Simon: nah bro l'm on a job already

\section{Example 45}

1 Ginette: can you bring up another pallet

2 X: $\quad$ oh bro can you turn the radio down a bit please bro

3 Dennis: yeah

4 Ginette: thanks bro

$5 \quad \mathrm{X}: \quad$ thanks bro

As previously mentioned, this use of please bro and thanks bro is frequent throughout the blue-collar data. This demonstrates that forms of politeness are, while still in the succinct interactional style typical of the factory floor, common practice in their workplace.

Although mitigating features were much less common in the blue-collar discourse, bro can be found in hedging structures similar to that of mate. In line 6 of example 44 for instance, Simon's use of bro could be interpreted as abating the force of his refusal. This is further evidence of how the term functions as an affiliative and often affectionate familiariser within their CofP.

Bro tokens outside of the blue-collar data were sparse, however those that did occur were often found in reported speech. Example 46 is taken from an unscripted speech in the ICE data. 


\section{Example 46}

1 Sp1: $\quad$ you stand back and you ask um Māori claimants well what's really motivating you to put up with all of this in in er the slurs etcetera that you're wanting a freebie etcetera

2 you didn't really suffer what you claim you suffered

3 they say well it's what our tupunas would have wanted

4 I say okay what does that mean

5 well they want to get back rangatiratanga

6 so what does that mean well it's in the treaty bro well what does that mean it means we've had enough of Pākehās and white people telling us how to do things

This speaker's use of bro differs significantly from the factory data tokens discussed above, in that it is functioning as a marker of the ethnicity of a speaker not present. The speaker himself is Māori and he is reporting the, perhaps hypothetical, speech of other Māori people. If we use Goffman's (1981) distinctions between different types of speaker roles, the speaker here is the animator and the original user of bro the author. It is suggested that the original user of bro is both the author and principal, however, we have no way to tell if the Māori claimants have in fact taken the position the speaker claims they have. The inclusion of bro in this reconstructed dialogue is suggesting that both the animator and author are of Māori ethnicity, and is helping to evoke the Māori identity of people not present. Thus the term here is acting as a marker of ethnicity, and serving a different function from the in-group solidarity it indexes in the blue-collar workplace. Unlike on the factory floor where bro serves a collaborative function, here the constructed dialogue is oppositional, and can be interpreted as a marker of ethnic distinction between Māori and Pākehā. 
The final example in this section is perhaps the most explicit illustration of bro being used to index Māori identity. This interaction, taken from the WSC data is between three Māori friends in their twenties, two females (SU, RN) and one male (TM).

\section{Example 47}

$\begin{array}{lll}1 & \text { SU: } & \text { which ethnic group do you identify with } \\ 2 & \text { RN: } & \text { MĀORI } \\ 3 & \text { SU: } & \text { Māori that's Renata } \\ 4 & \text { SU: } & \text { what about you } \\ 5 & \text { TM: } & \text { yo bro } \\ 6 & \text { SU: } & \text { [laughs] yo bro [laughs] MĀORI okay }\end{array}$

The connection here between bro and the speaker's ethnicity is unequivocal. Instead of saying 'Māori' (as Renata does), TM simply replies yo bro. The pragmatics of this exchange tell us that yo bro is not functioning as a greeting, as it would elsewhere in conversation, but is an answer to the question regarding TM's ethnic identity. His implicature is understood by SU, suggesting that to these young speakers, the phrase yo bro is so strongly associated with their Māori identity that it can successfully denote it. This example shows us that while the term bro can index other social functions (such as the solidarity we have seen in the factory CofP), it can also be a powerful marker of ethnicity.

\subsection{Functions of bro in the media data}

As we will see in the following media examples, bro, like mate, is being used to serve various functions in NZE. Moreover, we will observe how bro is capable of communicating quite different attitudes from those we have seen so far in the corpus data. Female tokens of bro were virtually non-existent in the media data, with none found in scripted speech whatsoever. Consequently, this section does not divide speakers by gender.

\section{Spontaneous speech}

As was anticipated, tokens of bro were regularly found in the speech of Māori males, and used most prominently by younger speakers. While by no means exclusively used by Māori, it did appear to function as a marker of ethnic solidarity in many instances. The 
following example taken from talent show The $X$ Factor is an interaction between judge Stan Walker, who identifies as Māori, and Whenua, a Māori contestant.

\section{Example 48: The X Factor (1) ${ }^{22}$}

1 Stan: oh broooo [singing]

2 Stan: I feel like I have to sing that now to try and be better than you

3 Daniel: I'm not sure you can

4 Stan: you know, we're looking for the $x$ factor, we're looking for the package, we're looking for that but, first of all, cause I'm a singer, I'm looking for that voice, and bro you are the mantis!

5 Stan: bro, do you know the one thing that cracks me off about people when they come on stage [imitates contestants] yeah well I'm actually a soul singer, I actually love soul, you know that deep RnB, and then they sing so pussy and so soft

6 Stan: but you came out with blimmin' balls bro, like, it was wicked, like you sang like a man and you sung so deep and soulful, and oh bro, you're the man

7 Whenua: thank you bro

Stan's repeated use of bro, both vocative and exclamative, can be interpreted as performing a similar kind of social function as that discussed with regards to the factory CofP, in that the term signals a kind of group membership. Here, however, the solidarity relates to ethnicity rather than workplace culture. There is a traditional Māori emphasis on rituals of encounter, one of which is that Māori will always acknowledge and greet each other (King, 1999; Metge, 1975). The use of a term clearly associated with Māori English can be understood to indicate solidarity, as it has been observed that "being part of a group who speak Māori English gives feelings of belonging" (King, 1999: 26). It is likely that Stan recognises Whenua as a fellow Māori, and this is potentially what motivates his extensive use of bro ( 5 tokens in under a minute). Although Stan seems to

\footnotetext{
${ }^{22}$ Due to copyright issues, this clip was not able to be used and has therefore been transcribed, however, the extract that this analysis refers to can be found at https://www.youtube.com/watch?v=Rl6qLuGnVJw $(4: 05-5: 00)$.
} 
be consistent in his use of Māori English, (i.e. he uses it in all the interactions I viewed on The X Factor), he uses bro more frequently (yet not exclusively) to Māori and Pasifika contestants. This observation is based on watching numerous exchanges between Stan and a variety of contestants. Notable here is how Whenua replies to the praise with thank you bro, reinforcing the notion of group membership. This is demonstrated further in the following example between Stan and another contestant Beau.

\section{Example 49: The X Factor (2)}

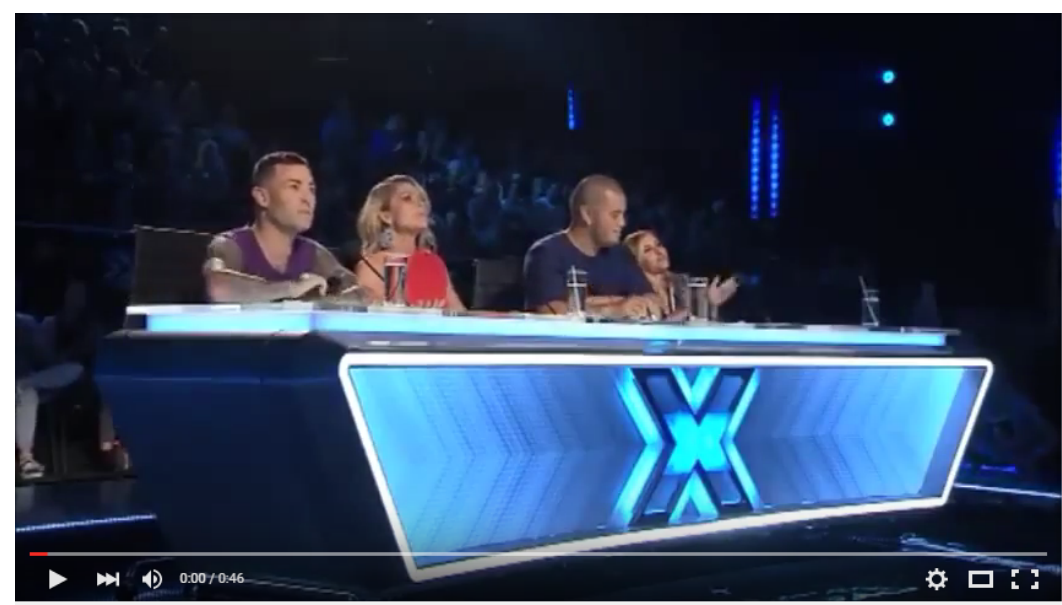

Once again Stan repeatedly addresses a fellow Māori as bro, whilst praising his performance. Again, based on ample viewing of Stan in his role as an X Factor judge, it was observed that he used bro more frequently when displaying strong approval, signalling that the term was often functioning concurrently as a marker of solidarity and of praise.

Interestingly, in this clip a further use of the term materialises, as Beau thanks Stan with the remark sup bro. Beau repeats this after the following judge's feedback (further on in the episode), suggesting that to some young speakers what is typically recognised as a question + vocative [what']s up bro? is in fact functioning as a statement of thanks or acknowledgement. It is possible that what we are seeing here is a phatic expression shifting from a greeting to another context of positive phatic communication - thanks and/or the acknowledgement of receiving encouragement. What is evident in this usage is that the expression should not be taken literally (a question) or even as its most commonly interpreted (a greeting), but as something else, which needs to be 
pragmatically inferred from context and intonation. This use of bro was not produced by any other speakers in the current data, however, it would certainly be interesting to see if it is occurring in any other speech environments.

While bro was regularly used to address Māori and Pasifika, it was not uncommon to find Pākehā males both using, and being the recipient of, the term. The following example is taken from Motorway Patrol and features both a male and a female addressing a policeman as bro.

\section{Example 50: Motorway Patrol (4)}

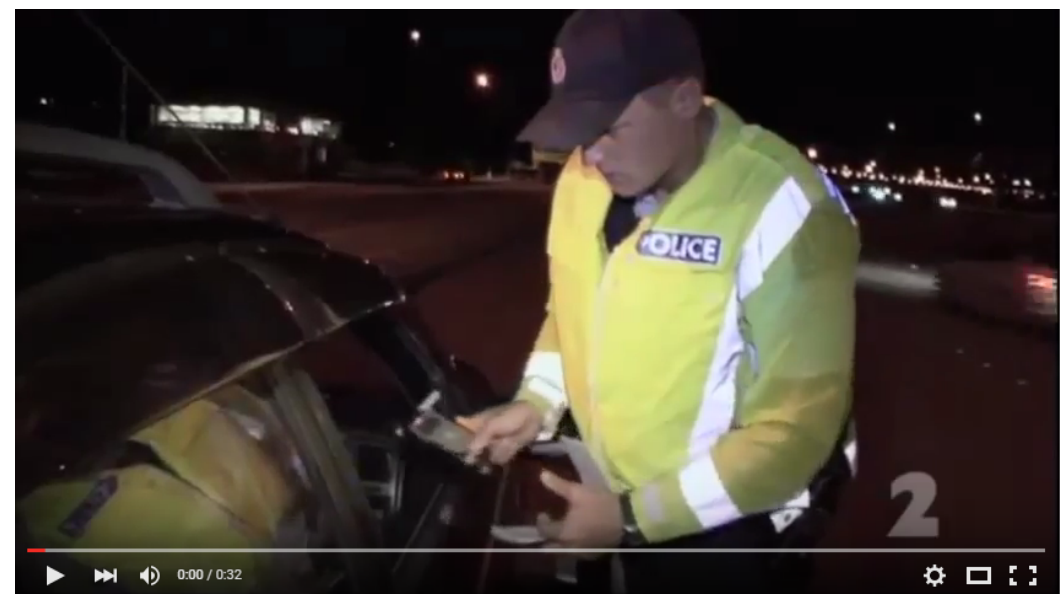

The two bro tokens here occur in quite different speech acts. The woman attempts to negotiate with the police officer by offering an alternative reading of the meter ( drank heaps of coffee, bro), yet her tone is not argumentative, implying she is prepared to be co-operative. The man is much more antagonistic in tone. In both his remarks (I wouldn't do that, cause bro,... and you listen to me bro) the intended meaning is clear - he is both disagreeing with the officer's decision and warning him off taking certain actions. This use expresses the same kind of hostility we saw when we looked at some tokens of mate, which also incidentally involved addressing someone in a position of institutional, situational or legal power.

This hostile use of bro was not as prevalent in the data as it was with mate, yet as demonstrated by the following example it is certainly capable of being used in belligerent speech. Example 51 is two extracts from Radio New Zealand reports covering the Blessie 
Gotingco trial ${ }^{23}$, both interactions between the accused man and crown prosecutor Kieran Raftery.

\section{Example 51: Radio New Zealand - Blessie Gotingco trial}
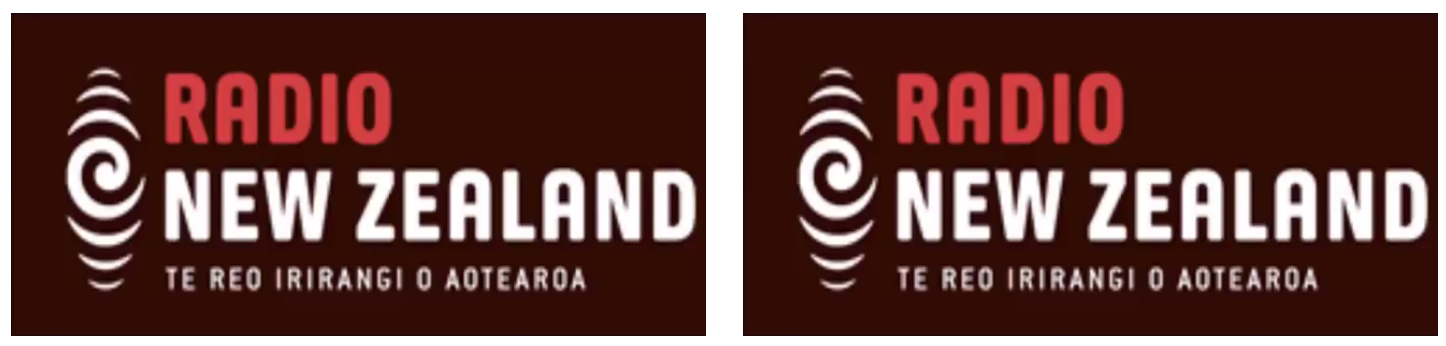

What is evident from these exchanges is that bro is by no means limited to performing positive social functions such as enhancing solidarity. Moreover, it appears to be a distinct marker of hostility and aggression, demonstrated by the fact that the defendant only selects the term when he becomes angry and discomposed. Compared to his language use in other parts of the cross-examination the speech acts that include bro appear combative and much less controlled, suggesting the usage is a (perhaps involuntary) reaction to questioning he dislikes. In both examples, I don't care what you say bro, fucking <unclear>, and take what you want from my answers bro, I don't give a fuck man. I fucking told you what happened bro, the defendant uses expletives and declares his disdain for the crown prosecutor's judgements, whilst addressing him as bro. Bearing in mind that Kieran Raftery is an older Pākehā man in a position of power, who is interrogating him, it seems reasonable to assume that the defendant's use of bro here is expressing something quite the opposite to the affection it can represent elsewhere, and is more closely related to the instances we saw with the traffic patrol in examples 28 and 29. These examples vividly demonstrate how the use of bro is by no means restricted to affiliative moves.

As previously mentioned, tokens of bro produced by women were scarce, and tokens by Pākehā females were particularly rare, the only example being the following extract taken from the documentary The Truth about Teenagers.

\footnotetext{
${ }^{23}$ The Blessie Gotingco trial was a 2015 trial in which Tony Robertson was found guilty of raping and murdering Auckland woman, Blessie Gotingco.
} 


\section{Example 52: The Truth about Teenagers}

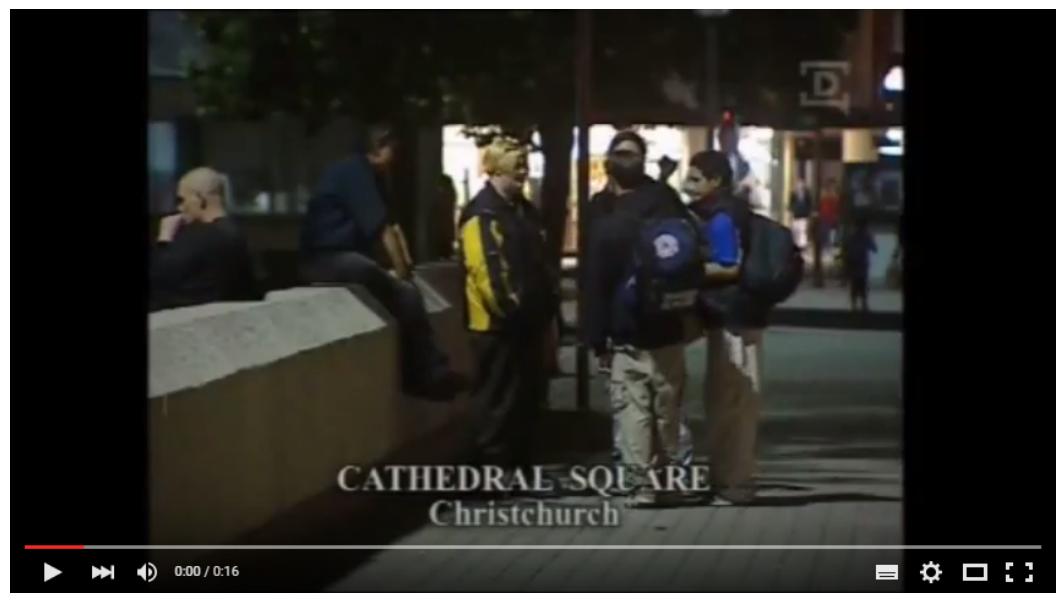

Julia's use of bro in this example can be interpreted as serving a mitigating function, as it occurs between two challenges (nah that's not funny, what are you doing?) that threaten her peer's positive face. The implicature of her challenges is explicit - don't make fun of me making positive life changes. While the interrogative is quite confronting, her tone in nah that's not funny bro is more corrective than antagonistic. This suggests that the bro here is indexing in-group membership rather than the hostility we have seen in examples 50 and 51 above.

Interestingly, Julia noticeably changes her accent when she is speaking to her peers and when she speaks to the interviewer. Her use of bro and a more Māori English accent (e.g. marked intonation contours, cf. Holmes, 2005; Vowell et al., 2014) appear natural in her peer group, as does her use of a more standard NZE when she speaks to the camera. This suggests that for some young speakers of NZE, a Māori English style of speech is one point of a continuum that is at their linguistic disposal. Furthermore, it raises the question of when these young speakers use a register that includes features like bro as a vocative or address form, are they not exactly targeting 'Māori English' but rather an informal vernacular which is suitable for use in specific environments, i.e. amongst peers.

Although the term is being used by Pākehā, and Pākehā speakers appear to be using it with more frequency, it still appears to stand out in some speaker's vernacular, as illustrated in the following example taken from comedy show Best Bits. 


\section{Example 53: Best Bits}

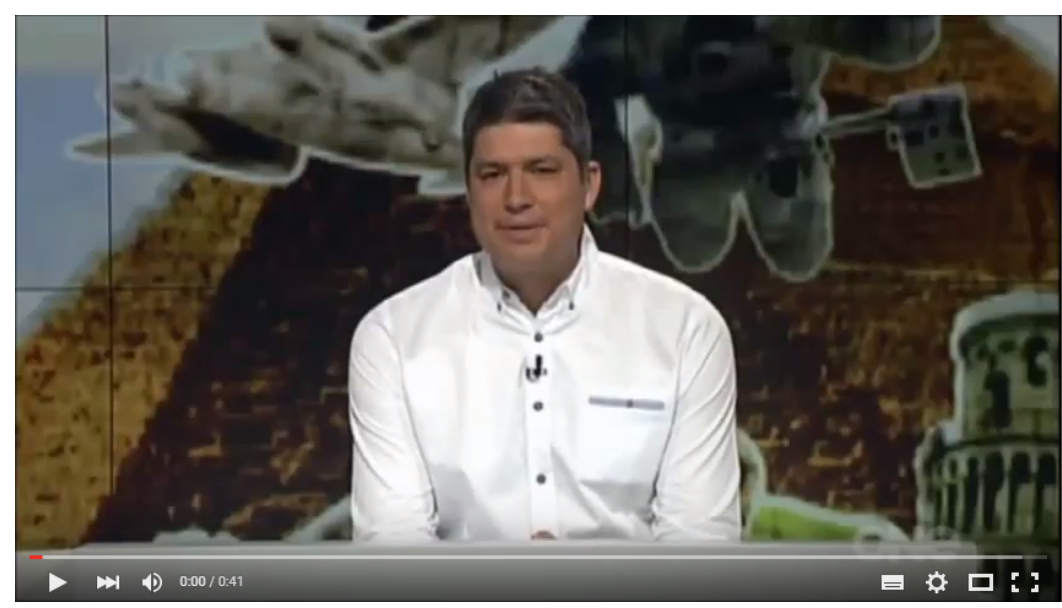

John Campbell's somewhat awkward thanks bro suggests that the term, at this point in NZE, is essentially only unmarked in younger Pākehā speaker's discourse. This may differ in Māori English, however no tokens throughout the media data came from speakers over 40-45 in either variety. The panellist's parody of John Campbell, oh bro, can I take a hit from that legitimately packed bong there bro, nicely illustrates how the term can sound amiss when used in atypical speech, in this case a faux upper-class accent. Although the vocative is capable of occurring in sentence initial positon, the oh bro here appears particularly unnatural. The unusual vowel length and exaggerated rising intonation the panellist uses in both bro tokens further adds to the parody, as they sound quite different from the term when it's used in natural speech, such as in examples 48-52 discussed above.

Given that John Campbell's usage appears marked or abnormal yet Julia's does not, it seems likely that not only age but class is a factor here. Elsewhere in The Truth about Teenagers it is implied that Julia is from a lower socioeconomic background, whereas John Campbell is self-confessed upper middle-class (Hubbard, 2008). As Māori English does not function in linguistic terms as a status variety (King, 1999), it is reasonable to assume that terms associated with it, such as bro, are not commonplace in the speech of upper class speakers. 


\section{Scripted Speech}

Male tokens of bro were commonplace in the scripted speech data. The characters producing them were predominantly Māori, however Pākehā speakers did account for several tokens in a range of broadcasts. In contrast to the somewhat unnatural use of bro in example 53 (Best Bits), the following extracts demonstrate that the use of bro is standard within certain Pākehā demographics, namely young males. Example 54 is taken from Coverband, and example 55 from the drama Brokenwood Mysteries.

\section{Example 54: Coverband (2)}

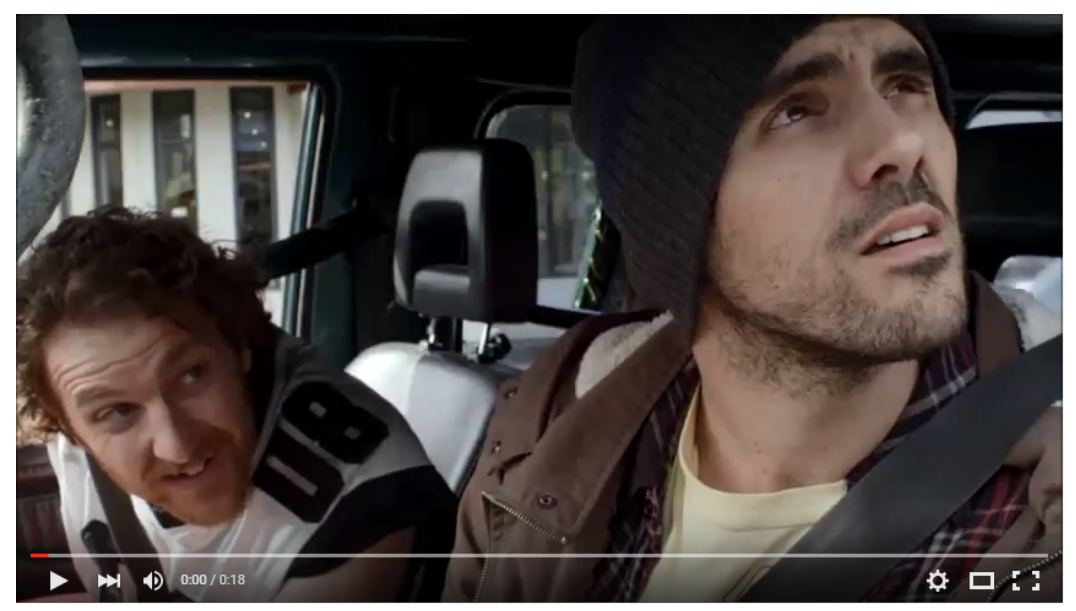

\section{Example 55: Brokenwood (3)}

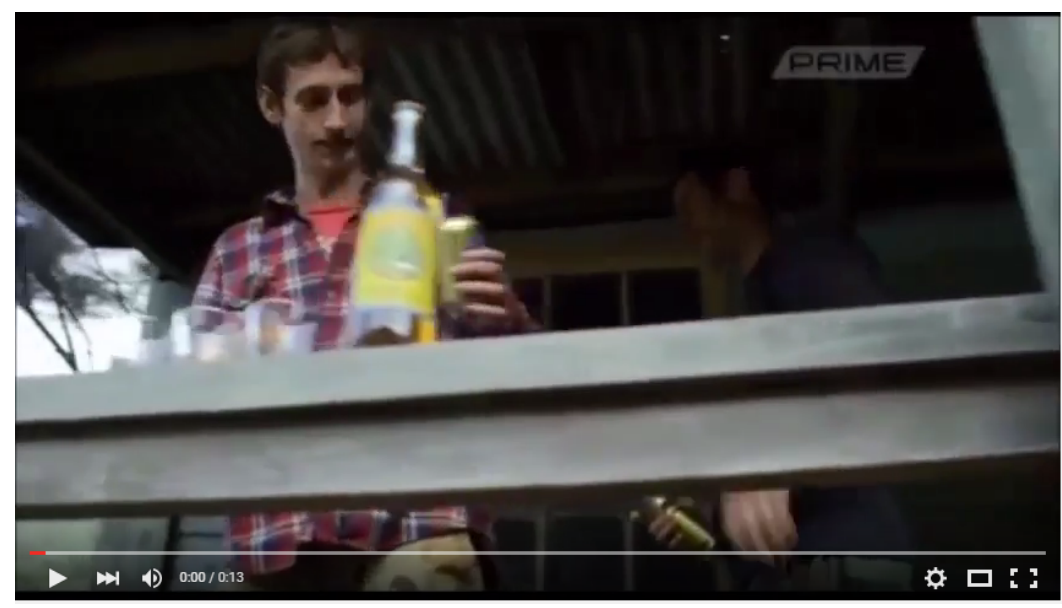

Both of these extracts show bro functioning as a marker of friendship. In the Coverband example, the pragmatics of the exchange tell us that the speech act is designed to comfort his upset friend. The bro here is multifunctional. Firstly, it indexes a familiarity 
and affection towards his friend, expressing a kind of solidarity similar to that we have seen in the factory setting (e.g. example 43, example 45). Secondly, it seems to make the nature of the exchange less earnest, not dissimilar to how we have seen it being used to acknowledge directives in the corpus data (example 42). Thirdly, the use of bro helps the speaker moderate the positive face threat that is imposed on the hearer - he is having to pass judgement on his friend's position in his ex-girlfriend's life. He abates the force of the face threat by disagreeing with his friend's negative self-assessment (you're not the mole bro) and making a favourable contribution to the 'mole' metaphor (you're like a really cute freckle or something). This positive face saving technique has been observed above in both the corpus (example 44) and media data (example 52), demonstrating how the use of bro can effectively communicate and maintain social alliances.

In the Brokenwood Mysteries example we see bro occurring in another speech act designed to provide encouragement to a friend, this time as part of congratulatory toast. The familiariser is once again indexing familiarity and affection. Notable here is that example 54 features young urban males from Auckland, while in example 55 the characters are young rural men. This suggests that the usage is perceived to be quite widespread among younger men and not confined to areas where there is a preponderance of Māori English speakers. Furthermore, it reveals how the term can index a stance of intimacy or solidarity, while being unmarked for ethnicity.

The scripted speech data didn't produce tokens of bro in the same kinds of hostile speech acts observed in the spontaneous speech, however it was not restricted to indexing friendship qualities. The following exchanges, between a high school student and his teacher, are taken from comedy series Seven Periods with Mr Gormsby. 


\section{Example 56: Seven Periods (1)}

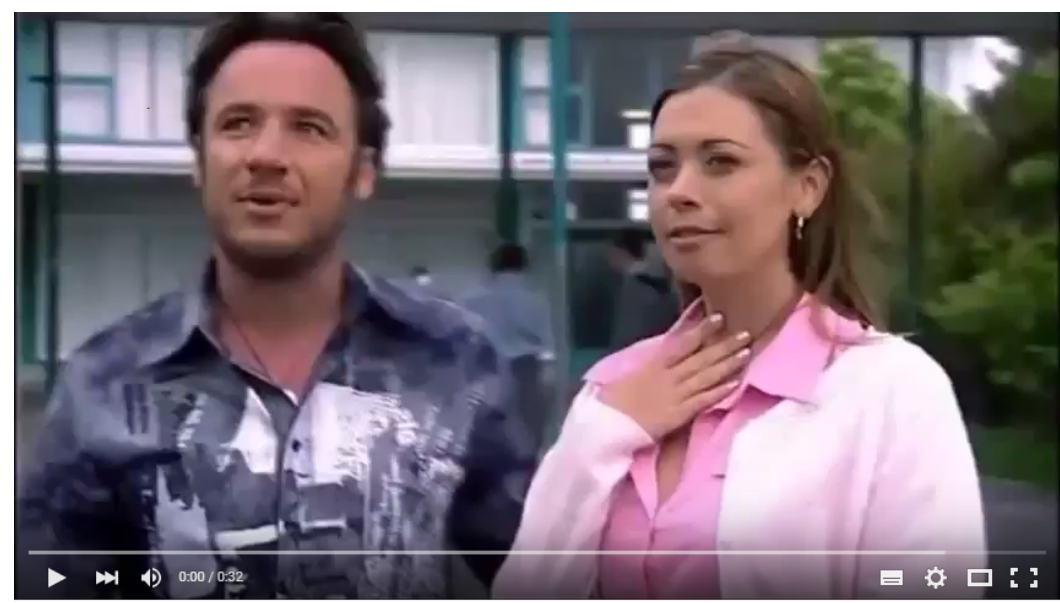

\section{Example 57: Seven Periods (2)}

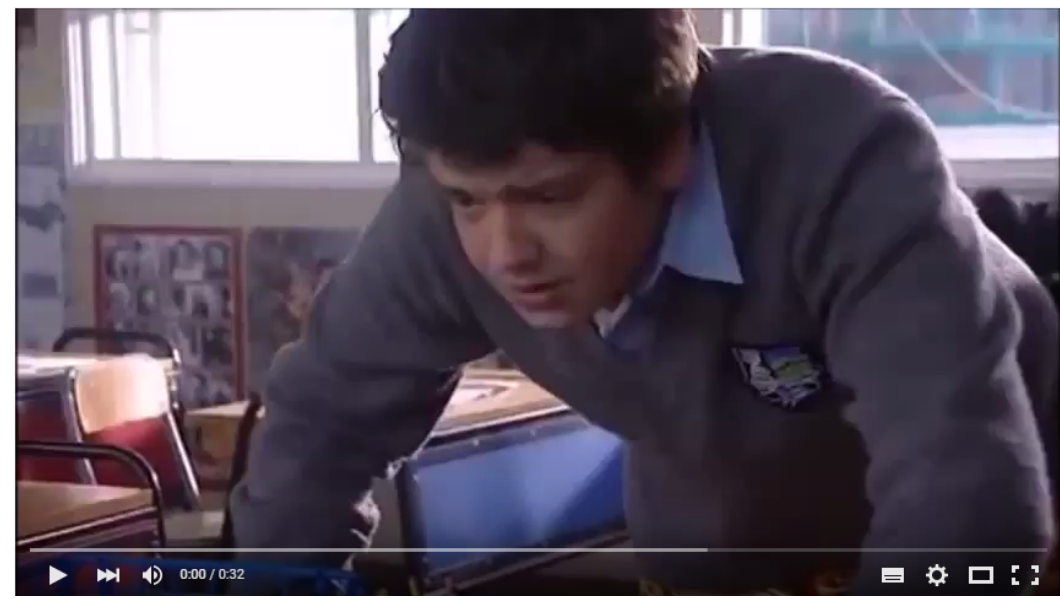

Hohepa's comment shame bro here is clearly ironic - he feels no real compassion or empathy for Mr Gormsby, and the use of bro is not a genuine statement of in-group membership, as it likely is when used amongst his peers. The ironical bro utterance here conversationally implicates the opposite of what it typically, or literally, means. This ironic usage illustrates how bro can be used in moves intended to distance the speaker from the hearer, unlike the affiliative function we have seen it serve in examples above (e.g. example 54, example 55).

In example 56 we see how the term can function as a marker of the speaker's identity, entirely independent of the person being addressed. As Mr Gormsby is obviously not a friend nor a speaker of Māori English, the bro is a reference to Hohepa's own ethnicity, 
and not remotely associated with the older, upper-class, Pākehā authority figure he is addressing. This index of ethnicity, unrelated to the addressee, was observed above in the courtroom exchanges (example 51), suggesting that the power relationship between interlocutors is a factor here.

Mr Gormsby's retaliation, designed to embarrass him in front of his classmates, reinforces the usage as ironic and indicates how anomalous being both the speaker and the referent of the term is for him. Furthermore, the intonation in Mr Gormsby's shame bro makes it clear that this is mention and not use, as he is not socially licensed to use the term. His mention of bro in this context echoes Hohepa's past use of it to show disdain and distance, indicating that these same qualities continue to characterise the relationship.

After expressing solidarity, the most prevalent use of bro in the fictional data was by males speaking Māori English or with Māori English characteristics, and it was common to see the term used to reinforce a character's Māori identity. The following extracts are once again taken from Brokenwood Mysteries, and the speech of one of the show's few Māori characters, Jared Morehu.

\section{Example 58: Brokenwood (4)}

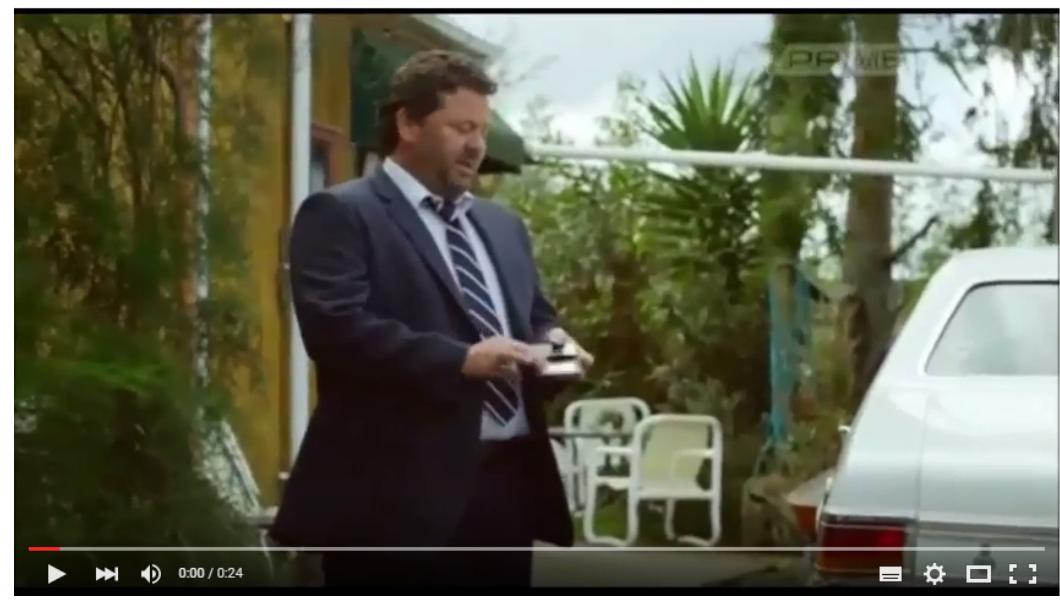




\section{Example 59: Brokenwood (5)}

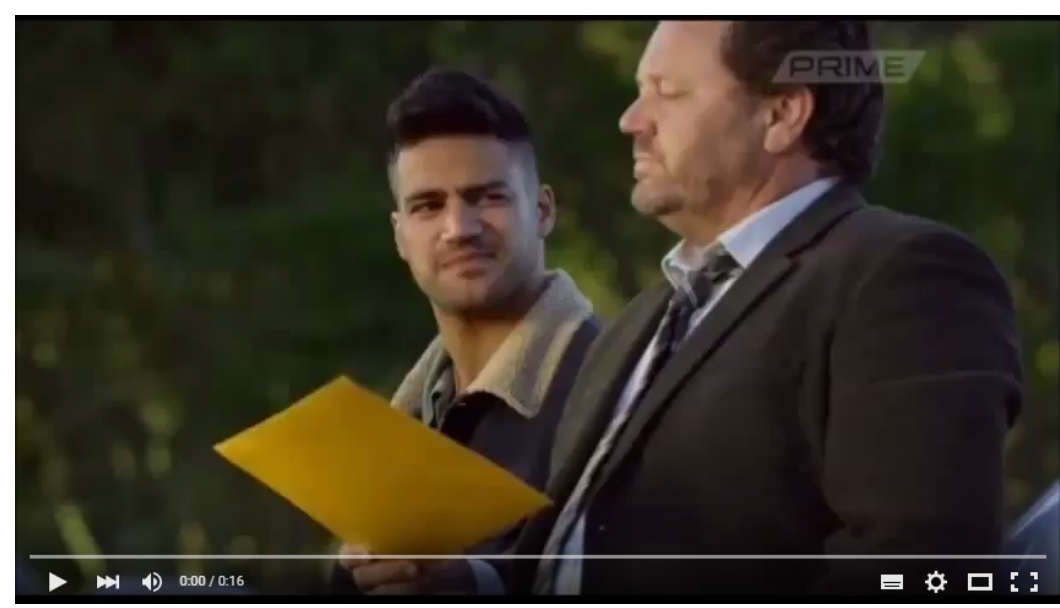

In each of these exchanges, Jared's character projects a Māori identity through the language he uses. He achieves this in several ways - by making a direct reference to his culture (technically, that's culturally offensive), the use of Māori words such as kai and kina, and by using lexical items associated with Māori English such as bro and the tag particle eh (Meyerhoff, 1994). Example 60, an anti-drink driving commercial, is further evidence of bro being used to create and represent Māori identity.

\section{Example 60: NZ Police (2)}

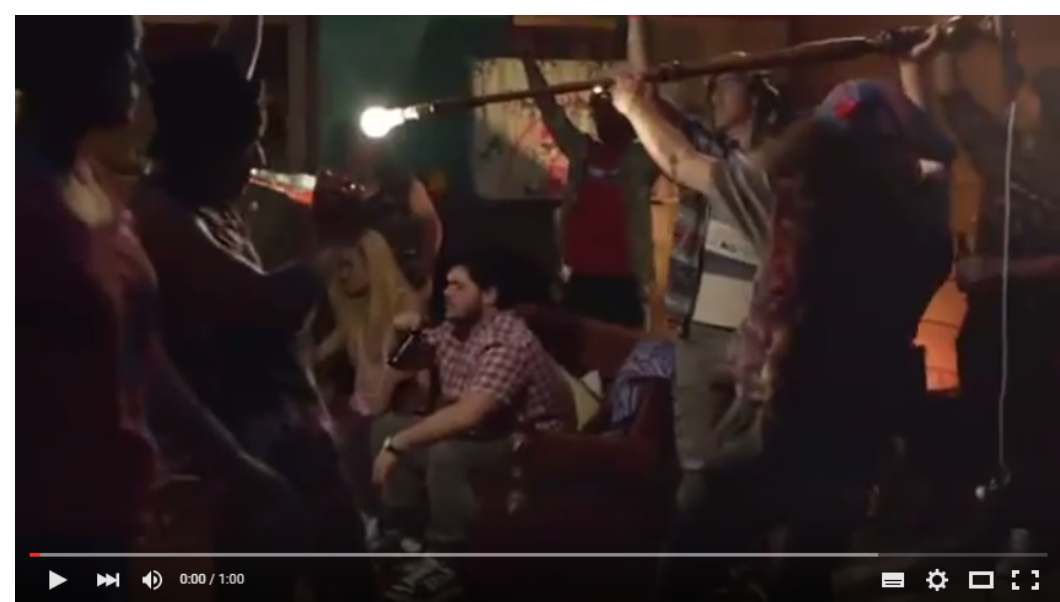

In direct contrast to the anti-drink driving advert that features the use of mate and is predominantly Pākehā, this is clearly representative of a Māori community. Three bro tokens from three different speakers demonstrate prototypical uses of the term in the speech of young Māori males, and show how it is commonly used to affectionately address fellow members of an in-group. While this is highly scripted data and therefore 
arguably presents a broad brushstroke portrayal of a speech community, findings from the spontaneous speech data suggest this is an accurate representation of the current linguistic situation. Furthermore it is consistent with King's (1999) work in which she concluded that use of familial terms of address is a feature of Māori English commonly used by the younger demographic.

As we have seen, the media data set is dominated by male tokens of bro which indicates that in this domain the term is still closely associated with its historic semantics, i.e. a word denoting a male referent. However, the final example in this section illustrates how what we have seen so far is not entirely representative of the current NZE situation. Example 61, is an extract from a Radio New Zealand program on Kiwi Slang, and illustrates what we might be missing.

\section{Example 61: Radio New Zealand - Kiwi Slang}

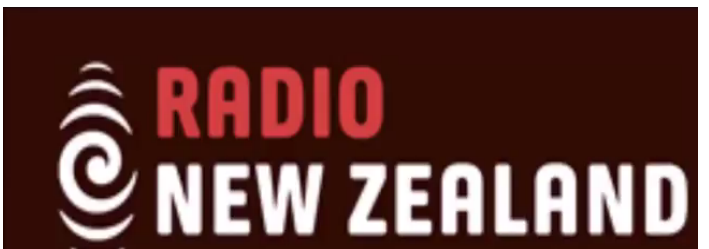

TE REO IRIRANGI O AOTEAROA

Leilani is a well-known journalist, blogger and model and is an urban Pacific Islander living in Auckland. It is arguable that the female use of bro (both as speaker and referent) is specific to her demographic, however, her presence in the public sphere indicates that she has extensive communication with a broad range of young New Zealanders, and is therefore well-informed as to what is happening in their speech. This suggests that the media representation of bro seems to be an inaccurately conservative one, which is lagging behind the actual usage. It seems likely that this is, in part, related to bro having ethnic marking (unlike mate, as we have seen), for as Leilani has suggested, and as we have seen in the corpus data, it is unmarked for gender in many cases.

\subsection{Discussion}

We have seen in this analysis that bro is both polyfunctional and imparts different kinds of pragmatic meaning to an utterance based on speaker, context and setting. 
In particular, the blue-collar data set, presented some interesting information about how a conventionally gendered term of address can function within a specific CofP. Because of the substantial number of bro tokens spoken by Ginette, the corpus data provided a much more extensive analysis of female usage than was possible in the media data set. This resulted in the media analysis being dominated by male tokens, which in turn meant that bro came across as being more heavily gendered in the media than in the corpora. However, as example 61 with Leilani illustrates, this gendering is contested even in some parts of the media. A more comprehensive study of natural speech from young female NZE speakers would be valuable in order to track changes and document how bro is currently being used.

In terms of ethnicity, Māori and Pasifika are the dominant users of bro, and as the above examples have shown, it is still potently marked for ethnicity in many environments. However, it was observed that Pākehā - Pākehā tokens were more common in the media data than in the corpora, and the relative frequency with which Pākehā tokens occurred in the media data suggests that the semantic field of bro is in the process of being renegotiated. This renegotiation seems to be perceived as being led by young males, given the distribution of tokens of bro in the media data, but as we have also seen (example 61), some young women may be actively participating in this renegotiation too.

In the scripted data it was common to find Māori characters using bro, where their Pākehā counterparts may have used mate or no address term at all. I have argued that bro is a device used to foreground or reinforce the character's Māori identity, however, we have to consider the possibility that fictional characters are assigned embellished features that stereotype their ethnicity.

Although there was a disparity between how often female and male speakers used bro, and although we saw evidence of a potential increase in Pākehā usage of the term, the functions of bro were fairly consistent across the two data sets. While bro was observed in a small number of hostile speech acts in the spontaneous speech data, an overwhelming majority of bro tokens across both sets were used to index solidarity, 
familiarity and intimacy, demonstrating that as a familial address term it primarily functions as a bonding device.

Both mate and bro have been found to function predominantly as an index of solidarity, however some functional contrasts were observed between the familiarisers. For example, mate was not found to index ethnicity (in most cases).

As in the discussion of mate, it is important to consider the usage of bro with specific reference to young NZE speakers. The data collected suggests that bro is becoming widespread in male speakers of standard NZE. Unlike mate, it seems to be associated with a younger demographic, consistent with King's (1999) findings. The paucity of female tokens in the current media data demonstrates that it has not achieved the kind of gender neutral status that Rendle-Short (2009) observed with mate, yet there is some evidence that it may be a candidate for gender neutrality in the future. As noted above, more research into young New Zealanders' vernacular would be greatly beneficial in gaining a more in-depth understanding of the use of bro, as the data I have reviewed seems to suggest that it is a particularly dynamic form in the repertoire of younger NZE speakers. 


\section{Man}

An analysis of man differs from the previous analyses of mate and bro for several reasons. Firstly, via a process of semantic bleaching man has lost its [+male] feature and as a result has an already established status as largely gender neutral for both speaker and referent, i.e. it is being used by and to both males and females. Therefore tokens of man produced by women were more abundant than either tokens of mate or bro. Additionally, man seems to be widespread enough in usage that it is typically unmarked not only for gender, but for ethnicity and class. In a further point of difference, an overwhelming number of man tokens were being used as secondary interjections (often functioning as pragmatic markers), or the boundary between interjection and address term was blurred, compared to the use of mate and bro. Thus, in this section we will discuss the extent to which the grammar of man is a factor in what appears to be its continued expansion in use. As will be illustrated, particularly by the media data, man is a popular term with young NZE speakers of both sexes, a trend we have not observed in the preceding analyses. I begin my analysis of the data by considering the grammaticalisation of man. I then examine its usage in both the corpus and media data sets, before giving a brief discussion of my findings.

\subsection{Considerations of the grammaticalisation of man}

Grammaticalisation is commonly recognised as a process of language change whereby lexical items develop grammatical meaning (Hopper \& Traugott, 2003). The tendency observed across the data for man to perform an exclamative function demonstrates that it is has gone through a process of grammaticalisation, from noun to interjection. While man has not changed (in present-day English) in terms of form, the fact that it can now function as an interjection means the term has gone through such semantic changes that in many cases it can act as an expression of emotion, completely independent of its original semantics. Nevertheless, man also still functions as an address term, demonstrating that the differing meanings co-exist alongside each other in what has been defined as a 'layering' effect (Hopper, 1993; Hopper \& Traugott, 2003). Hopper (1993) describes how within a broad functional domain new layers are continuously developing yet old layers are not necessarily discarded, but remain and co-exist with new ones. Such 
an effect results in a kind of spectrum where category boundaries often overlap and, as in the case with man, it is sometimes difficult to say definitively what category the term is functioning as.

Recent research in Multicultural London English (MLE) has suggested that, for some young speakers, man is developing as a first person singular pronoun (Cheshire, 2013). Cheshire notes that a likely factor in the emergence of this new pronoun is the frequency with which young people in inner-city areas use man as both address term and pragmatic marker. The potential emergence of man in yet another grammatical category is significant to my analysis as it demonstrates how functionally flexible the form is (as Cheshire points out, for those MLE speakers using the pronoun form, man is acting as a singular noun, a plural noun, a pragmatic marker and an address term). However, while the future growth of the pronoun is uncertain, the pragmatic marker man can be understood as fully grammaticalised.

Cheshire (2013) found only 3 instances of females using the pronoun form in MLE and suggests that is due to its incomplete desemanticisation - it still carries a [+male] feature. The man I discuss here, however, appears to have lost the [+male] feature, resulting in a form that no longer indexes masculine gender and is therefore used both by and to females as well as males. As a likely result of the grammaticalisation of man, as an address term, it also appears to have gone through a process of semantic bleaching. It seems highly probable that this desemanticisation is directly linked to its current state of (relative) gender neutrality. As we will see shortly, this loss of a masculine index means that man is much more widely distributed in female New Zealanders' speech than we have seen with either mate or bro. I turn now to an examination of the use of man in the corpora.

\subsection{Man in the corpus data}

I begin my analysis of man in the corpus data by first looking at the raw frequency of tokens, and the distribution of tokens in terms of their grammatical function, before examining some examples from the corpora. Table 19 presents the raw frequency of tokens in each of the four corpora. 
Table 19: Frequency of man tokens in the corpus data

\begin{tabular}{|l|c|c|c|}
\hline Corpus & Total tokens & $\begin{array}{c}\text { Male tokens } \\
\text { (Tokens uttered by men) }\end{array}$ & $\begin{array}{c}\text { Female tokens } \\
\text { (Tokens uttered by women) }\end{array}$ \\
\hline White-collar workplace & 39 & 27 & 12 \\
\hline Blue-collar workplace & 78 & 72 & 6 \\
\hline WSC & 96 & 62 & 34 \\
\hline ICE & 24 & 16 & 8 \\
\hline Total: & 237 & 177 & 60 \\
\hline
\end{tabular}

Note: Corpus sizes are as follows: White-collar workplace (approx. 2,000,000), Blue-collar workplace (approx. 250,000 words), WSC (1,000,000 words), ICE (600,000 words).

What is perhaps most striking about the results presented in Table 19 is the relatively high frequency with which female tokens occur, in comparison with the data for mate and bro. Although male tokens still dominate the data, the distribution between the sexes is considerably more reduced. Similar to the trend we observed in the mate data, in the white-collar workplace, WSC and ICE corpora roughly the same proportion of tokens of man were produced by female speakers (at $30.8 \%, 35.4 \%$ and $33.3 \%$ respectively). The blue-collar data was anomalous in this respect (7.7\% of tokens by female speakers), however, this is likely to be a result of the male-female ratio in the factory setting; where the other three corpora were fairly equally weighted in terms of gender (see methods section), only seven of the thirty-one factory participants were women.

Once again it is the blue-collar workplace that produces the most tokens (relative to words per corpus) of man, a trend we have observed in both the mate and bro analyses.

As much of the discussion in this chapter concerns a distinction between man as an address term and man as an interjection ${ }^{24}$, it seems necessary to once again mention the limitations that fall on the corpus data analysis due to having no audio. For instance, intonation contours are relied on heavily to interpret interjections (Norrick, 2009), but as these paralinguistic cues were not available some man tokens that may obviously fall into one category when heard will appear ambiguous in the written data. Hence, where I have interpreted the token as a clear address term/interjection I have labelled it as so; where a token could quite feasibly be either address term or interjection, or, where it is likely to

\footnotetext{
${ }^{24}$ For example, hey man (address term) and man it was hot (interjection).
} 
be functioning simultaneously as both, it has been labelled as ambiguous ${ }^{25}$. These results are presented in Table 20.

Table 20: Distribution of man tokens by category (part of speech) in the corpus data

\begin{tabular}{|l|c|c|c|}
\hline Corpus & Address term & Interjection & Ambiguous \\
\hline White-collar workplace & 7 & 23 & 9 \\
\hline Blue-collar workplace & 17 & 34 & 27 \\
\hline WSC & 28 & 39 & 29 \\
\hline ICE & 6 & 11 & 7 \\
\hline Total: & 58 & 107 & 72 \\
\hline
\end{tabular}

Note: Corpus sizes are as follows: White-collar workplace (approx. 2,000,000), Blue-collar workplace (approx. 250,000 words), WSC (1,000,000 words), ICE (600,000 words).

As we can see in Table 20, the distribution of tokens is somewhat varied across the four corpora, however some trends were observed. In each corpus, interjection tokens occur more frequently than address terms, demonstrating how grammaticalised man is in NZE, and suggesting that the strong tendency towards unidirectionality that is associated with grammaticalisation (Hopper \& Traugott, 2003) is at play here. Once again, relative to the size of the corpus, it is the blue-collar data that accounts for the greatest number of address terms, suggesting that it is not simply that the more masculine workplace culture of blue-collar employment favour the use of a [+male] address term, but that informal address forms in general are more habitual in the factory setting. This pattern, and some possible explanations as to what it motivating it, will be discussed further in Chapter 8 .

I turn now to some examples from the corpus data, where I consider how the term performs both grammatically and functionally, in its role as both vocative and interjection.

\section{Vocative vs interjection}

Although the boundaries between categories are often blurred it is still possible to distinguish arguably distinct cases of each. This is demonstrated in the following vocative - interjection pairs, taken from the blue-collar workplace.

\footnotetext{
${ }^{25}$ For example, in I was still in the car man, the man could be functioning as address term or interjection/pragmatic marker (or concurrently as both).
} 


\section{Example 62}

1 Russell: hey man did you hear about Lesia + fuck he got Sue pregnant again

2 Robert: who

3 Russell: Sue again

\section{Example 63}

1 Russell: man it was hot yesterday

2 Gerald: yeah last night

In example 62, hey man is clearly a vocative, as Russell is addressing Robert and summoning his attention before continuing with his turn. In example 63 however, Russell is using man as an interjection, with the aim of intensifying his following statement about the weather. This distinction is observed further below.

\section{Example 64}

1 Lesia: copy laser man

2 Russell: what's up man

3 Lesia: $\quad$ yeah bro we need six more bins for line two

4 Russell: okay man I'm on that

\section{Example 65}

1 Ginette: she did them again and didn't do the stuff that I wanted ++ fuck man + said to [name] you can BLOODY have her back

In example 64 Russell's use of man is again clearly a vocative, in both his question what's up man? and his acknowledgement okay man I'm on that. The okay man here can be interpreted as functioning in the same way as Lesia's yeah bro in the previous turn, with both affirmative statements performing the same function of social bonding previously discussed in the bro analysis (e.g. example 43). In contrast, Ginette's usage in example 65 is clearly an interjection. The fuck man is not addressing anyone in particular but used to express her emotion, which is further emphasised by her use of an expletive. We will see 
shortly how it is often difficult to conclusively separate these competing forms of man, however these examples illustrate how they can function quite distinctly from each other.

\section{Man as a wildcard item}

Man can be regarded as an 'anything goes' item which functions as a kind of wildcard (a term used by Buchstaller (2001) to illustrate the flexibility of the quotative like), in that it is largely unrestricted, and displays complex patterns of distribution and function. Moreover, it is syntactically quite free. For instance, the tokens in Example 63 (man it was hot) and example 65 (fuck man) demonstrate that man as an interjection is not restricted to either clause-initial or clause-final position, and as we will see in example 66, it can also occur clause-medially. In addition to the vocative and exclamative functions man can occur as a pragmatic marker that acts as a focusing or highlighting device. The following example from the WSC, of two males in their thirties, illustrates man in this role.

\section{Example 66}

$1 \quad$ LY: I remember pinching a car once and this security guard came over and I was still in the car man

2 MK: $\quad \mathrm{mhm}$

3 LY: $\quad$ and I was right underneath the dashboard you know and he flashed the torch in the

$4 \quad$ LY: $\quad$ and the adrenalin man was running out I was thinking [drawls] oh [drawls] it was exciting you know

LY's use of man in line 1 could be functioning as address term or pragmatic marker (or concurrently as both). In line 4 (the adrenalin man was running out) the man occurs in clause-medial position, and instead appears to be highlighting either the subject or the predicate, or perhaps both. Furthermore, man here could feasibly be replaced with another pragmatic marker such as like (e.g. the adrenalin, like, was running out), a substitute unlikely to happen in the vocative and interjection examples above. It is perhaps possible to argue that the man in line 4 is merely a pause filler, however, further tokens occurring in similarly constructed utterances suggest that it is being used to give 
prominence to the speaker's statement. Example 67 is an exchange between two young females.

\section{Example 67}

$1 \quad J N$ : it's a really stink production but um the story line was good

$2 \quad \mathrm{JN}$ : it was quite you know

3 MY: followed the book

$4 \quad$ MY: $\quad$ yes just some of the light man hurt your eyes severe

As in the previous example, the man here occurs directly in the middle of the statement and appears to be highlighting the predicate hurt your eyes severe. Once again the token could easily be replaced with like, yet does not seem a natural place for the speaker to pause, evidence that man is not acting as a mere filler. Interestingly, we have seen a similar highlighting and focusing function when mate occurred in atypical structural positions (see Table 11).

\section{Creating emphasis}

Closely related to the above highlighting examples are tokens where is man being used to emphasis a speech act. Evidence of its grammaticalisation is visible in the numerous instances where it occurs as an emphatic interjection that is functioning as a pragmatic marker. It is also able to act as an intensifier of the following item. This is illustrated by the following interaction, between a male in his thirties (BB) and a male in his twenties (RT).

\section{Example 68}

1 BB: yeah well you can't even grow dope down there because it's not warm enough

2 RT: yes you can

3 BB: can?

4 RT: for the summer man yes 
RT's use of man yes here is acting in much the same way as something like hell yes would. The man is functioning as an intensifier of the following yes. It is acting not as a pragmatic marker with an independent meaning, but instead forms a unit with yes.

While several tokens could be analysed as intensifying a statement, this appeared to be achieved in a variety of different ways, demonstrated in the following examples, which simultaneously create emphasis through schemes of repetition, and the addition of man.

\section{Example 69}

1 AL: Max was trying to tell us that all the woman in Tokomaru are tame

2 MM: oh they're they're very tame they're they're tame man tame

\section{Example 70}
$1 \quad P:$
got a sore gut
$2 \quad P:$
feel like a big filthy fart
$3 \quad M$
[sniggers] do it man do it [laughs]

\section{Example 71}

1 Daniel: what you should have said is that this is not on you fellas is- bloody parparties [laughs]

[general laughter]

2 Caleb: [laughs] yeah that's right he's in charge of it slap him man slap him

In each of these examples, man occurs in between repeated pairs of statements resulting in emphasis being added to the utterance before and after the man token, and the whole speech act being somewhat amplified. It has been claimed that when man occurs frequently in a stretch of discourse that it seems to function as a punctor (Vincent \& Sankoff, 1992) and can have a breaking up effect much the same as a comma does in writing. This is an interesting observation as the man tokens here could be interpreted as functioning as a kind of partition between the pairs of utterances. However, I would argue that rather than acting as fillers, or signs of hesitation, these man tokens are 
functioning simultaneously as familiarisers (as they could happily be replaced with an address term, e.g. they're tame mate tame; do it Tom do it), and pragmatic markers designed to add emphasis to the force of the utterance. Cheshire (2013) has suggested that the intertwined function of man as address term and man as pragmatic marker helps construct solidarity in discourse. Based on what we have seen so far of address terms being indexes of solidarity, it seems likely that man is serving a similarly affiliative function in NZE. This will be considered in more detail below.

\section{Reported speech (constructed dialogue)}

As with mate and bro, man occurred on several occasions in reported speech within a narrative, and like mate, it was often interpreted as conveying a person's attitude. Notably however, man tokens appeared to be much more expressive of the speaker's emotion, a likely result of its ability to function as an interjection. Ameka (1992) distinguishes a specific functional category of interjections that focus on the mental or emotional state of the speaker. This function was particularly apparent in reported speech, as we will see. The following example is taken from an interaction in the ICE data, between two young males.

\section{Example 72}

$1 \quad$ P: $\quad$ well we went out there did all these handbrake slides and wheel spins and stuff like that and he was just getting real loose and we were getting close to the cliffs

$2 \mathrm{M}: \quad \mathrm{mm}$

$3 \quad$ P: $\quad$ and I just said fuck man I just said stop stop stop

4 P: I said get off here man

$5 \quad$ P: $\quad$ I thought he was going to kill us

Regardless of whether or not $\mathrm{P}$ is reconstructing his own speech verbatim, the man tokens in the example help express his emotional state at the time of the event. Although he gives explicit details that describe the alarming nature of the event (we were getting close to the cliffs; I thought he was going to kill us) the man tokens help convey how emotionally charged he felt in the situation. 
Man being used to express emotion is observed again in the reported speech of a third party. Example 73 is an exchange between two female primary school teachers.

\section{Example 73}

1 RW: and he was going oh what and I was going no there's no need for that kind of lip

$2 \mathrm{KT}: \quad \mathrm{mm}$ [laughs]

3 RW: now come on snap out of it Rawiri and he was going MAN [imitates Rawiri complaining]

$4 \quad$ RW: $\quad$ and I says I'm not saying this just for the hell of it

While reporting the interaction, RW's use of the stressed man here aptly conveys Rawiri's emotional state in the prior interaction, while also emphasising the term's presence in young speakers' vernacular. Additionally, we see how the pragmatic force of the solitary man token can convey a complete expression of (presumably) protest or objection. This is in contrast to the solitary use of mate, which (as we saw in Table 11) was only used to signal agreement or direct attention. This presents an interesting paradox, as although man is able to be used to express a negative reaction (much like that in the exclamative use of dude Kiesling, 2004), it was not found to express direct hostility in the way that we have seen speakers use mate.

The notion that man can index strong feelings of emotion is perhaps strengthened by its tendency to appear in reconstructed dialogue regarding thoughts rather than verbal speech. The following examples, taken from the white-collar workplace data, illustrate this.

\section{Example 74}

1 Daniel: and her moko ${ }^{26}$ makes her look really you know it's really striking you know like it's it's a really and oh I just thought man I mean it was all I could you know like wow you beautiful I didn't say that [laughs]

\footnotetext{
${ }^{26} \mathrm{~A}$ moko (Tā moko) is a traditional Māori tattoo, often worn on the face.
} 


\section{Example 75}

1 Jill: I couldn't beli- when I came in I thought man I've had this

2 Kiwa: yeah

3 Jill: $\quad$ so you haven't lost it are you sure you haven't lost this

Both man tokens here are indexing the speaker's attitude and emotion, something that is perhaps highlighted by the fact that they relate directly to their thoughts and internal experience of an event, rather than a past or hypothetical conversation. The speaker's use of man in these examples seems to implicate that the following utterance is of emotional importance. In example 74, Daniel is expressing how beautiful he finds someone, and in example $75 \mathrm{Jill}$ is conveying her disbelief/frustration at some situation. Here the interjections act as pragmatic markers in the sense that they signal that a certain amount of sentiment should be added to the basic message they're trying to convey, i.e. they index the speaker's emotional involvement with the information they are imparting.

Here we see a further evidence of man's polyfunctionality - it acts here as a marker of the speaker's sentiment and to emphasise a following utterance, the primary function we saw in examples 67-71 above. The fact that man was the only address term found in any I thought sequences across the data, and that both tokens here are arguably interjections, suggests that the grammaticalised form of man is making the term a more pervasive and polyfunctional tool for NZE speakers. Furthermore, as these examples from the corpus data have demonstrated, man interjections acting as pragmatic markers have distinctly identifiable functions, such as signalling that certain utterances deserve emphasis (e.g. example 67-71) and implying an additional level of emotion (e.g. example 74,75).

\subsection{Man in the media data}

We have seen in the corpus data that man contrasts with mate and bro for two reasons: first that it is more frequent in female speech, and second that in many instances it 
functions as a fully grammaticalised interjection. Findings in the media data firmly reinforced these contrasts. Table 21 shows the raw frequency of tokens in both spontaneous and scripted speech.

Table 21: Token frequency of man in the media data

\begin{tabular}{|l|c|c|c|c|c|}
\hline Type of speech & $\begin{array}{c}\text { Total } \\
\text { tokens }\end{array}$ & $\begin{array}{c}\text { Male tokens } \\
\text { (Tokens uttered } \\
\text { by men) }\end{array}$ & $\begin{array}{c}\text { Female tokens } \\
\text { (Tokens uttered } \\
\text { by women) }\end{array}$ & $\begin{array}{c}\text { Male } \\
\text { addressee } \\
\text { (Tokens uttered } \\
\text { to men) }\end{array}$ & $\begin{array}{c}\text { Female } \\
\text { addressee } \\
\text { (Tokens uttered to } \\
\text { women) }\end{array}$ \\
\hline $\begin{array}{l}\text { Spontaneous } \\
\text { speech }\end{array}$ & 54 & 34 & 20 & 37 & 17 \\
\hline Scripted speech & 68 & 41 & 27 & 42 & 26 \\
\hline Total: & 122 & 75 & 47 & 79 & 43 \\
\hline
\end{tabular}

As we saw with both the bro and the mate analyses, we can see in Table 21 that the raw frequency of man in the spontaneous and scripted data are not dissimilar, nor is addresser/addressee ratio. What differs from previous analyses, however, is that female speakers use man almost as often as male speakers in the media data. Indeed, female speakers account for a slightly higher percentage of the tokens of man than in the corpus data (corpus data $-25.3 \%$, media data $-38.5 \%$ ). This increase suggests that female usage of the term is expanding and is a possible indication that the use of man is becoming more prevalent in general, which is likely to be motivated by the loss of a [+male] feature. As I have mentioned above, it seems probable that this is closely linked to the frequency with which it functions as an interjection. Table 22 shows the distribution of address terms and interjections.

Table 22: Distribution of man tokens by category

\begin{tabular}{|l|c|c|c|}
\hline Type of speech & Address term & Interjection & Ambiguous \\
\hline Spontaneous speech & 11 & 18 & 25 \\
\hline Scripted speech & 13 & 24 & 31 \\
\hline Total: & 24 & 42 & 56 \\
\hline
\end{tabular}

Here we can see that address terms account for the lowest frequency of tokens. Of all man tokens collected in the media data, address terms accounted for just $19.7 \%(20.4 \%$ in spontaneous speech and $19.1 \%$ in scripted speech). This is a decrease from the corpus data, where address terms made up $24.5 \%$ of the overall token count. While this decrease may be a result of the different types of data analysed (e.g. the high frequency 
of blue-collar address term tokens potentially connected to workplace culture), it could also be an indication that use of man as an address term is in decline in New Zealanders' speech. It is necessary to note here that the relatively high frequency of ambiguous tokens in the corpus data was largely due to the aforementioned lack of audio, i.e. it was often difficult to make a clear judgement without hearing the intonation etc. However, the high frequency of ambiguous tokens in the media data is the result of it being difficult to separate the two functions, i.e. even with intonation cues the man tokens were arguably acting as both address term and interjection simultaneously.

We turn now to some examples from the media. As a result of the data producing little distinction between the sexes and limited functional variation, this section is brief, and focuses on the contrasting functions of man as a distinct address term, as a clear interjection, and fulfilling both of these functions concurrently.

\section{Spontaneous speech}

The following examples demonstrate the subtle, yet arguably distinct functions of man in spontaneous speech environments. The first example, taken once again from Motorway Patrol shows man as an address term. The second example is from the The Edge interview with Lorde and demonstrates man as a clear interjection. In the third example, from music show NZOwn, we see man's dual-functionality.

\section{Example 76: Motorway Patrol (5)}

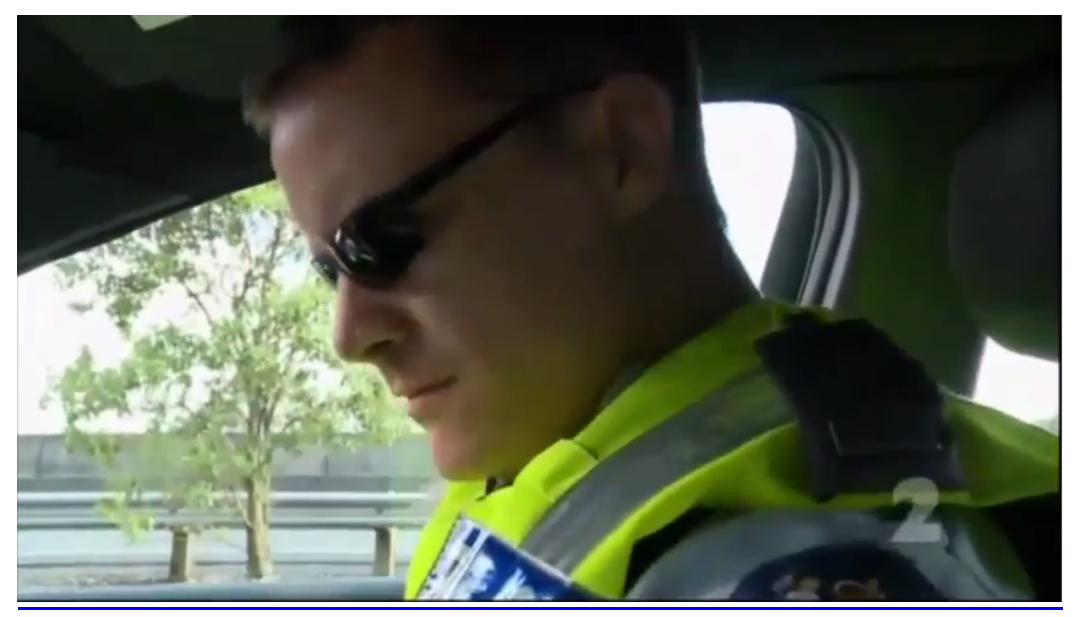




\section{Example 77: The Edge (2)}

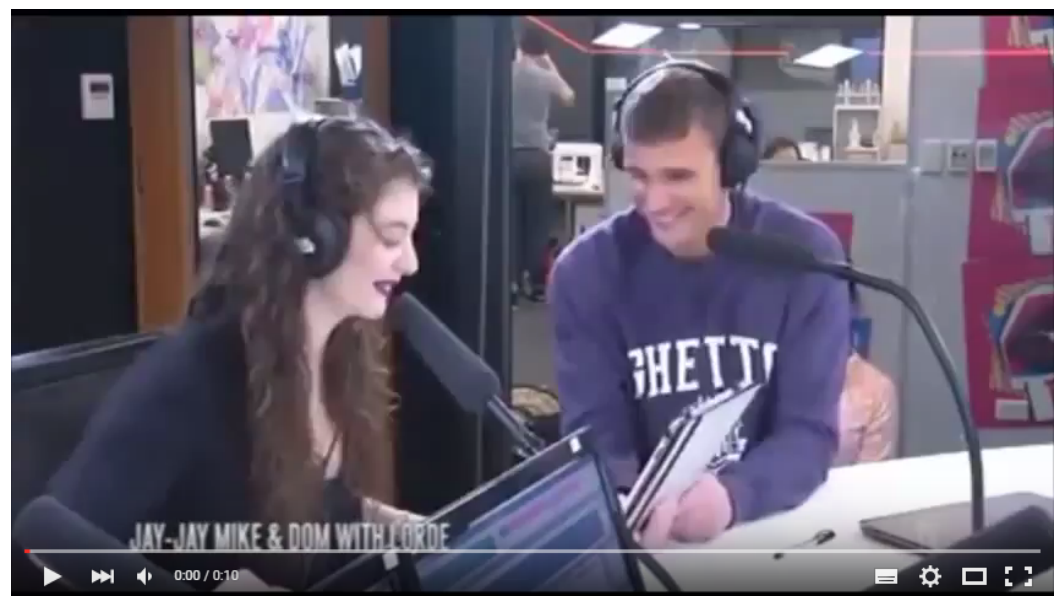

\section{Example 78: NZOwn}

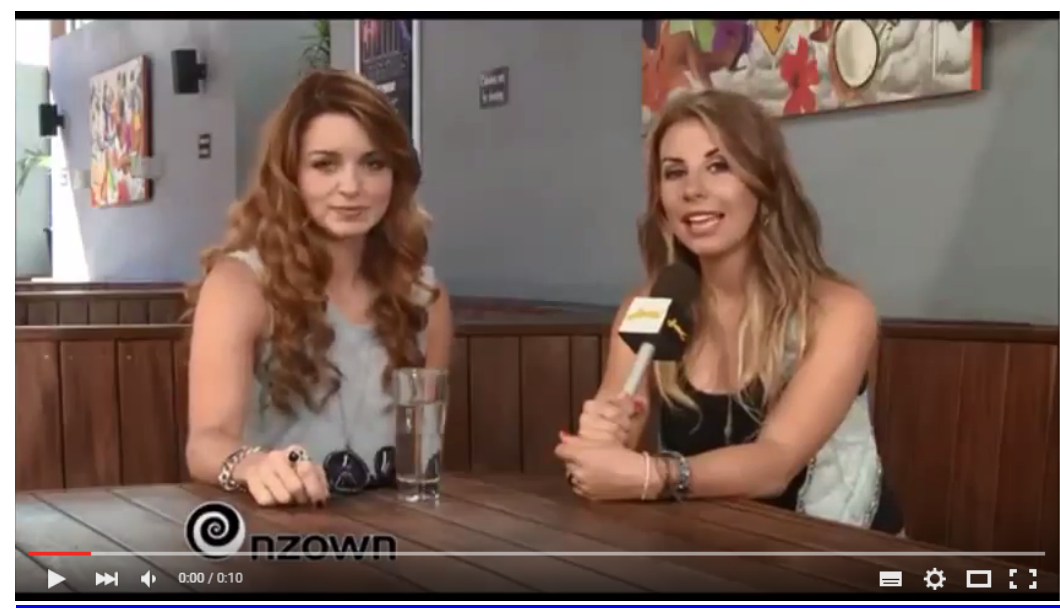

In example 76 we see the policeman clearly addressing the driver (when did our windscreen get smashed up man?), his use of man is a form of address and could easily be substituted with another vocative (e.g. mate, John, Mr. Smith). Notable in this example is how we see man being used as an index of solidarity, as we have seen with mate and bro. The pragmatics of the policeman's speech act tell us that he means to convey a friendly informality, both by using the familiariser man and the plural possessive our, which lessens the positive face threat to the driver, bought about by the mention of his broken windscreen. 
In contrast, Lorde's oh man in example 77 is quite clearly an interjection, expressing sentiment regarding the photo being shown. As Norrick (2009) points out, oh frequently occurs with (and always precedes) other interjections. Here we see man acting as a secondary interjection (after the primary interjection oh) that is very distinct from the address form in example 76.

The function of the presenter's I'm choice man in example 78 is not nearly as clear cut however. It could be argued that man is functioning as an address term, in the same way that I'm choice mate would, or that it is a pragmatic marker used to emphasise her response choice. My analysis however, is that the two functions are intertwined, which results in an expression that is both familiar (by the presence of the familiariser) and expressive (by the presence of the interjection). We can see these distinctions further demonstrated in examples from the scripted speech data.

\section{Scripted speech}

As with the above spontaneous speech examples, the following clips demonstrate the polyfunctional use of man in three different broadcasts. Example 79 is from teen sitcom Girl vs Boy and shows man functioning as an address term, example 80 is an extract from Go Girls and is further evidence of man as an interjection, and example 81, from Coverband, is another instance of man acting simultaneously as both.

\section{Example 79: Girl vs Boy}

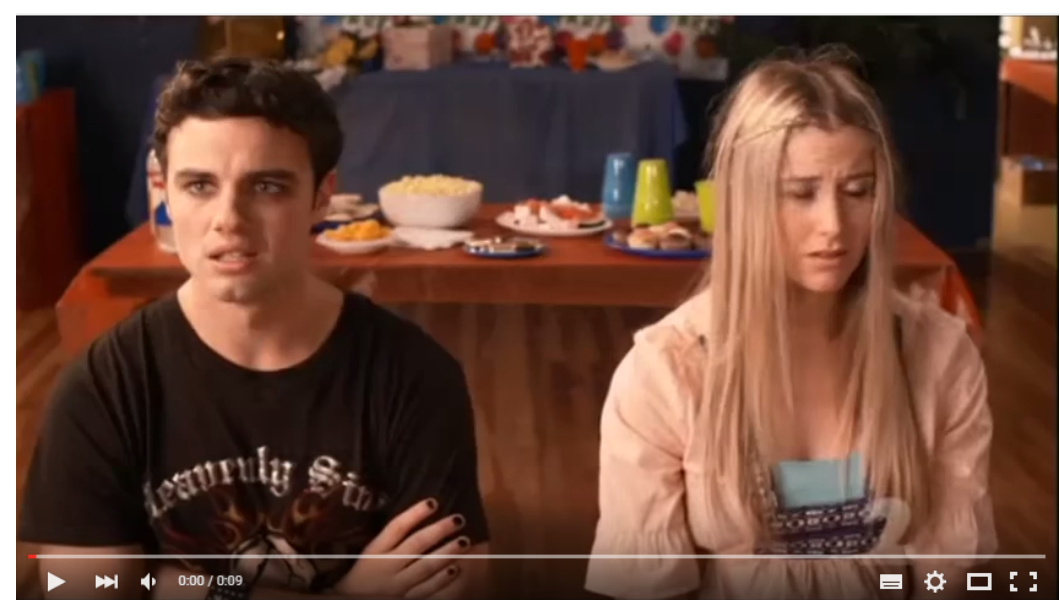




\section{Example 80: Go Girls (2)}

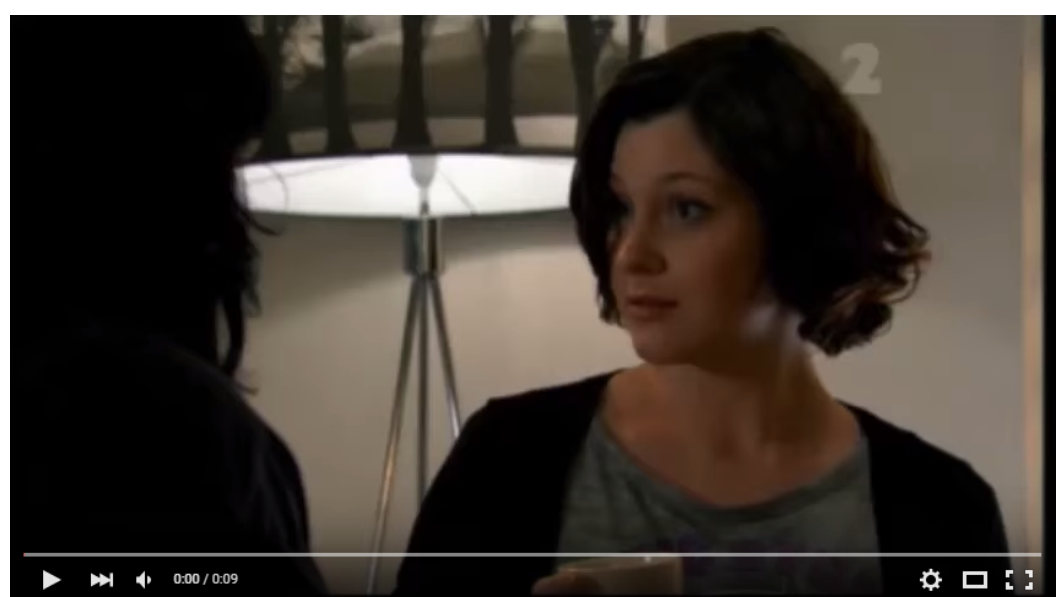

\section{Example 81: Coverband (2)}

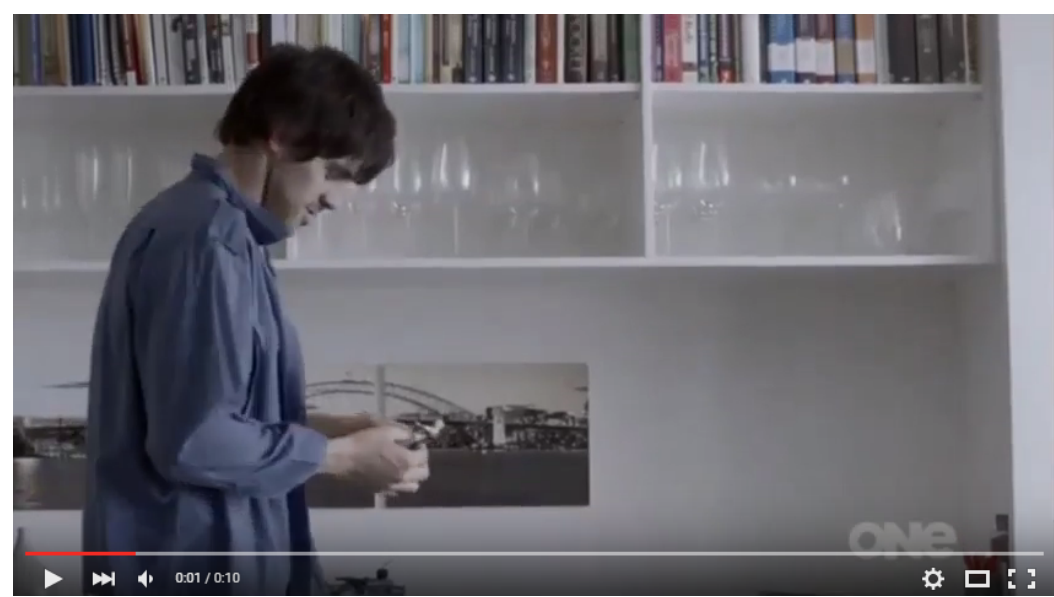

In example 79 the speaker follows his interrogative by addressing his friend as man (what happened to your eye man?). The man here is an address term, and is functionally and syntactically similar to the policeman's use in example 76.

In example 80 we see another example of the primary + secondary interjection combination (oh man!) that was observed above in The Edge interview (example 77). The character ('Cody' - who we encountered in the mate analysis) is clearly using man as an interjection designed to express emotion, which adds emphasis to her following utterance (I was so close to hitting her). 
In example 81 however, the man token once again has an indefinite function, as both address term and interjection are possible interpretations. In the speaker's utterance (yeah man, you can hold on to it) man could arguably be a vocative (much like yeah mate, yeah bro), or it could be understood as part of another interjection - interjection construction (this time with two secondary interjections), where man is adding emphasis to the yeah he uses to signal that his offer is genuine. However, as in example 78 (NZOwn), it seems to me that we are seeing in fact a combination of these functions. Furthermore, the interlaced function of address term and interjection seems to construct a solidarity stance that is both affiliative and expressive of the speaker's emotional involvement (Ameka, 1992)

The final example in this section, taken once again from Go Girls, is further evidence for the occurrence of man in 'thought sequences,' similar to those discussed above in examples 74 and 75 .

\section{Example 82: Go Girls (3)}

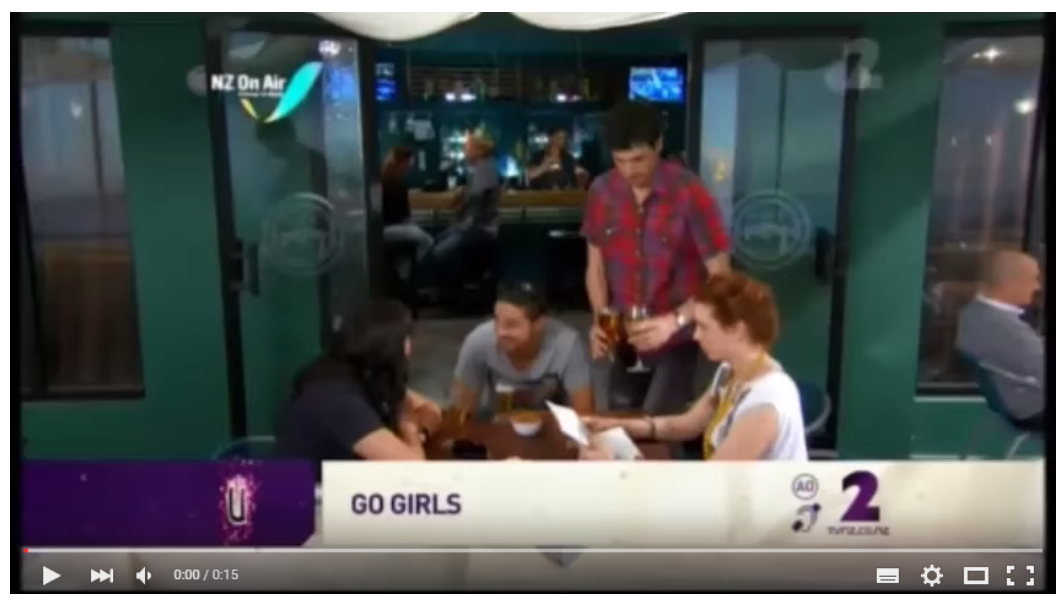

Although this sequence differs in that it's not a reported utterance, it nicely illustrates the personal, expressive quality of man that we saw in examples 74 and 75 . In the character's thought sequence (man, how come I don't know any girls like that), we see man functioning as a pragmatic marker that is able to convey a great deal of meaning (the hearer can infer that the speaker is impressed, envious etc.) while giving the next part of the utterance (how come I don't know any girls like that) added emphasis. 
What we can determine from these examples from the media data is that man is commonplace in the speech of young New Zealanders. In both the spontaneous and scripted examples we see young people of both sexes using the term in broadcasts which, it is reasonable to assume, are largely shows marketed towards a younger audience.

\subsection{Discussion}

Examples from both the corpus and the media data have shown us that man is multifunctional, and being used by both male and female speakers of NZE. It is capable of encoding pragmatic meaning, while being relatively free of its historic semantics.

As we have seen with both mate and bro, man can be used to index solidarity (e.g. example 76) and the interlaced function of address term and interjection, in some instances, appears to construct an affiliative solidarity stance (e.g. example 78, 81). However, in contrast to what we saw in the analyses of mate and bro, there were no instances of man being used as a hostile term of address. Although it is certainly capable of expressing a negative reaction (e.g. example 73), it was not used to address someone in an antagonistic manner, something we encountered with bro, and that was particularly apparent in the analysis of mate.

Although the grammaticalised form of man is predominant in both sets of data, we have seen that it is still functioning as an address term in many instances, and possesses clear characteristics of vocatives, such as summoning attention (hey man, e.g. example 62) and social bond-maintaining (e.g. example 64)(Leech, 1999).

Despite this, there is some evidence to suggest that man may be declining as an address form in NZE. As Table 22 showed, it occurs more often as an interjection or in ambiguous contexts. This decline in the lexical use of man is entirely consistent with the overarching story of grammaticalisation that I have put forward, and supports the unidirectionality hypothesis that states that linguistic change will be in the direction of lexical word to grammatical word, and not the other way round (Hopper \& Traugott, 2003). Man, therefore, would be going through a process change from the propositional (man as address term) to the expressive (man as interjection) (Traugott, 1990). Hence, unlike 
mate, which genuinely seems to be in retreat among younger speakers, man may simply be developing a more grammaticalised function. Indeed, the overall picture with regards to man in this study seems to suggest that if anything, its usage is expanding. Furthermore, it seems likely to me that the usage will continue to grow, and that the functional flexibility of man is one of the primary reasons for this.

The fact that it appears to have lost much of its 'male' semantic properties is a further factor that facilitates the increasing use of man. In direct contrast to mate, which we have seen is essentially a marker of masculinity (and does not seem to be expanding in use), man seems to be largely unmarked for gender and therefore considerably more accessible to females, demonstrated by the relatively high frequency of tokens produced by women across both sets of data.

As I mentioned above, the media data particularly, has shown how man is fairly typical in the speech of young New Zealanders, of both sexes. Furthermore, it was not found to be marked for ethnicity or class, indicating that the only social index that man possesses is one associated with age. These factors, combined with the abovementioned functional flexibility, suggest that man is a robust and dynamic tool for NZE speakers, which is firmly established, and quite possible expanding. 


\section{Guys}

The gender neutral use of guys is so ubiquitous in NZE that an analysis of it differs notably from the preceding terms of address. We have seen how mate is marked for masculinity and bro can be an index of ethnicity, age, gender and potentially class. Even man, which can be understood as largely unmarked in NZE, is representative of younger speakers. However, guys does not appear to possess any of the social indexicalities we have encountered in the previous analyses. Furthermore, despite its historic semantics, it frequently occurs as a semantically unmarked generic noun. Guys also differs significantly from the other forms we have looked at, in that it is only used as an address term in its plural form, i.e. you can't use guy as a second person vocative.

As we saw with man in the previous chapter, it is quite possible for historically [+male] vocatives to become semantically bleached of their masculine meaning and to develop a grammatical function. The extensive use of guys for female referents suggests that this process of sematic bleaching has gone to completion, and it is arguable that guys (specifically you guys) is on the road to grammaticalisation, as a second person plural pronoun (Heyd, 2010). As we will see shortly, it is certainly serving this function in the speech of New Zealanders across a range of demographics.

Due to the use ubiquity and largely grammaticalised function for guys, this chapter, rather than a detailed account of usage and functions, considers how and why it has come to be so pervasive in NZE. I begin the discussion with a brief review of guys as a gender neutral term, before looking at the usage in both the corpus and media data sets. I then turn to a consideration of some potential factors that have contributed to the predominance of guys as an address and reference term, and male generics more generally. Finally, I conclude with a discussion, and summary of findings.

\subsection{Guys as a gender neutral address term}

It is clear that guys is widely used to refer to groups of females and mixed groups in Western English speaking countries (e.g. Wales, 1996), particularly in the United States (Heyd, 2010; Maynor, 2000). What is much less clear is how a quite obviously masculine 
word has become widely accepted as a gender neutral term, in an age where formerly generic male terms have become almost obsolete.

Feminist scholars have been arguing for decades that he and man cannot carry generic and gender specific meanings simultaneously, as they are fundamentally contradictory (Curzan, 2003). The same could surely be argued for guys, and it seems ironic that during the same decades that saw active opposition to he and man as generic, that gender neutral guys was largely overlooked, and has even grown in popularity. Its emergence has not been unnoticed; the use of guys as a generic has been criticised, particularly from feminist vantage points (e.g. Hofstadter, 1997; Kleinman, 2002).

Feminist critiques tend to condemn the usage and argue that it reinforces the notion that men are the norm against which women are compared. Kleinman (2002) argues that male-based generics are an indicator and a reinforcer of a system in which men are privileged over women, and that by making women linguistically a subset of men it reduces them to objects. A cursory search of online discussion platforms such as the liberal web community, AlterNet, show that, specifically in American English, the generic use of guys is both well discussed and the source of much controversy. However, much less discussion of the term can be found with relation to NZE speakers, and consequently, it is not clear to what degree speakers of NZE feel the gender bias of guys. What is evident nevertheless, and will be illustrated by the data, is that the term is hugely popular with males and females, as both addressers and addressees.

\subsection{Guys in the corpora}

The preceding analyses have been largely concerned with the interactional functions that the respective address terms perform. However, the high frequency of guys as a gender neutral grammatical form (resembling a second person plural pronoun), meant that the focus wasn't on the functional variety we have observed in, for example, mate and bro, but rather, to document the frequency of use alongside the other forms, in order to present the complete picture. As Table 23 shows, the raw frequency of tokens of guys was high. 
Table 23: Token frequency of guys in the corpus data

\begin{tabular}{|l|c|c|c|}
\hline Corpus & Total tokens & $\begin{array}{c}\text { Male tokens } \\
\text { (Tokens uttered by men) }\end{array}$ & $\begin{array}{c}\text { Female tokens } \\
\text { (Tokens uttered by } \\
\text { women) }\end{array}$ \\
\hline White-collar & 248 & 192 & 56 \\
\hline Blue-collar & 28 & 17 & 11 \\
\hline WSC & 47 & 21 & 26 \\
\hline ICE & 26 & 11 & 15 \\
\hline Total: & 349 & 241 & 108 \\
\hline
\end{tabular}

Note: Corpus sizes are as follows: White-collar workplace (approx. 2,000,000), Blue-collar workplace (approx. 250,000 words), WSC (1,000,000 words), ICE (600,000 words)

Aside from the high frequency of use of guys (the highest of the four terms analysed), perhaps the most notable feature of Table 23 is that in both the ICE and the WSC corpora, female speakers produced more tokens than males. An additional deviation from the patterns we have observed in the previous analyses is that it is the white-collar, rather than the blue-collar setting that provides the largest number of tokens. It may be the case that the high frequency of tokens in the white-collar corpus relates to the type of environment the data came from, i.e. white-collar workplaces might have more situations where a group of people need to be addressed (e.g. meetings, administrative discussions) than blue-collar, and therefore a plural form of address is utilised more often. However, it is also supportive of its status as an unmarked form.

Unfortunately, the white-collar corpus data that I had access to did not provide information on all the participants present during an interaction, so it was not always possible to know the genders of the referents. However, based on the near equal division of male and female speakers, it seems reasonable to assume that women were being included as addressees.

In the blue-collar data, Ginette was responsible for 11 of the 28 tokens (the only female speaker) and it was observed that in nine of these eleven instances she was giving directives or imparting information directly related to work. This is in contrast to her use of bro in the workplace, which as we saw, often occurred in utterances that were more concerned with 'office banter' or social bond-maintaining. Based on this observation, and the unusually high frequency of tokens from the white-collar data (in comparison to the 
other terms analysed), my inference is that guys plays a much more practical role in the workplace than the other address terms we have looked at. Namely, rather than its primary function being to maintain or improve social relationships (e.g. a mitigation tool, a solidarity index, a strategy for positive self-portrayal), it is a convenient tool used to select multiple addressees at once, while still remaining somewhat informal. It is performing a much more grammatical function, and carries much less pragmatic meaning.

Heyd (2010) has investigated you guys as an emerging quasi-pronoun in American English, which is especially significant to the workplace data in this study, as an overwhelming majority of the tokens from the workplace corpora were a you+guys construction (96.4\% blue-collar, $95.2 \%$ white-collar). Although guys was a prominent form throughout all of the data, this extremely high percentage of you guys tokens was not mirrored in either the ICE and WSC corpora, or the media data. It therefore seems likely that the collocation you guys may be related to the workplace settings and the type of speech acts that characterise them (e.g. directives and imperatives).

As the focus here is not on functional variety in the data, a presentation of corpus examples to the degree we have seen in previous analyses would be superfluous. However, the following interactions succinctly illustrate how guys is being used across gender lines. Example 83 is from the blue-collar workplace.

\section{Example 83}

1 Lesia: Sam ++ Ginette er + meet you guys upstairs for ten minutes + yeah and um the boys

2 Sam: us two

This example is particularly insightful, as Lesia addresses Ginette and Sam as guys and then adds additional people by referring to them as the boys. This aptly demonstrates how guys is functioning as a plural form for both sexes, which contrasts with another gendered plural term (boys), reserved for an all-male group. The following examples are from the WSC data and show guys being used to female referents. 


\section{Example 84}

$\begin{array}{lll}1 & \text { WL: } & \text { so l'll leave you guys to do } \\ 2 & \text { TR: } & \text { yep } \\ 3 & \text { WL: } & \text { do those } \\ 4 & \text { XX: } & \text { sure yeah thank you }\end{array}$

\section{Example 85}

$1 \quad \mathrm{XX}: \quad$ [sound of spoon clanking on bottom of plate] I've done it again guys

2 CR: [laughs] it means the end of the custard

3 JM: [laughs] Laurie wins the race

$4 \quad X X: \quad$ for a change

5 JM: [laughs]

$6 \quad X X: \quad I$ think I should handicap myself or something give you guys ten minute head start

In example 84 the exchange is part of a staff meeting in a bookshop, consisting of only one male - WL, a Company Director in his fifties, who addresses the three females as guys. In example 85, the interaction is between three female flatmates in their twenties, and $X X$ refers twice to her peers as guys. From these examples, which are representative of numerous exchanges from the corpus data, we can see that the gender neutral use of guys is widespread in terms of speaker identity, and semantic referent.

Despite the above examples being relatively transparent in terms of what the speaker means by his or her utterance, a certain amount of pragmatic knowledge must be relied on in many cases, in order to understand the correct denotation of guys. Consider the final example in this section, between two female friends in their twenties. 


\section{Example 86}

1 AN: he sort of like started at the beginning wanted to dance blah blah blah and I just sort of stayed away from him

2 but it was hard because I was with about four guys

3 I was with the guys

$4 \quad \mathrm{Kl}: \quad \mathrm{mm}$ yeah but did you have one dance with him

From AN's first use of guys here (I was with about four guys) we can infer with some certainty that she is referring to four males. On the basis of that inference we can also deduce that in her second use of guys ( $/$ was with the guys) she is referring to males, however, this is perhaps not quite as clear, i.e. she uses the definite article rather than a numeral modifier which seems to lessen the clarity of the guys' gender. Moreover, should the first guys utterance not have been there at all, and had the speaker simply stated, I just sort of stayed away from him, I was with the guys, the gender of the guys could feasibly be ambiguous. While it's not explicitly clear why the modifier prompts a change in the semantics here, a tentative explanation is that guy as a singular noun is still most commonly used to refer to a male, and the numerical modifier (four) indicates four individual male entities. Conversely, the determiner the, used in plural noun phrases such as the guys, seems to be a universal quantifier, meaning 'all' (Kearns, 2000), which in the case of the guys suggests a gender-inclusive reading of guys, hence the gender of the referents being somewhat opaque. Although in most cases speakers will avoid ambiguity (Grice, 1981), with a term of reference that is polysemous such as guys, confusion may arise if there isn't a sufficient amount of context, or enough socio-pragmatic cues for the hearer to pick up on.

\subsection{Guys in the media}

Much like in the corpus data, functional variety was limited in the media, yet token frequency was high, as shown in Table 24. 
Table 24: Token frequency of guys in the media data

\begin{tabular}{|l|c|c|c|c|c|}
\hline Type of speech & $\begin{array}{c}\text { Total } \\
\text { tokens }\end{array}$ & $\begin{array}{c}\text { Male tokens } \\
\text { (Tokens uttered } \\
\text { by men) }\end{array}$ & $\begin{array}{c}\text { Female } \\
\text { tokens } \\
\text { (Tokens uttered } \\
\text { by women) }\end{array}$ & $\begin{array}{c}\text { Male } \\
\text { addressee } \\
\text { (Tokens uttered } \\
\text { to men) }\end{array}$ & $\begin{array}{c}\text { Female } \\
\text { addressee } \\
\text { (Tokens uttered } \\
\text { to women) }\end{array}$ \\
\hline $\begin{array}{l}\text { Spontaneous } \\
\text { speech }\end{array}$ & 209 & 107 & 102 & 99 & 110 \\
\hline Scripted speech & 174 & 88 & 86 & 83 & 91 \\
\hline Total: & 383 & 190 & 183 & 182 & 201 \\
\hline
\end{tabular}

What is made clear by the results in Table 24 is how close the distribution of tokens is between the sexes, in both speech environments. Of the four address terms examined, guys is the only one that, based on the results in this study, is currently being used equally by, and to, males and females. As the examples that follow will indicate, the term is used generically in terms of referent gender as well as speaker identity.

As has been the trend with each of the address terms, total token frequency in the spontaneous and the scripted speech data is similar. Although it is slightly higher in spontaneous speech here, this is partially a result of a specific type of broadcast viewed as part of the data collection, namely, online video blogs (e.g. review blogs, video diaries). In these environments the blogger speaks directly to the camera, and guys is frequently used as way of addressing viewers. This usage can be seen in example 87 , an online 'beauty review,' and example 88 from The X Factor Video Diaries. 


\section{Example 87: Beauty Review}

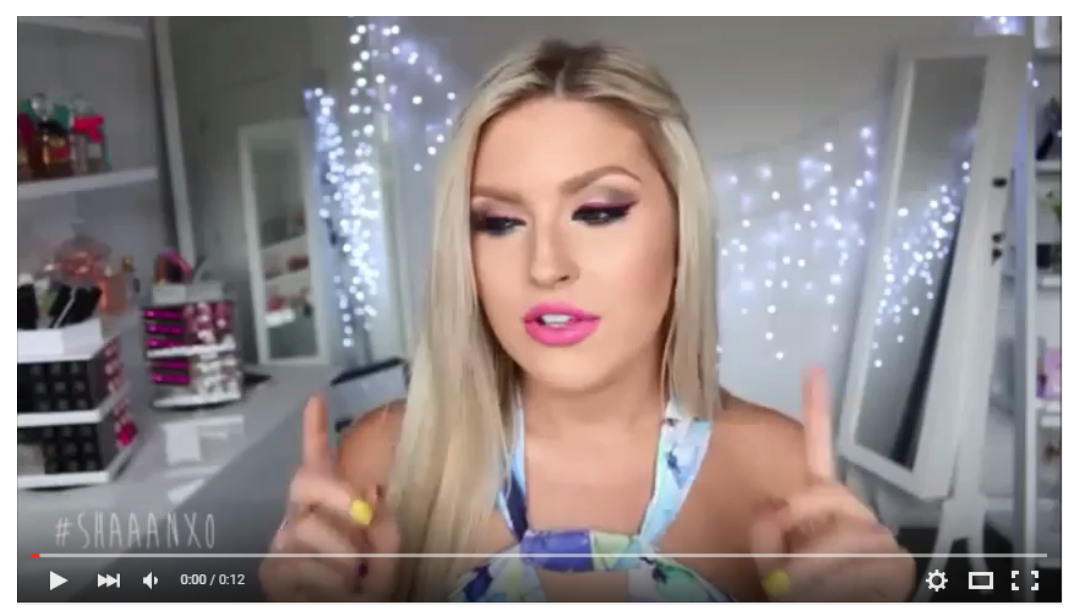

Example 88: The $X$ Factor Video Diaries

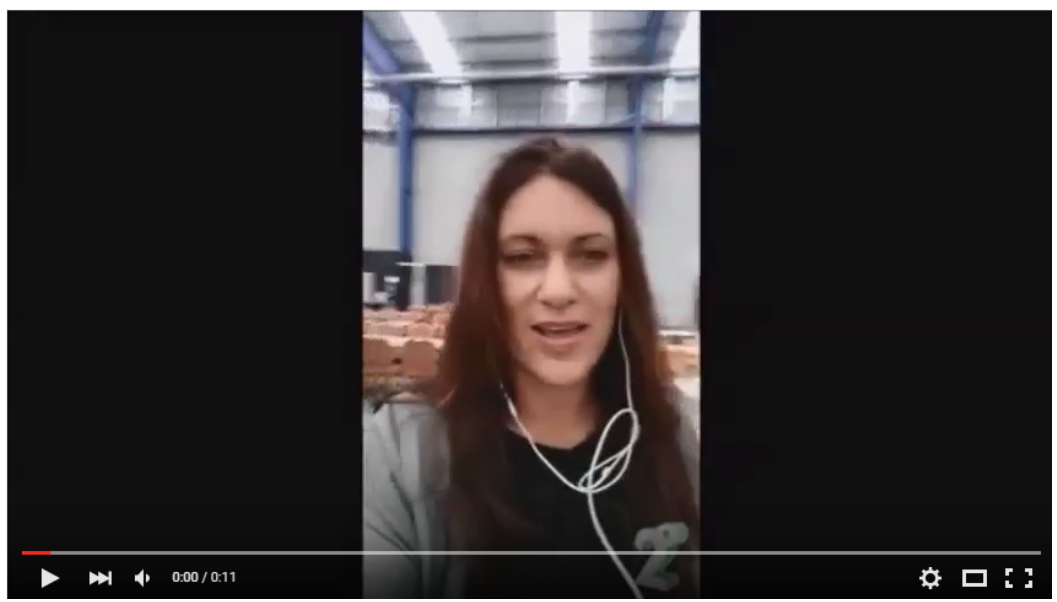

Here we can see guys being used to address an indefinite, and in a sense abstract, group of referents. Notable here is the types of subject matter the blogs relate to. The X Factor is not particularly gender specific and therefore viewers in example 88 are likely to be a mixture of both sexes. However, beauty products are a much more gendered topic, and we can assume that example 87 is targeted primarily towards a female audience. This illustrates how guys can be used to address groups of referents that do not include males, as we have seen demonstrated in the corpus data above (examples 84 and 85). These examples show how guys is being used naturally, and in quite different contexts, by female speakers (of different age groups) and to refer to both sexes.

The following example, taken from Masterchef, further demonstrates the pervasive use of guys by and to females, this time with tangible referents. 


\section{Example 89: Masterchef (2)}

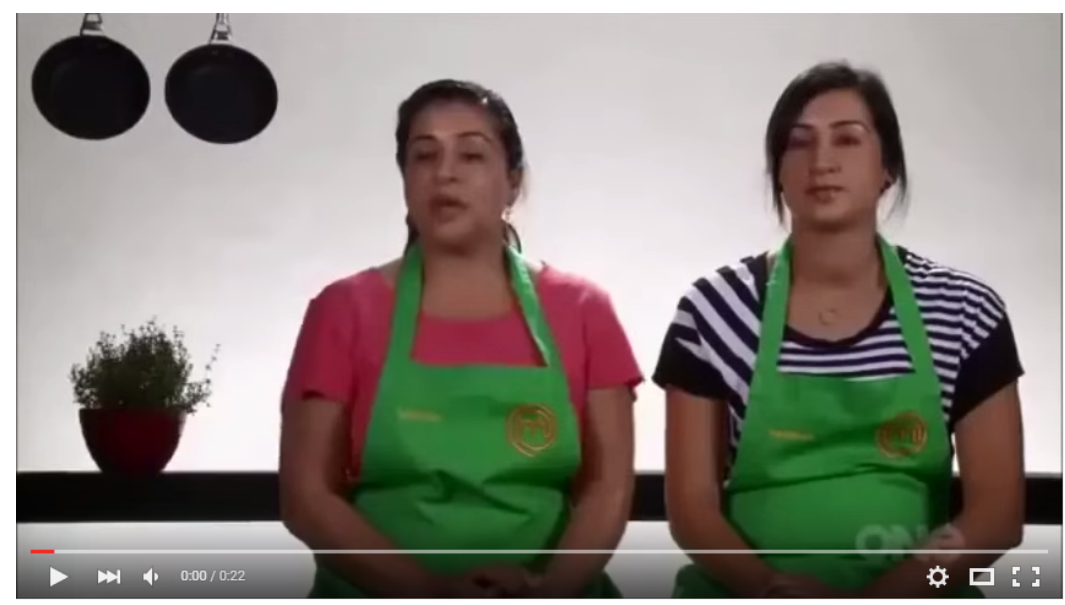

In example 89, we see guys being used by several different speakers (both male and female) in a very short space of time. As the women here are participating in a team challenge, their use of guys to address each other could be interpreted as building and maintaining solidarity, as we have seen mate and bro do. However, as will be discussed shortly, it may simply be the case that guys is one of the few plural options available to them. The most interesting observation in this example can be found in the final few seconds of the clip, when we hear a female New Zealander saying come on guys, followed by an American woman saying come on girls. Although guys is clearly being used in the U.S., and it wouldn't seem strange for a New Zealander to use girls, this contrastive set of utterances seems to highlight how organic the use of guys is for female NZE speakers.

The final example in this section, once again from Masterchef, shows the use of guys in males' speech, illustrating quite how ingrained the term is in current NZE. 


\section{Example 90: Masterchef (3)}

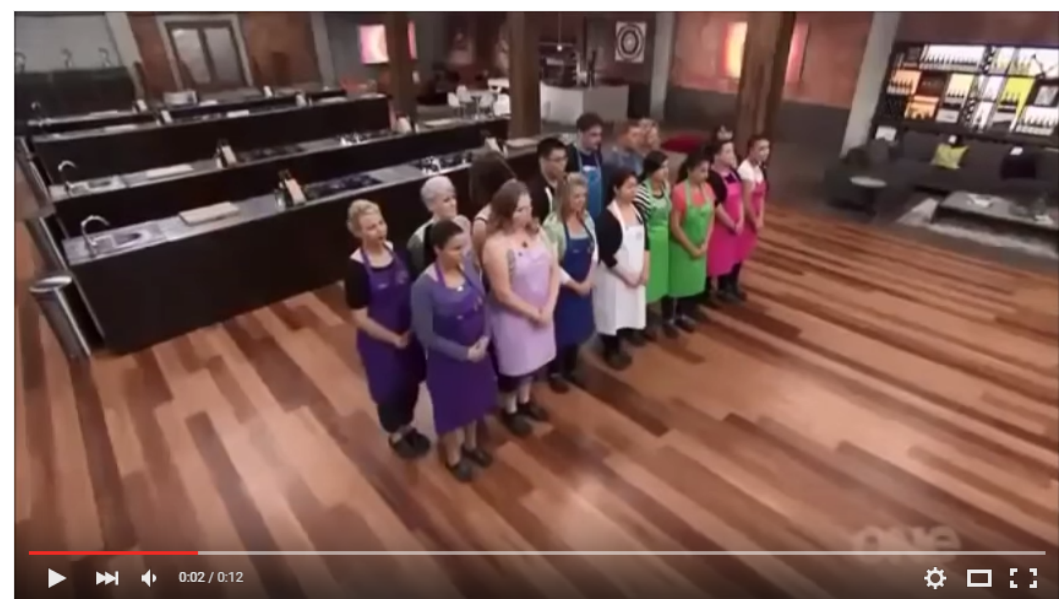

In example 90 we see both male judges using guys to address the mixed group of contestants. When we take into account the relative popularity of Masterchef (the 2015 season finale drew an average audience of 260,050 viewers, Regan, 2015) and the presumption that known television personalities would avoid using unsuitable language, this example suggests that the gender neutral use of guys is deep-seated in New Zealand, both in mainstream media, and in NZE itself.

From this set of examples, representative of the extensive media data set, we can see the prevalence with which guys exists in current NZE. In the episode of Masterchef that examples 89 and 90 were taken from, there were 24 tokens alone. Furthermore, we have seen that tokens of guys tend to be equally distributed between men and women, both with regards to speaker and referent.

Having looked at both the corpus and the media data, we can see how established guys is as a gender neutral term of address. As noted above, there is a certain irony that a word with clear [+male] features is so ubiquitous for general referents across the sexes in our vernacular, while others have been widely rebuked. We turn now to a consideration of some potential factors that have influenced this linguistic situation, and reflect on some of the social restraints associated with male generics in general. 


\subsection{Generic guys: some potential factors}

It seems likely that a variety of factors have contributed to the use of guys being so extensive in NZE. In this section I consider some of these with regards to register, grammar, and aspects of gender bias in everyday speech.

\section{Register}

One possible explanation for the relatively low level of criticism towards the use of guys is its informal register. Specifically, that guys really only occurs in informal discourse, unlike for example, (the generic use of) he and man. Due to the growing awareness of nonsexist language, it would be unusual to find gender-exclusive language in public or formal writing (e.g. newspapers, academic writing). Likewise, professional associations and government mandates are increasingly specifying that writing avoids sexist terminology (Sczesny, Moser, \& Wood, 2015). New Zealand appears to be at the forefront of such developments. Maclagan (2015) notes that it has gone farther than many other countries in becoming gender neutral in language.

In addition to written publications, it seems unlikely that gender-exclusive language would be used in formal spoken discourse (e.g. news bulletins, political speeches, academic talks). However, outside of these formal environments, speakers have a choice as to whether they use gender-inclusive language. At present guys is rarely used in official domains, but in informal, casual speech - a very different register. Perhaps this is a principal reason one masculine term has prevailed while others are reproved, because guys is not commonplace in formal registers and it has not undergone such critical analysis. As Clancy (1999) has suggested, the relative lack of an outcry against guy up to this point seems to be due to its absence in print.

\section{Grammar}

It is necessary to touch on grammatical considerations in a discussion about the popularity of guys, due to the fact that there is a gap in our grammar regarding a second person plural pronoun. While there is the merged singular/plural you, spoken discourse in second person contexts clearly needs an alternative, illustrated by the various regionally marked forms that are derived from you (e.g. you guys, yous, y'all, you lot). In NZE, the 
only alternative to you guys appears to be yous, found most commonly in the speech of school aged children, and Māori English (Hay, Maclagan, \& Gordon, 2008). However, the form yous is highly stigmatised (much like the Southern U.S y'all, Maynor, 2000) and this makes it an extremely unlikely candidate for standardisation. In NZE, this leaves you guys, a form which interestingly has not suffered stigmatisation due to its potential for sexism, open for generalisation.

\section{Social factors}

Aside from the issue of register, and the absence of a standard option in our grammar, a more global question is why masculine or [+male] words are entirely capable of achieving gender neutral status, while feminine, or [+female] words almost invariably are not. As this study is concerned with ongoing linguistic changes in New Zealand, this section considers some possible reasons as to why this is the case in NZE.

A potential argument for both the adoption of guys (for female referents) and the lack of generic female words in NZE, is the dearth of terms available in the vernacular. Namely, there is no [+female] equivalent to guys. The possible exception is of course with girls, used to refer to women in common phrases such as girl's night out. However, it is reasonable to assume that a large portion of the female population would oppose being called girls due to it not having particularly positive connotations (unlike, for example, the reclaiming of girl by some African American women, Meyerhoff, 2011), and because it essentially refers to grown women as children. Furthermore, and perhaps most saliently, it seems extremely doubtful that males across the board would accept being referred to as girls, meaning the adoption of it as a generic term for both sexes seems beyond remote.

The above conjecture that most males would be unlikely to accept an obviously female word as generic is a significant point to consider. It is feasible, for example, that certain terms prevail because women are less likely to object to being referred to by masculine words than men are to by feminine ones. It is not often overtly insulting for a woman to be attributed male qualities (although there are exceptions, for example the negative 'angry butch' lesbian stereotype Geiger, Harwood, \& Hummert, 2006) and while 
expressions such as tom boy and career woman can undoubtedly be used in a derogatory manner, they're not definitively negative. In contrast, comparing males to females is nearly always done with negative intent. Expressions such as throws/hits/runs like a girl, don't be such a girl's blouse, and crying like a girl, all serve to insult, while drawing comparisons with supposed female weakness. In most circles at least, to approach a group of heterosexual males and refer to them as ladies or girls would be done either in jest, or to cause offense. As Kleinman (2002) notes, there could be serious consequences for referring to a man as a woman. It may be the case that attempts to shame males by way of negative comparisons with the female sex helps to reinforce unhelpful gender stereotypes, and aid in preventing feminine words becoming gender free. Moreover, there is perhaps such a tendency for informal female terms to carry potentially demeaning connotations, or sexual undertones (Spender, 1985), that a suitable contender for inclusive use hasn't yet entered the language.

It certainly seems somewhat far-fetched that the quintessential 'Kiwi bloke,' such as the one discussed earlier in the mate analysis, would welcome being referred to by a term usually reserved for the female sex. It is arguable that while there is a resolute 'Kiwi bloke' image, there is no such distinct female equivalent. The absence of such a defined New Zealand woman stereotype perhaps made it easily accessible for women to adopt a masculine term to refer to themselves - having less of a societal gender norm to adhere to. However, the prevalence of the use of gender neutral guys in the U.S. suggests there is a much more complex set of motivations at play.

A further possibility for females using male terms to refer to themselves is suggested by Kleinman (2002). She argues that women want to be included in the term that refers to the higher-status group - men, in order to feel included. Kleinman illustrates her point with an example of female university students choosing for themselves the label brother over sister when joining a fraternity that had recently been made open to both sexes. She notes that as with the usage of guys, the women wanted to affiliate themselves with the word that has more value. This view would suggest that the use of guys by female speakers to female referents is in fact indexing a desire to be included in a social group they perceive as superior. 
In this discussion of (the lack of) female generics in NZE one small exception did become apparent, namely, the use of she in the Australasian saying she'll be right. Rather than a reference to a person, however, the she represents 'it' or 'everything' in the common idiom. Although it is a rare case of using a female word for a generic entity, the saying itself has strong associations with the 'Kiwi bloke' image discussed above, evidence of which can be found in Peter Cape's 1955 folk song She'll be right, which celebrates the pig-hunting and rugby rituals of young New Zealand males.

\subsection{Discussion}

We have seen in this examination of guys that its usage is widespread and polysemous across gender lines. Because of the use of it in a pronoun construction, guys performs a much more practical role than the other terms we have looked at, which is quite likely the reason why it appears so frequently. Despite this practical, grammatical use, it remains an informal and affiliative term of address that is being used across a range of different demographics. As we have seen, it appears to be almost entirely unmarked for gender, ethnicity, class and age.

The findings from the workplace sections of the corpus data, where the percentage of guys tokens in you guys constructions was extremely high, supports the hypothesis that you guys is in an ongoing process of grammaticalisation. Likewise, results from the media data that revealed high token frequency in general (by both sexes), suggest that guys is increasing in usage in NZE much like it is in American English (Heyd, 2010; Maynor, 2000). It is not immediately clear the precise motivations for this growth in usage, nevertheless, I have proposed that it is likely to be a combination of factors associated with register, grammar and gender bias in our speech.

The relationship between grammar and meaning is particularly interesting with regards to guys. We have seen that when used in the second person it is gender neutral, yet in the first and third person it retains a lot of its masculine connotations (as we touched on in example 86 above). This distinction illustrates how pragmatic knowledge must be relied on when searching for meaning, in utterances that include a conventionally gendered address term, a notion we will return to in more detail in the following chapter. 
It seems that concerns over the 'correctness' of gender neutral guys are felt largely in academia, but also in wider parts of society as well. However, it seems like the underlying issue is the tendency for words with specifically male meanings to develop into terms that carry gender specific and generic meanings simultaneously, as this does tend to present a linguistic situation that reinforces unhelpful gender ideologies, such as men being the benchmark sex, and women a secondary subset.

As noted above, it is by no means clear to what degree the gender bias of guys is actually felt by speakers and referents in New Zealand. So far in my discussion of the respective address terms I have avoided presenting anecdotal evidence to support my analysis, however, it is perhaps significant to mention that during the course of this study I spoke to numerous female speakers of NZE, most of whom reported they were both users and referents of guys, and that they felt neither offended nor marginalised by the term. A self-report/attitudes study of a wider range of female NZE speakers would provide compelling information to either support or invalidate this. 


\section{General Discussion}

The purpose of this study was to examine the use of conventionally masculine, informal address terms in NZE. The aim was to explore what social indexicalities the terms mate, bro, man and guys possess, and to investigate any shifts towards gender neutrality. The findings in this study suggest that mate is not becoming more gender neutral and it that it may be declining in young people's speech more generally. Bro on the other hand appears to be growing in usage, particularly among young males, with some evidence to suggest that it may be a candidate for gender neutrality in the future. Both man and guys were found to be in frequent use by and to speakers and referents of both sexes, indicating that they have already gained gender neutral status in NZE, with guys being particularly ubiquitous. The findings suggest that the high frequency of usage of man and guys is a likely result of their semantic bleaching and grammaticalisation.

These findings are valuable as they give us some insight into what is happening linguistically, but also potentially highlight some shifts in attitude and New Zealand identity in a broader sense. The fact that there is evidence to suggest that mate is in retreat among younger speakers and is not being renegotiated as it appears to be in AusE (Rendle-Short, 2009), seems to indicate that young NZE speakers are moving away from the kinds of conventional identifications of New Zealand identity that mate tends to be associated with. For example, the socially constructed 'Kiwi bloke,' typified by national icons such as Barry Crump or (in parody) 'Fred Dagg.' Although in this study mate (in natural spontaneous speech) was found to be unmarked for ethnicity, the term is often used in representations that are not particularly inclusive of New Zealand's multiculturalism, and, as I pointed out in the mate analysis, that are not especially relevant to young New Zealanders.

As is illustrated, particularly in the media data, the reverse is true with regards to bro. Although we have seen that it is a potent index of ethnicity in some environments, we've also seen that it is being used with no ethnic marking, and, unlike mate, appears to be increasing in young people's speech. I suggest that this is, at least in part, due to it being more relevant to young people (than mate), as it is arguably more representative of 
contemporary New Zealand identity. Consider the iconic phrase sweet as, bro. Although it is almost certainly not used in some speech communities, and it may well be more mythologised than actually present in our vernacular (there were very few instances of it found in either data sets), it is undoubtedly emblematic of a more contemporary set of New Zealand values, such as: a considered stance of familiarity, unflappability and a growing 'give it a go' attitude (Smart, 2014). In that sense, bro can perhaps be viewed as replacing mate as an iconic form (compare, for instance, sweet as, bro and good on ya, mate), and therefore surely more relevant to a younger generation of New Zealanders. It is also quite possible that this symbolic status of bro is motivating a shift towards the term becoming unmarked.

If inferences made from this study are correct and we are seeing a term closely associated with Māori English becoming more mainstream, this is perhaps indicative of the ways that New Zealand is changing in a broader sense, i.e. increasing multiculturalism and a growing urban population are potentially motivating a trend towards non-Pākehā norms appearing in standard NZE. We have seen that bro is being used by males of a range of ethnicities. Although there were very few tokens of bro by and to females in the media data, I speculate that I would get different results (to what degree I'm not sure) with access to spontaneous speech in natural environments, i.e. not from media sources. For instance, we have seen that there is evidence to suggest that the media representation of bro is overly conservative, and it also seems likely that, like in the blue-collar workplace, there are other communities of practice, and indeed communities, where bro is largely unmarked for gender. Further research into, and wider data collection among younger NZE speakers in natural speech environments would be needed to either support or invalidate this hypothesis, and would be greatly beneficial in gaining a broader understanding of how bro is being used.

We have seen that both man and guys have a largely gender neutral status in NZE. Due to the ubiquitous use of guys especially, this finding is not surprising, particularly as both terms as address forms have gained gender neutrality elsewhere (e.g. guys in the U.S., man in the U.S. and parts of the U.K.). However, it highlights some interesting issues about the masculine nature of address terms used by New Zealand women. Something 
that was unanticipated in this study was the observation that female NZE speakers, on the whole, are not using many other address terms with much frequency, i.e. forms with $\left[+\right.$ female] connotations ${ }^{27}$ or (historically) gender free semantics. Thus, the only forms they were found to use systematically were conventionally masculine ones - man and guys. The extensive use of these forms can be explained by their respective grammatical functions (man as an interjection and pragmatic marker, guys as a second person plural pronoun), however, the lack of specifically feminine address terms is harder to explain. It seems quite probable, as I mentioned above with regards to bro, that other forms might be found in natural speech environments, yet it is interesting that none have spread so as to become anything close to standard. Consider, for example, how bro has spread from Māori English into some non-Māori vernaculars yet other female or gender neutral familial address forms haven't, i.e. cuz, sis, bub (meaning younger female, King, 1999) ${ }^{28}$.

The preference for male terms of reference is of course not unique to New Zealand speakers and can be observed in various English speaking cultures. Perhaps the most fundamental reason for the scarcity of female terms can be explained by the wellestablished argument, particularly in feminist scholarship, that women's speech (and some would argue, women themselves, Tannen, 1993) is essentially marked. Even a cursory glance at present-day English shows that the unmarked form of many reference words carry a 'male' meaning (e.g. actor/actress). It is arguable that the English language reflects the power that males have held (and arguably still do) in many areas of society. Namely, our language reflects this social power by regarding terms that refer to women as marked while most unmarked words refer first to men, and then to both men and women. Furthermore, the marking itself of some [+female] words (e.g. the suffixes -ess and -ette) can result in them acquiring additional meanings that often have common associations with the female gender that are childish, frivolous or have sexual undertones. As Tannen (1993) aptly notes, would people feel safe entrusting their lives to a doctorette? Parallel additional meanings are also attached to conventionally female

\footnotetext{
${ }^{27}$ The only exception to this was the use of babe which occurred with some frequency in certain scripted broadcasts, and was used amongst close female friends and to romantic partners.

${ }^{28}$ It has since been pointed out to me that bub is used (by a Pākehā speaker to his daughter) in a recent Tucson Hyundai advertisement (https://www.youtube.com/watch?v=60n8CW-JZoo). It will be interesting to see if this is an anomalous usage or if it is in fact becoming more widely used.
} 
address terms, for example, babe and chick have connotations that are both sexual and infantile.

As I touched upon briefly in the analysis of guys, the adoption of male words used by and to females is also potentially motivated by our societal power structure: women may want to be included in the term that refers to the higher-status group or affiliate themselves with the word that has the most value. As Lakoff (1975) observed, by the 70s, "men's language" was increasingly being used by women yet "women's language" was not being adopted by men (except for non-normative speakers such as homosexuals).

It is reasonable to assume that the preference for male reference words in English speaking cultures is at least in part due to the markedness of [+female] terms and a general gravitation towards unmarked forms and/or forms that are used by the group of speakers that hold the most power. However, a further potential explanation for the lack of dominant [+female] forms with specific reference to NZE relates to the strong representations of masculinity in conventional New Zealand identity. In the analysis of guys I touched briefly on the notion that there is no female equivalent to the 'Kiwi bloke,' an icon that has been strongly associated with New Zealand national identity (Bannister, 2005). As an equivalent female icon (or really any Kiwi woman stereotype at all) doesn't exist, neither are there any terms of address or reference (unlike the mate - 'Kiwi bloke' association we have observed) specific to New Zealand women. This seems a likely reason why NZE doesn't have a female equivalent to mate. It has been noted that the dominant iconography of New Zealand identity is masculine (Bannister, 2005), that there is a strong literary tradition concerned with masculinity, and that masculine themes have often been central to New Zealand film, television and advertising (Law et al., 1999). It certainly appears that New Zealand masculinities have been more widely discussed (e.g. Bannister, 2005; Honeyfield, 1997; Law et al., 1999; Phillips, 1987), and have a much more identifiable place in a conventional New Zealand identity than any distinct femininities. It seems possible that this strong association between masculinity and New Zealand identity has contributed to both a lack of feminine terms that are distinctly 'Kiwi,' and the apparent ease with which female NZE speakers have become the referents of conventionally [+male] address forms. Specifically, the national identity is embodied in a 
masculine archetype and therefore women can also embody that archetype, in order to identify with the national identity.

Law et al. (1999) have highlighted how celebrated Kiwi men are embraced as representative of the national character yet notable New Zealand women (such as Kate Sheppard, Katherine Mansfield and Keri Hulme) are more likely to be seen as resolutely idiosyncratic. It is perhaps meaningful to note that since the New Zealander of the Year Awards began in 2010 only one of the seven winners of New Zealander of the Year has been female, and only a further two women have won any of the secondary awards, e.g. Lydia Ko for Young New Zealander of the Year 2015 (Kiwibank New Zealander of the Year Awards, n.d.). Furthermore, it is arguable that the female New Zealanders that can be viewed as icons are not ones that we are invited to identify with, for instance, Ginette McDonald's satirical character 'Lynn of Tawa'.

If the above conjectures that both the 'Kiwi bloke' iconography and the address term mate are losing relevance are correct, it will be interesting to see whether this will make way for any contemporary address forms that have originally gender free semantics. Or, if (as has been indicated by bro in the findings from this study), we will simply continue to see different male gendered terms moving towards gender neutrality.

Despite the speculation that access to a wider range of natural speech would produce slightly different results in this study (specifically with relation to bro), the media data set provided a fairly comprehensive view of the current use of address forms in NZE. However, although there were no real disparities in token frequency between spontaneous and scripted speech in any of the four terms analysed, we did see some evidence that bro is being underrepresented in the media. This is in contrast to the results from Cheshire's (2013) study, where the use of the pronoun man seemed to be inflated in the data collected from media sources - more tokens were obtained from media sources, in a shorter stretch of time, than from natural speech recordings. Cheshire concludes, however, that the use of the pronoun is much more widespread than her corpus of natural speech suggests, as she claims it is easily overheard in public places 
where MLE is spoken. Parallels then can be drawn between this and my hypothesis that bro is being used with more frequency than the media data suggests.

A further issue with the media data was the potential misrepresentation of ethnicity in the female's use of mate, where we saw that Māori and Pasifika speakers dominated the scripted data, yet Pākehā dominated the spontaneous speech. However, a greater number of tokens would need to be collected in order to see if the pattern we began to see emerging would be maintained on a larger scale. The representation of ethnicity is a salient issue in the New Zealand media as we have seen it playing a role in promoting serious messages, in the explicit portrayals of (predominantly) Pākehā/Māori communities in the NZ Police ads.

Although the corpus data had the benefit of avoiding misrepresentation, it did present some limitations, such as not having audio files, and as we saw this hampered the analysis of the ambiguous nature of man. Additionally, the fact that it was compiled in the nineties meant that it wasn't able to contribute information about current usage. However, having the two sets of data from contrasting time periods (a then and now aspect) meant that we were able to see trends that remained constant over time, and potential shifts in usage - such as a decline in mate produced by females, and the increase of man as an interjection form.

The corpus data also provided an invaluable source of information about the role address terms play in things like social bond-maintaining in a specific setting, i.e. the workplace. For example, in the blue-collar data specifically, we were able to see clear evidence that bro can be unmarked for gender and have a primary index of solidarity rather than ethnicity. With the exception of guys, which as we have seen is somewhat anomalous in this study, it was the blue-collar workplace speakers that used the highest percentage of address terms. I suggest that the reasons for this are three-fold. Firstly, the nature of the discourse used in the factory setting is typically informal, often irrespective of power relationships (as we saw in interactions with Ginette), and the address terms I have analysed are forms most likely to be found in casual, informal speech. Secondly, we have seen that the factory is a CofP where address terms are able to fulfil specific functions 
that are compatible with their goal-orientated workplace, for example the high frequency of tokens found in the acknowledgement of information and please and thank you utterances. Thirdly, we have seen that males are the prevailing users (again with the exception of guys) of the address terms analysed, and the blue-collar workplace is a male-dominated CofP, typified by a normatively masculine interactional style. The contrasting data sets were beneficial in gaining a well-rounded picture of NZE speakers and the forms being used. The extensive access to spontaneous speech in conversation in the corpus data provided invaluable information about the interactional functions of address terms. In addition, the media data gave us current speech samples, with the benefit of visual and audio information, which allowed more insight into paralinguistic and socio-pragmatic cues.

Approaching my analysis from a socio-pragmatic perspective was beneficial in this study, as an understanding of the interactional function of a form often came down to different types of social meaning. There was a systematic division between the semantic and the pragmatic meaning of the forms, which illustrated how socio-pragmatic competence is crucial in the use of informal address terms. This was demonstrated on the most basic level by the fact that the familiarisers I have analysed (with the exception of some uses of mate) are not intended to be taken literally. Specifically with bro, man and guys (all lexical items that have a semantic form denoting a male person) there is a mutual understanding between speaker and hearer that the literal meaning is irrelevant. There surely must be situations where female referents of the terms reject the reference (e.g. a woman objecting to being referred to as a guy), however no instances of this were found in this study, and from that, paired with a substantial amount of anecdotal evidence, I have inferred that such rejections are uncommon.

Socio-pragmatic ability was also a salient factor in the interpretation of address forms used in an antagonistic manner, specifically with regards to mate and bro. Bro was only found to be used as a distancing device on a few occasions, yet mate occurred in hostile or distancing speech acts with a frequency that wasn't anticipated at the beginning of this study, based on observations made in the preliminary pilot data collection phase. This use of mate presents us with an interesting paradoxical situation whereby it can be used 
to denote the direct opposite of its original semantics, and is therefore, somewhat of a contronym. As I touched on earlier in Chapter 4, the use of mate with negative intent seems particularly unusual when you take into account the frequent use of it as a term of reference (e.g. my mate) which has only positive connotations. I would suggest that it is useful to distinguish between one form that is semantically fixed and one that is flexible, as despite being closely related, mate as an address form and mate as a term of reference are often homonyms that carry distinctly different meanings. For example, mate as term of reference is invariably synonymous with 'friend,' yet mate as an address term is capable of communicating a wide range of meanings (as we have seen address terms do), e.g. an ironic marker of sarcasm, to signal agreement or express an exclamative response, and, as is under discussion here, to indicate a hostile stance. I suggest therefore, that the paradox presented by the two forms having opposing meanings is partially a result of mate, as an address form, developing a rich polysemy and polyfunctionality.

The question I posed earlier was whether the friendly meaning of mate actively enables the semantically antagonistic uses of it or whether these occur despite the original affiliative sense of the word. I would speculate that it is indeed mate's affectionate parallel meaning that allows it to be used antagonistically, as we know that address terms can be used ironically and can in fact stand for the exact opposite of what they are expected to. Consider, for instance, nigger in AAE or cunt in some Scottish vernaculars both terms that are usually considered derogatory and insulting are, in certain contexts, terms of endearment. As we saw in the earlier analysis, mate has been being used in adverse contexts for some time (e.g. Barry Crump's Hang on a Minute Mate) and is perhaps best explained by the relative frequency with which speakers use irony, or to use the Grice's (1981) formulation of conversational implicature, flout the maxim of quality. That is, to make an utterance that is so obviously contrary to the literal meaning that the recipient must search for another intended implicature. Grice takes it as one of the principal properties of an implicature that the intended meaning must be possible to calculate given the Co-operative Principle, his maxims and the textual and situational contexts (Birner, 2013). If a familiariser is used in a context that is clearly not intended to be friendly, the hearer can deduce that it is in fact intended to be antagonistic, rendering 
informal address terms such as mate powerful tools for implying diverse and opposing meanings.

In terms of meaning, the four address terms examined in this study can be divided into two camps. The use of mate and bro generally tends to imply a positive statement about the speaker and the hearer's relations, whereas man and guys seem to 'mean' less with regards to the interlocutor's relationship. While man does carry some social meaning, i.e. it can index youth, neither man or guys seem to impart as much pragmatic information in an interaction, or for that matter require as much pragmatic competence from interlocutors, as mate and bro. This suggests that there is a correlation between an address form being semantically bleached and the amount of pragmatic ambiguity it carries.

Both pragmatic and semantic meaning are central to the main findings in this study, and illustrate nicely Birner's (2013) point that the boundary between the fields is somewhat blurred. We've seen that the semantic bleaching of man and guys is quite probably the catalyst for the high frequency of usage. We have also seen that bro has undergone a considerable amount of semantic bleaching. My conjecture is that if the process continues the likelihood of its candidacy for gender neutrality increases. This likelihood is further supported by the capacity for it to be unmarked for ethnicity in some speakers. Although at this point those speakers may be primarily male, if bro continues to lose its male connotations it seems probable that we will see a growth in usage by young NZE speakers of both sexes. 


\section{Conclusion}

The purpose of this study was to examine the use of informal address terms in NZE. In particular, forms that are conventionally considered to be masculine, i.e. mate, bro, man and guys. The aim was to explore how these terms are being used by New Zealanders, their interactional functions and the social indexicalities they possess. Of specific interest was what the terms index with regards to gender, and whether there are any shifts towards these conventionally masculine forms being used increasingly by and to women, as Rendle-Short (2009) found happening in Australia with mate and Kiesling (2004) with dude in the U.S. In order to address these research questions two distinct data sets were used for analysis: (i) The corpus data, comprised of approximately 3,850,000 words of spoken NZE collected primarily in the 1990s, and (ii) the media data, comprised of approximately 1,764,000 words from both spontaneous and scripted speech environments, collected from current New Zealand media sources in 2015.

Contrary to a tentative assumption made in the very early stages of this study that New Zealander's speech may be aligned with Rendle-Short's findings in Australia, mate does not appear to be an actively evolving form in NZE. This may mean that a term which helped define the emergence of a shared Australasian/ANZAC identity and set of values in the twentieth century is the point of separation for New Zealand and Australia in the twenty-first century. Rather, it seems likely that bro, which is arguably emblematic of a more contemporary set of New Zealand values, is in the process of being renegotiated by younger NZE speakers.

While the results that show man and guys being used as gender neutral forms were anticipated based on observations of the everyday speech of New Zealanders (my own included), they are still noteworthy in that they highlight a gender bias in our language. Compared to the U.S., there appears to be a lack of discussion about [+male] forms becoming generic in NZE, despite the comprehensive amount of writing on New Zealand masculinities and their associations with New Zealand identity. Although it doesn't appear to be an issue for many New Zealanders, it is surely the case that a bias in our language promotes or reinforces gender inequities in our society. Regardless of this 
concern, however, it certainly seems that in the case of guys (and specifically you guys) we will continue to see it becoming more and more standard in New Zealand and in other English speaking countries.

The goal of this study is to contribute to the growing interest sociolinguists are taking in informal terms of address, and to analyse what is happening in the speech of everyday New Zealanders, with regards to address terms and gender. It is hoped that the findings will highlight the need for further research into young New Zealanders' speech particularly, in order to track and document informal forms that provide telling information about constructs of gender, identity and a potentially changing national character. 


\section{References}

Alimoradian, K. (2014). "Makes Me Feel More Aussie": Ethnic Identity and Vocative Mate in Australia. Australian Journal of Linguistics, 34(4), 599-623.

Ameka, F. (1992). Interjections: The universal yet neglected part of speech. Journal of Pragmatics, 18(2), 101-118.

Bannister, M. (2005). Kiwi blokes: Recontextualising white New Zealand masculinities in a global setting. Genders OnLine, 42.

Bauer, L., \& Bauer, W. (2002). Terms of Address. Retrieved from http://www.victoria.ac.nz/lals/research/projects/language-in-the-playgroundproject/publications/lip32.pdf

Bell, A. (2000). Māori and Pākehā English: a case study. In A. Bell \& K. Kuiper (Eds.), Varieties of English Around the World, Vol. G25. JB/Victoria UP: John Benjamins Publishing Company, 221-248.

Bell, A. (2007). Style in dialogue: Bakhtin and sociolinguistic theory. In R. Bayley \& C. Lucas (Eds.), Sociolinguistic Variation: Theories, Methods, and Applications. Cambridge: Cambridge University Press, 90-109.

Berman, B. R., \& Keegan, D. (1999). Humor in the hotel kitchen. Humor - International Journal of Humor Research, 12(1), 47-70.

Bianchi, C. (2004). The Semantics/pragmatics Distinction. Stanford, California: CSLI Publications, Center for the Study of Language and Information.

Birner, B. J. (2013). Introduction to pragmatics. Chichester, West Sussex: Wiley-Blackwell.

Braun, F. (1988). Terms of address : problems of patterns and usage in various languages and cultures. Berlin ; New York: Mouton de Gruyter.

Brown, P., \& Levinson, S. (1987). Politeness : some universals in language usage. Cambridge ; New York: Cambridge University Press.

Brown, R., \& Gilman, A. (1960). The Pronouns of Power and Solidarity. In T. A. Sebeok (Ed.), Style in Language. Cambridge, Mass: MIT Press, 253-276.

Buchstaller, I. (2001). He goes and I'm like: The new Quotatives re-visited. Presented at the New Ways of Analyzing Variation (NWAV 30), Raleigh, N.C. 
Campbell, R. (1995). Dismembering the Kiwi Bloke: Representations of Masculinity in Braindead, Desperate Remedies and The Piano. Illusions, 24(Spring), 2-9.

Charpentier, J. D. (2006). Teasing in Adult Peer Relationships: Using Lazarus' Model of Stress and Coping to Understand the Effects of Teasing (PhD Thesis in Communication studies.). University of Minnesota.

Cheshire, J. (2013). Grammaticalisation in social context: The emergence of a new English pronoun. Journal of Sociolinguistics, 17(5), 608-633.

Clancy, S. J. (1999). The Ascent of Guy. American Speech, 74(3), 282-297.

Coates, J. (2013). Women, Men and Language ( $3^{\text {rd }}$ ed.). London ; New York: Routledge.

Creswell, J. W., \& Plano Clark, V. L. (2011). Designing and conducting mixed methods research (2nd ed.). Los Angeles: SAGE Publications.

Curzan, A. (2003). Gender Shifts in the History of English. New York: Cambridge University Press.

Dascal, M. (2003). Interpretation and Understanding. Amsterdam: John Benjamins Publishing.

Dickey, E. (1997). Forms of address and terms of reference. Journal of Linguistics, 33(02), $255-274$.

Eckert, P., \& McConnell-Ginet, S. (2003). Language and Gender. Cambridge: Cambridge University Press.

Fitch, K. L. (1991). The interplay of linguistic universals and cultural knowledge in personal address: Colombian Madre terms. Communication Monographs, 58(3), 254-272.

Geiger, W., Harwood, J., \& Hummert, M. L. (2006). College students' multiple stereotypes of lesbians: A cognitive perspective. Journal of Homosexuality, 51(3), 165-182.

Goffman, E. (1981). Forms of talk. Oxford: Blackwell.

Goodwin, M. H. (1990). He-said-she-said: Talk as Social Organization Among Black Children. Bloomington ; Indianapolis: Indiana University Press.

Grice, H. (1981). Presupposition and Conversational Implicature. In P. Cole (Ed.), Radical Pragmatics. New York: Academic Press, 183-97.

Harker, C. (2013). Humour - The origins of Kiwi humour. Retrieved from http://www.teara.govt.nz/en/humour/page-1\#ref6

Hay, J., Maclagan, M., \& Gordon, E. (2008). New Zealand English. Edinburgh: Edinburgh University Press. 
Heyd, T. (2010). How You Guys Doin'? Staged Orality and Emerging Plural Address in the Television Series Friends. American Speech, 85(1), 33-66.

Higgs, J. (2001). Charting standpoints in qualitative research. Critical Moments in Qualitative Research. Oxford: Butterworth Heinemann.

Hofstadter, D. (1997). Hey, You Guys: Girls Are Just as Good as Guys! Some personal musings on the word "Guys" and the relative social esteem attached to femininity and masculinity. CRCC 135. Bloomington, Ind.: Center for Research on Concepts and Cognition.

Holmes, J. (1997). Māori and Pākehā English: Some New Zealand social dialect data. Language in Society, 26(01), 65-101.

Holmes, J. (2005). Using Māori English in New Zealand. International Journal of the Sociology of Language, 2005(172), 91-115.

Holmes, J. (2006a). Gendered Talk at Work: Constructing Gender Identity Through Workplace Discourse. Oxford: Blackwell.

Holmes, J. (2006b). Sharing a laugh: Pragmatic aspects of humor and gender in the workplace. Journal of Pragmatics, 38(1), 26-50.

Holmes, J., \& Marra, M. (2002). Having a laugh at work: how humour contributes to workplace culture. Journal of Pragmatics, 34(12), 1683-1710.

Holmes, J., \& Stubbe, M. (2015). Power and Politeness in the Workplace: A Sociolinguistic Analysis of Talk at Work. London; New York: Routledge.

Holmes, J.,Vine, B., \& Johnson, G. (1998). Guide to Wellington Corpus of Spoken New Zealand English. Wellington: School of Linguistics and Applied Language Studies, Victoria University of Wellington.

Honeyfield, J. (1997). Red-blooded Blood Brothers: Representations of Place and Hard Man Masculinity in Television Advertising for Beer (Masters Thesis in Geography). University of Waikato, New Zealand.

Hopper, P. J. (1993). Grammaticalization. Cambridge ; New York: Cambridge University Press.

Hopper, P. J., \& Traugott, E. C. (2003). Grammaticalization (2nd Edition). Cambridge: Cambridge University Press.

Hubbard, A. (2008, June 7). John Campbell. Stuff.co.nz. Retrieved from http://www.stuff.co.nz/sunday-star-times/features/profiles/476997/John-Campbell 
Kearns, K. (2000). Semantics. Basingstoke: Macmillan.

Keltner, D., Capps, L., Kring, A. M., Young, R. C., \& Heerey, E. A. (2001). Just teasing: A conceptual analysis and empirical review. Psychological Bulletin, 127(2), 229-248.

Kiesling, S. (2004). Dude. American Speech, 79(3), 281-305.

Kiesling, S. (2005). Homosocial desire in men's talk: Balancing and re-creating cultural discourses of masculinity. Language in Society, 34(05), 695-726.

Kiesling, S. (2007). Men, Masculinities, and Language. Language and Linguistics Compass, 1(6), 653-673.

King, J. (1999). Talking Bro: Māori English in the University Setting. Te Reo, 42, 20-38.

Kiwibank New Zealander of the Year Awards (n.d.). Retrieved from http://nzawards.org.nz/

Kleinman, S. (2002). Why Sexist Language Matters. Qualitative Sociology, Vol. 25(2), 299304.

Kleinman, S., \& Ezzell, M. (2002). The King's English: A Campus Fable. Feminist Teacher, 14(2), 179-184.

Koester, A. (2010). Workplace Discourse (1st ed.). London ; New York: Continuum.

The Language in the Workplace Project. (2014). Language in the Workplace. Retrieved from http://www.victoria.ac.nz/lals/centres-and-institutes/language-in-theworkplace

Labov, W. (1972). Sociolinguistic Patterns. Philadelphia: University of Pennsylvania Press.

Lakoff, R. (1975). Language and Woman's Place. New York: Harper \& Row.

Law, R., Campbell, H. R., \& Dolan, J. C. (1999). Masculinities in Aotearoa/New Zealand. Palmerston North: Dunmore Press.

Leech, G. (1999). The Distribution and Function of Vocatives in American and British English Conversation. In H. Hasselgård \& S. Oksefjell (Eds.), Out of Corpora: Studies in Honour of Stig Johansson. Amsterdam: Rodopi, 107-121.

Lindsay, A. (1982). Hang on a Minute Mate. Retrieved from http://www.nzonscreen.com/title/hang-on-a-minute-mate-1982

Maclagan, M. (2015, March 2). New Zealand Retro: Kiwi Slang. Retrieved from http://www.radionz.co.nz/national/programmes/afternoons/audio/20169236/new -zealand-retro-kiwi-slang 
Maynor, N. (2000). Battle of the Pronouns: Y'all versus you-guys. American Speech, 75(4), 416-418.

Metge, J. (1975). The Māoris of New Zealand : a bibliography. Wellington: s.n.

Meyerhoff, M. (1994). Sounds Pretty Ethnic, eh?: A Pragmatic Particle in New Zealand English. Language in Society, 23(3), 367-388.

Meyerhoff, M. (2011). Introducing sociolinguistics (2nd ed.). London ; New York: Routledge.

Norrick, N. R. (2009). Interjections as pragmatic markers. Journal of Pragmatics, 41(5), 866-891.

Parliament guards told no more "mate." (2005, August 18). ABC News. Retrieved from http://www.abc.net.au/news/2005-08-18/parliament-guards-told-no-moremate/2083806

Perry, N. (2013). The Dominion of Signs: Television, Advertising and Other New Zealand Fictions. Auckland: Auckland University Press.

Phillips, J. (1987). A Man's Country?: The Image of the Pākehā Male, a History. Auckland: Penguin Books.

Phillips, J. (1996). A Man's Country? The Image of the Pākehā Male-a History (Revised edition). Auckland: Penguin Books.

Queen, R. (2015). Vox Popular: The Surprising Life of Language in the Media. Chichester, West Sussex; Malden, MA: Wiley-Blackwell.

Rendle-Short, J. (2009). The Address Term Mate in Australian English: Is it Still a Masculine Term? Australian Journal of Linguistics, 29(2), 245-268.

Rendle-Short, J. (2010). "Mate" as a term of address in ordinary interaction. Journal of Pragmatics, 42(5), 1201-1218.

Sczesny, S., Moser, F., \& Wood, W. (2015). Beyond Sexist Beliefs: How Do People Decide to Use Gender-Inclusive Language? Personality and Social Psychology Bulletin, 41(7), 943-954.

Searle, J. R. (1969). Speech Acts: An Essay in the Philosophy of Language. Cambridge: Cambridge University Press.

Searle, J. R. (1979). Expression and Meaning: Studies in the Theory of Speech Acts. Cambridge: Cambridge University Press. 
Sequeira, D. L. (1993). Personal Address as Negotiated Meaning in an American Church Community. Research on Language and Social Interaction, 26(3), 259-285.

Smart, J. (2014, September 8). Jacqueline Smart on youth vote [interview]. Retrieved from http://www.radionz.co.nz/national/programmes/sunday/audio/20148672/jacqueli ne-smart-on-youth-vote

Spender, D. (1985). Man Made Language (2nd ed.). London: Routledge \& Kegan Paul.

Sperber, D., \& Wilson, D. (1981). On verbal Irony. In P. Cole (Ed.), Radical Pragmatics, 295- 318.

Spry, I. (2005). The hostile use of "mate" and "mateship." National Observer, (66 Spring), $11-12$.

Statistics New Zealand. (n.d.). 2013 Census QuickStats about a place: Auckland Region. Retrieved from http://www.stats.govt.nz/Census/2013-census/profile-andsummary-reports/quickstats-about-aplace.aspx?request_value $=13170 \&$ tabname $=$ Culturaldiversity

Stojanovic, I. (2008). The Semantics/Pragmatics Distinction. Synthese, 165(3), 317-319.

Stubbe, M., \& Holmes, J. (1995). You Know, eh and Other "Exasperating Expressions": An Analysis of Social and Stylistic Variation in the Use of Pragmatic Devices in a Sample of New Zealand English. Language and Communication, 15(1), 63-88.

Szabó, Z. G. (2006). The Distinction Between Semantics and Pragmatics. In E. L. and B. Smith (Ed.), The Oxford Handbook of Philosophy of Language. Oxford: Oxford University Press, 361-389.

Tagliamonte, S. A. (2006). Analysing Sociolinguistic Variation. Cambridge: Cambridge University Press.

Tagliamonte, S. A., \& D’Arcy, A. (2009). Peaks Beyond Phonology: Adolescence, Incrementation, and Language Change. Language, 85(1), 58-108.

Tagliamonte, S., \& Roberts, C. (2005). So Weird; So Cool; So Innovative: The Use of Intensifiers in the Television Series Friends. American Speech, 80(3), 280-300.

Tannen, D. (1993). Marked Women, Unmarked Men. New York Times Magazine. Retrieved from http://www2.bakersfieldcollege.edu/driess/Readings_files/Marked\%20Women.pdf Tannen, D. (2007). Talking Voices: Repetition, Dialogue, and Imagery in Conversational Discourse. New York: Cambridge University Press. 
Vincent, D., \& Sankoff, D. (1992). Punctors: A pragmatic variable. Language Variation and Change, 4(02), 205-216.

Vine, B. (1999). Guide to the New Zealand Component of the International Corpus of English (ICE-NZ). Wellington, NZ: Victoria University of Wellington.

Vowell, B., Maclagan, M., \& King, J. (2014). The English spoken by Māori: changes in rhythm over time. Te Reo, 56-57, 63.

Wales, K. (1996). Personal Pronouns in Present-Day English. Cambridge: Cambridge University Press.

Wilson, N. (2010). Bros, Boys and Guys: Address term function and communities of practice in a New Zealand rugby team. New Zealand English Journal, 24, 33-54. 


\section{Appendix}

\section{Media transcripts}

\section{Example 23: Family Recipes}

1 Chef: a few balls floating around, see there's one there

2 Sister 1: leave, leave, touching the balls

$3 \quad$ Sister 2: $\quad$ stop stop stop stop [singing]

$4 \quad$ Sister 1: I mean dad will be looking for meatballs

$5 \quad$ Sister 2: for meatballs

6 Chef: maybe l'll sort some out and just give them to your father

$7 \quad$ Sister 1: there are going to be questions tonight

$8 \quad$ Sister 2: yep, you're in trouble mate

$9 \quad$ Sister 1: he's still going

10 Sister 2: he couldn't help himself really

11 Sister 1: he could not help himself

12 Sister 2: he could not help himself

\section{Example 24: The Edge (1)}

1 Dom: cause Jay-Jay, Jay-Jay just invested in ah two thousand fifteen diaries for us, and I was like

2: Lorde: that is so nice of you

3 Dom: and I was like, shit lady you're stressing me out it's only August

4: Jay-Jay: hey mate you might not be busy but l've got appointments

\section{Example 26: Go Girls (1)}

1 Cody: this is used? 
2 Britta: only by me

3 Cody: mate, there are some things even best friends don't share

\section{Example 27: Coverband (1)}

1 Bartender: hey mate

2 Jukebox: what? No wait wait what? What

\section{Example 28: Motorway Patrol (1)}

1 Cop: have you got your driver's license on you please

2 Narrator: but this motorist has decided to give John something to be going on with

3 Driver: mate, you bored or something, man?

4 Cop: sorry?

5 Driver: you bored or something man, cause like

$6 \quad$ Cop: $\quad$ no, I'm just doing my job

\section{Example 29: Motorway Patrol (2)}

1 Man: so go and get [beeped out expletive]

2 Cop: you had a bit to drink tonight?

3 Man: what's it to you? I'll talk to my lawyer mate, cos' he told me, don't speak to you

4 Para 1: mate, you've just been a hell of a fall, and there's a good chance you've broken your back if you can't move one leg, so from now on you've just gotta stay still, okay, we're gonna get you out in somewhere, outta there, when we've got more hands

5 Man: I just wanna sit up 
6 Para 1: no, if you sit up, that'll be the last time you move, I'll tell you that, so stay as you are

7 Narrator: the man needs pain relief so the St Johns crew can get him out of the ditch, but frustratingly, he won't take the needle

8 Para 2: relax your arm

9 Man: how can you relax when you're in pain

10 Man oh shit

11 Para 1: that's what we're trying to get rid of mate, and it would be quicker if you helped, stay down, come on

\section{Example 30: Motorway Patrol (3)}

1 Cop 1: $\quad$ so you've got no other damage to your car?

2 Driver: no

3 Narrator: Clay smells a rat, and alcohol

4 Cop 2: anything to drink tonight?

5 Cop 2: eh?

6 Driver: not much, just a few

7 Cop 2: how old are you?

8 Driver: eighteen

9 Cop 2: eighteen

10 Driver: just turned eighteen

11 Cop 2: you've got the tyre round the wrong way too mate 


\section{Example 31: 7 Days (1)}

1 Jeremy: dairy giant Fonterra has announced it will freeze the price of milk till the end of this year

2 milk actually costs more than petrol these days, so logically I'm putting unleaded on the old weetbix [laughter]

3 not premium unleaded though, you know, gotta watch the old [pats belly] [laughter]

$4 \quad$ Paul: $\quad$ it'll take more than that mate [laughter]

\section{Example 32: 7 Days (2)}

1 Jesse: how many calories do you ingest during a standard pash with Gerry Brownlee [laughter]

2 Jeremy on that theme, how many cousins has Dai Henwood kissed [laughter]

3 Dai: I'm glad you're rounding down mate

4 [laughter]

\section{Example 33: Masterchef (1)}

1 Simon: asparagus soup with a salmon foam on top, and then a salmon croque monsieur, and I tell you what, that is the best mini looking croque monsieur l've ever seen 
and you know you were worried about that foam but mate that's foam, I can see the bubbles in it, spectacular

\section{Example 34: New Zealand's Got Talent}

1 Jason: I don't know how you don't look at the guitar but play the chords you're playing [laughs], blows me away, it's astonishing and it's so good to see you connecting with the audience and being who you are and um, being true to yourself, and nailing it mate

2 Cont: cheers, thank you

\section{Example 35: Mitre 10}

$1 \quad$ Kiwi kid 1: what are ya doing this weekend?

$2 \quad$ Kiwi kid 2: I'm putting up a retaining wall

$3 \quad$ Kiwi kid 1: doing it yourself?

$4 \quad$ Kiwi kid 2: nah, I'm going to get some bloke in

$5 \quad$ Kiwi kid 1: oh come on mate, do it yourself

$6 \quad$ Kiwi kid 2: she's pretty big job

$7 \quad$ Kiwi kid 1: you'll be right, hey Jonesy

8 Aussie kid: huh?

$9 \quad$ Kiwi kid 1: give us a hand with a job Saturday

10 Aussie kid: mate, you're dreaming

11 Kiwi kid 2: Aussies

12 Kiwi kid 1: no surprises there

13 Voiceover: DIY, it's in our DNA 


\section{Example 36: Brokenwood (1)}

1 Detective: wait, there's no reason for any of this, there's no reason for anyone to get hurt, specially me right?

2 I want to find a way out of this Dwayne and the way out of it is that you give me the gun and we talk about everything that's bugging you

3 how's that work for you mate?

4 just give me the gun, so that all this can go away

\section{Example 37: Nothing Trivial}

1 Father: look, I'm probably going to be working all weekend anyway so

2 Son 1: oh, so we're going to live with mum now

3 Father: no

$4 \quad$ Son 1: well if you're working all the time again

5 Father: no no not all the time, just this weekend

6 Son 2: believe that

7 Father: come on mate, teeth and I'll come and tuck you in eh

8 Son 1: I can do it myself

9 Father: mate

10 Son 2: yeah yeah, I get it, go to mum's or else

\section{Example 38: Brokenwood (2)}

1 Man 1: go home and sober up mate

2 Man 2: why, it's his fault

3 Man 3: you're a pig Nate, always were, always will be

4 Man 2: you won't be laughing at me tomorrow mate 


\section{Example 48: The X Factor (1)}

1 Stan: oh broooo [singing]

2 Stan: I feel like I have to sing that now to try and be better than you

3 Daniel: I'm not sure you can

4 Stan: you know, we're looking for the $\mathrm{x}$ factor, we're looking for the package, we're looking for that but, first of all, cause I'm a singer, I'm looking for that voice, and bro you are the mantis!

5 Stan: bro, do you know the one thing that cracks me off about people when they come on stage [imitates contestants] yeah well I'm actually a soul singer, I actually love soul, you know that deep $\mathrm{RnB}$, and then they sing so pussy and so soft

6 Stan: but you came out with blimmin' balls bro, like, it was wicked, like you sang like a man and you sung so deep and soulful, and oh bro, you're the man

7 Whenua: thank you bro

\section{Example 49: The $X$ Factor (2)}

1 Stan: bro, look at that, bro, you know the best thing bro is, is seeing you going from your confidence here, and you're just rising bro and you know what I love about you, you really take on board what we say, even though like, we're not here for, just just for show, know we're pretty, nahhh

2 Beau: oo e, oo e

3 Stan: but honestly bro I'm so proud of you, like what you just did there, you could be doing that on stages at your own concert bro, like, you're an artist, there's no one like you, you can sing, you can rap, you can dance, and you, oh you're mean beat boxer, you've got everything

4 Beau sup bro 
5 Stan solid

\section{Example 50: Motorway Patrol (4)}

1 Cop: fail general, so that's, telling me that's more than none drink that's telling me over the limit, yeah

2 so have you had some drinks

3 Driver: no, I haven't, I drank heaps of coffee bro, straight up, and I don't, I don't touch alcohol

4 Cop: $\quad \mathrm{hmm}$

5 Narrator: the EBA machine doesn't lie, maybe they were special coffees

$6 \quad$ [police radio]

7 Cop: [name] and

8 Man: I wouldn't do that cause bro, I'm not actually her father

9 Cop: what?

10: Driver: no, just shut up cause, yeah, she's got nowhere else to go

11: Man: nah you listen to me bro, I'm telling you now

\section{Example 51: Radio New Zealand - Blessie Gotingco trial}

1 CP: and that was more important to you than the life of Mrs Gotingco? Is that right

2 Accused: like I said at that time I just wasn't thinking straight, I don't care what you say bro [beeped out expletives] 
1 Accused: the only way I can describe how I was feeling at that time was what someone must feel when they're in survival mode, that's the only way I could describe it [unclear]

2 CP: if anyone was in survival mode that night it was Mrs Gotingco wasn't it?

3 Accused: you can take what you want from my answers bro, I don't give a fuck man, fucking told you what happened bro

\section{Example 52: The Truth about Teenagers}

1 Teen 1: where you at now?

2 Julia: um Odyssey, drug rehab

3 Teen 2: ah ha

4 Julia: nah that's not funny bro, I'm changing my life man, what are you doing?

5 Teen 3: yeah I'm going back up there in three months man

6 Julia: I'm ashamed of it cause what I did was wrong but I mean, I'm proud that I've moved on from it and I've stopped it, you know it's a habit l'd never pick up again

\section{Example 53: Best Bits}

1 Jesse: let's start with some of our favourite clips from the week, now John Campbell went out onto the streets last week to hang out with some young people John is no old fuddy duddy in a suit, he knows that if you wanna be down with the kids, you've got to learn to speak their lingo

2 John: oh, can I talk to you when you're finished? you buying some legal highs?

3 Customer: ah, possibly yeah 
4 John: can you come and talk to us when you're finished? come outside and talk to us

5 Customer: oh yeah

6 John: okay, would that be alright? What's your name?

7 Customer: ah Ryan

8 John: Ryan, okay thanks bro

[laughter]

9 Jesse: you know I don't think that guy even noticed that John was white [laughter]

10 Vaughan: oh bro, can I take a a hit from that legitimately packed bong there bro

\section{Example 54: Coverband (2)}

1 Man 1: oh, yeah, everywhere, they even photoshopped out that really gross mole she has on her cheek

2 Man 2: oh my god, I'm the mole

3 Man 1: oh, you're not the mole bro, you're like, you're like a really cute freckle or something

\section{Example 55: Brokenwood (3)}

1 Man 1: so I guess, to your wedding bro

2 Man 2: sweet, cheers

3 Man 3: yeah, you're doing well man, she's a real beaut

\section{Example 56: Seven Periods (1)}

1 Hohepa: gotta give three days notice for a detention

2 Gormsby: balderdash 
3 Hohepa: well, give me a detention and I might lose my afterschool job

$4 \quad$ Gormsby: what job?

5 Hohepa: oh, I don't have one eh

[laughter]

6 Teacher: touch that child and you'll never teach in a New Zealand classroom again

7 Hohepa: shame bro

[laughter]

\section{Example 57: Seven Periods (2)}

1 Hohepa: it was me

2 Gormsby: ah Hohepa, just as I thought

3

sit down [name] of course I wasn't going to roger you, this isn't a

Catholic school, it was simply a rouse to make Hohepa take

responsibility for his actions

4

shame bro

\section{Example 58: Brokenwood (4)}

1 Detective: Detective Inspector

2 Jared: Shepherd I know, I seen the car round town bro, the ah seventy-one model?

3 Detective: ah, you're familiar

4 Jared: well, they really should've put a V8 engine into eh

4 Detective: oh, you are familiar

5 Jared: Jared Morehu, neighbour 
6 Detective: technically I'm still on duty

7 Jared: well technically I don't give a rats

8 Detective: another time?

9 Jared: refusing my kai? technically that's culturally offensive

10 Detective: then technically I'm due a smoko

\section{Example 59: Brokenwood (5)}

1 Detective: was Tanya Freeman with Phillip the night Nate died?

2 Jared: yeah nah she was

3 Detective: how did you feel about that then?

4 Jared: ah, easy come easy go bro

5

besides, I prefer more than one kina in my rockpool if you know what I

mean

\section{Example 60: NZ Police (2)}

1 Teen 1: oh no, George is driving, he's too wasted

I should say something, but I could look dumb I front of Monique

2 Teen 2: bro, Monique says you're dumb

3 Teen 1: but if he crashes, $I^{\prime} l l$ have to live with his family

4 Woman: puzzle time

5 Teen 1: and if he dies, ghost George will haunt me forever

6 Ghost: grab a chip, wanna chip?

$7 \quad$ Teen 1: you know I can't grab your ghost chips

8 go away

$9 \quad$ Kid 1: $\quad$ spoon 
$10 \quad$ Kid 2: $\quad$ spacehead

11 Ghost: boo

12 George: hey, what are you doing bro?

13 Teen 1: oh I've been internalising a really complicated situation in my head

14 George: what are you on about?

15 Teen 1: I don't think you should drive

16 George: nah

17 Teen 1: nah you're too drunk bro, just crash here

18 Teen 3: yeah, just crash here

19 George: okay

20 Voiceover: stop a mate from driving drunk, legend

\section{Example 61: Radio New Zealand - Kiwi Slang}

1 Leilani: so the same way you'd say choice, oh that was tu meke, tu meke bro, you know, yeah

2 Presenter: oh just one more thing on bro

3 Leilani: yeah

4 Presenter: ah is that, you, would you only say bro when you're talking to a male

5 Leilani: nah, nah, you wouldn't, l'd say

6 Presenter: two women, two women could say bro, to each other

$7 \quad$ Leilani: yeah, yeah, for sure

8 Presenter: really?

8 Leilani: yeah

9 Presenter: that's interesting

9 Leilani: yeah I see no reason why, you wouldn't, I I say it 


\section{Example 76: Motorway Patrol (5)}

1 Narrator: Bruce is well used to colourful characters, the driver of this car may be into wind chimes and Jefferson Airplane

2 Cop: $\quad$ good afternoon, when did our, when did our windscreen get smashed up man?

\section{Example 77: The Edge (2)}

1 Lorde: um, oh man, look at my face in that I look like a new born baby

2 Dom: that is

3 Lorde: this is me meeting Beyonce

4 Jay-Jay: oh my god

5 Dom: that is you and Beyonce

6 Lorde: I look like a new born child, my eyes aren't even open

\section{Example 78: NZOwn}

1 Presenter: well Annabel Fay is back in the country, how's it going?

2 Annabel: good, how are you?

3 Presenter: I'm choice man, um it's been, what a pretty long summer for you over in Sydney, or what's the story, what've you been up to?

4 Annabel: yeah

\section{Example 79: Girl vs Boy}

1 Boy 1: you guys, what are you doing here?

2 Boy 2: chicks

3 Boy 3: free stuff 

4 Boy 1: unbelievable
5 Boy 3: what happened to your eye man?
6 Boy 2: ahh, he tripped, it wasn't eyeliner

\section{Example 80: Go Girls (2)}

1 Cody: bugger this face

\section{Example 81: Coverband (3)}

1 Man 1: oh yeah, [unclear] ninjas, so jealous when you got this

2 Man 2: you have it bro

3 Man 1: oh nah

$4 \quad$ Man 2: yeah man, you can hang on to it until my kid is old enough to play with it

\section{Example 82: Go Girls (3)}

1 Cody: can you believe it?

2 Man 1: what kind of a girl does that

3 Woman: wo, they got a separate room each, and used the minibar, and watched an in-house movie

$4 \quad$ Man 2: yeah, what did they watch?

5 Woman: it doesn't say

6 Man 2: porn

7 Man 2: [in his head] man, how come I don't know any girls like that

\section{Example 87: Beauty Review}


1 Blogger: if you guys like my make up I did film it and I'll probably be uploading it really really soon if you want to see it, so let me know I thought it was quite fun, it's quite retro and summery, I don't know I hope you guys have an amazing day, I love you guys so much and I'II talk to you soon

4 bye

\section{Example 88: $X$ Factor Video Diaries}

1 Blogger: hey guys

2 backstage

3 practicing

4 welcome to the X Factor, behind the scenes

\section{Example 89: Masterchef (2)}

$1 \quad$ Woman 1: it's called after dinner mint, it's a digestive

2 Woman 2: guys I haven't found cocoa

[several women talking at once]

3 Simon: here we go guys, we're counting it down now, five, four, three, two, one Jamie and Bec grab your team and bring 'em on out

$4 \quad$ Woman 3: let's go guys

$5 \quad$ Woman 4: let's go girls

6 Simon: oh they got the dry ice

\section{Example 90: Masterchef (3)}

1 Josh: welcome back guys, last week's Kiwi classic saw the downfall of Mel and Catherine 
2 Simon: good luck guys, we're really looking forward to this 
